Check for updates

Cite this: J. Mater. Chem. A, 2021, 9, 18994

Received 8th April 2021

Accepted 1st June 2021

DOI: $10.1039 / \mathrm{d} 1 \mathrm{ta0} 2953 \mathrm{c}$

rsc.li/materials-a

\section{Carbocatalytic ozonation toward advanced water purification}

\author{
Ya Liu, ${ }^{\text {ab }}$ Chunmao Chen, ${ }^{a}$ Xiaoguang Duan, (D) ${ }^{\mathrm{b}}$ Shaobin Wang (iD) ${ }^{\mathrm{b}}$ \\ and Yuxian Wang (D)*a
}

Carbon-based catalytic ozonation is state-of-the-art technology with high oxidation capabilities for wastewater remediation, taking advantage of the synergies of direct ozone oxidation and the generated reactive oxygen species (ROS). Replacing metal-based materials with active and robust carbonaceous catalysts in catalytic ozonation will lead to outperformed catalytic performance, minimized operational cost, and no secondary contamination. Additionally, the variety of allotropes and maneuverable surface chemistry of carbons facilitate structural and surface engineering, which enables the regulation of reactivity, stability and reaction pathways. This review summarizes the recent development of structural control and surface modification of carbocatalysts and their applications in catalytic ozonation. The structure-performance relations and mechanisms are elucidated by a novel model based on the interaction intensity between reactants and carbon surface. Meanwhile, influences of the water matrix parameters on the catalytic system are unveiled. Finally, we provide directions to the rational design of reaction-oriented carbocatalysts, the methodology for mechanistic explorations, and the implementation of ozone-based AOPs in real wastewater treatment.

\section{Introduction}

Advanced oxidation processes (AOPs) exploit reactive oxygen species (ROS), such as hydroxyl radicals ( $\left.\mathrm{HO}^{\circ}, E^{0}=2.7 \mathrm{~V}, \mathrm{NHE}\right)$ and sulfate radicals $\left(\mathrm{SO}_{4}{ }^{-}, E^{0}=2.5-3.1 \mathrm{~V}, \mathrm{NHE}\right)$ generated from diverse peroxides and have emerged as powerful

${ }^{a}$ State Key Laboratory of Heavy Oil Processing, State Key Laboratory of Petroleum Pollution Control, China University of Petroleum-Beijing, Beijing 102249, China. E-mail: yuxian.wang@cup.edu.cn

${ }^{b}$ School of Chemical Engineering and Advanced Materials, The University of Adelaide, Adelaide, SA 5005, Australia

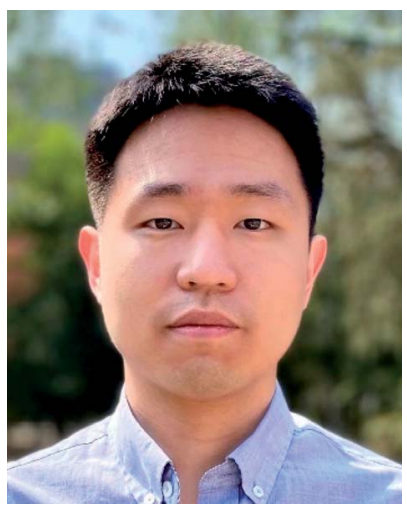

Yuxian Wang received his B.Eng. with first-class honor and PhD from Curtin University in 2013 and 2016, respectively. He then joined the College of Chemical and Environmental Engineering, China University of PetroleumBeijing as the associate professor. His current research interests include seeking feasible applications of nanomaterialbased advanced oxidation processes (AOPS) in environmental remediation and facilitating mechanistic insights into carbocatalysis with advanced protocols. techniques in wastewater decontamination. ${ }^{\mathbf{1} 2}$ Among AOPs, ozonation treatments relying on the high oxidation potential of $\mathrm{O}_{3}\left(E^{0}=2.05 \mathrm{~V}, \mathrm{NHE}\right)$ can directly destruct unsaturated organics via the Criegee reaction and outperform other AOPs in terms of low energy demand and facile implementation at a full-scale..$^{3,4}$ However, the selectivity and low solubility of $\mathrm{O}_{3}$ in the aqueous medium limited the mineralization efficiency of the ozonation process. ${ }^{5}$ Catalytic ozonation treatments achieve improved reaction kinetics and mineralization efficiency compared with ozonation treatment. The heterogeneous catalysts in the ozonated solutions accelerate $\mathrm{O}_{3}$ activation into ROS, which possess greater oxidation capacities and are less selective, thus facilitating the interactions of $\mathrm{O}_{3}$ molecules and organic contaminants. ${ }^{6}$ Additionally, the tunable oxidation regimes in catalytic ozonation improve the adaptability to complicated water matrixes. Various metal-based heterogeneous catalysts have been developed for $\mathrm{O}_{3}$ activation, yet the secondary pollution arising from metal leaching becomes the bottleneck in practical applications. ${ }^{7}$

The past two decades witness a rapid development of carbons to replace conventional metal-based systems in environmental remediations on account of fast reaction kinetics and environmentally benign nature of carbocatalysis. ${ }^{8}$ As a result, various carbonaceous materials, including bulky carbons (e.g., activated carbon, biochar and carbon fiber) and novel structured nanocarbons (e.g., carbon nanotubes, graphene-based materials and three-dimensional porous nanocarbons), have been applied in heterogeneous catalytic 
ozonation (Fig. 1). ${ }^{9}$ A broad range of allotropes with different dimensions and porous structures facilitate the in-depth investigation of the mechanism of dimensional effects on catalytic performance. Additionally, the facilely-tuned surface chemistry together with the large surface area of carbonaceous materials provide an advanced platform to build and maneuver surface engineered active sites such as defects, surface functionalities, heteroatom dopants, and anchored metal species. ${ }^{\mathbf{1 0 , 1 1}}$ Hence, the engineered carbonaceous materials with optimized physiochemical and electronic properties stimulate $\mathrm{O}_{3}$ activation to induce either radical or nonradical-based reaction pathways to destroy the recalcitrant organics.

The innovative carbocatalysis in AOPs significantly expedites the development of new carbocatalysts and excavation of the underlying mechanisms. Till now, several reviews have been reported to summarize the development of carbocatalysis in wastewater decontamination, ${ }^{\mathbf{9}, \mathbf{1 2}-\mathbf{1 4}}$ while few focused on the application of carbonaceous materials in catalytic ozonation. Recently, two reviews dedicated to the mechanistic investigations on nanocarbon-based catalytic ozonation. ${ }^{15,16}$ To the best of our knowledge, there is still lack of a review that comprehensively summarizes the recent advances in carbon-based catalytic ozonation treatments and the synthesis/modification strategies for advanced design of carbocatalysts with desirable activity, selectivity, and stability. In addition, the effects of water matrix parameters such as solution $\mathrm{pH}$ and background organic/inorganic substances on the performance of carbonbased catalytic ozonation treatments are rarely mentioned.

In this review, apart from showcasing the roadmap of catalytic ozonation treatments using different carbon allotropes, we

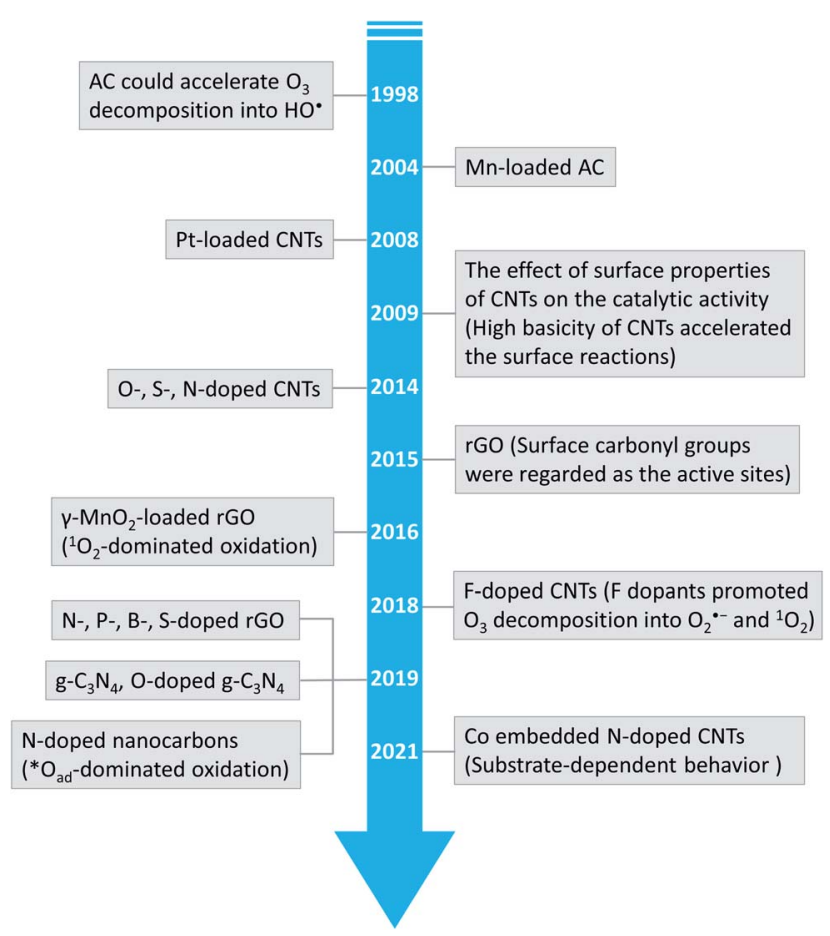

Fig. 1 Timeline of the important development of carbon-based catalysts in catalytic ozonation. will discuss the catalytic origin and establish the surface engineering strategies for rational design and fast screen of the highly efficient carbocatalysts. For better elucidation of the mechanistic insights into ROS generation and differentiation of reaction pathways, a novel concept based on the intensity of interactions between $\mathrm{O}_{3}$ and catalysts surface will be proposed. The environmental implications of solution $\mathrm{pH}$, ionic strength, and other background substances such as inorganic anions and natural organic matters (NOMs) on the efficiency of the carbonbased catalytic ozonation treatments will be analyzed. Furthermore, the challenges and future research opportunities for the elaborate design of reaction-oriented carbocatalysts and systematically unravelling the mechanistic insights into carbonbased catalytic ozonation will be envisaged.

\section{Synthesis and surface engineering protocols for surface active sites}

In general, pristine carbon catalysts are catalytically inactive and their catalytic performances are lower than those of metalbased homogeneous and heterogeneous catalysts. For example, pristine carbon nanotubes (CNTs) obtained by the chemical vapor deposition (CVD) method generally possess a low density of functional groups with $\mathrm{C}-\mathrm{H}$ terminations on the surface and poor dispersibility in aqueous solution. ${ }^{\mathbf{1 1 , 1 7}}$ Surface chemistry and pore structure are key properties of activated carbon (AC) that directly influence their performances in various applications. ${ }^{18}$ Thus, surface modification and functionalization are conducive to promoting their catalytic performances in the development of highly effective carbon-based materials. Diverse modification methods have been summarized in several reviews, ${ }^{\mathbf{8}, 17,19,20}$ in which all modification principles are dedicated to creation/tailoring of catalytically active sites and electronic structures of the carbocatalysts. To rationally design and synthesize catalysts with improved activity, selectivity, and stability for a target application, it is crucial to unravel the catalytic origin and intrinsic active sites that govern the catalytic activity.

\subsection{Carbon dimensions}

Dimensional effects have a great impact on the catalytic activities of catalysts, especially for carbon materials (Fig. 2a). The pristine graphene network with free-flowing $\pi$ electrons is beneficial to the adsorption and activation of reactants and the electron transfer process. In the catalytic ozonation processes, the conjugated $\pi$ system of the graphitic carbon framework facilitates the adsorption and activation of $\mathrm{O}_{3}$ molecules. ${ }^{21}$ The difference in the electron density between carbocatalysts and $\mathrm{O}_{3}$ /organics is of great significance to the strength of chargetransfer interactions. ${ }^{22}$ Generally speaking, strong activation/ binding is more likely to occur when charge density difference is significant. ${ }^{23,24}$ Moreover, the highly delocalized $\pi$ system endows $\mathrm{sp}^{2}$ carbon with a faster electron transfer rate, which helps the redox reactions for $\mathrm{O}_{3}$ activation and organics oxidation. ${ }^{25}$ The delocalized $\pi$ electrons were also reported to be closely correlative to superoxide radical $\left(\mathrm{O}_{2}{ }^{--}\right)$formation in 
(a)

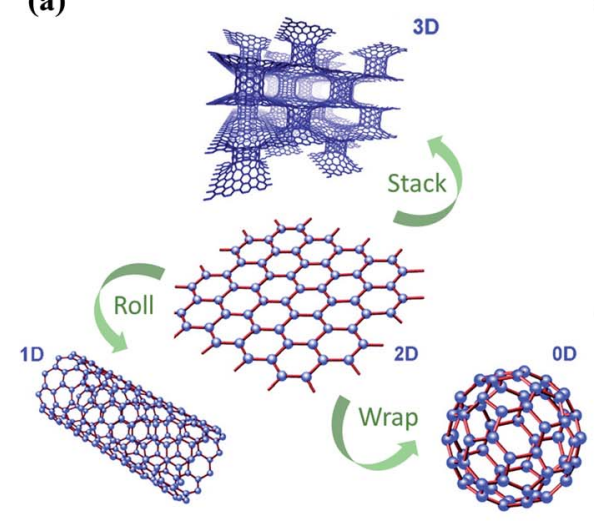

(b)

(c)
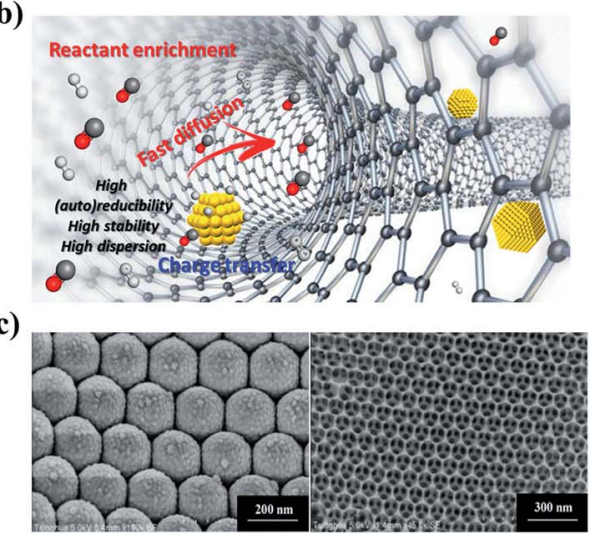

Fig. 2 (a) Construction of different dimensional carbon materials based on graphene. Elements are adapted with permission from ref. 32. Copyright 2012, American Chemical Society; adapted with permission from ref. 33. Copyright 2012, Elsevier. (b) Nanoconfinement effects in carbon nanotubes. Reprinted with permission from ref. 28. Copyright 2020, American Chemical Society. (c) HRTEM images of 3DOM structures. Reprinted with permission from ref. 34. Copyright 2015, Wiley-VCH.

catalytic $\mathrm{O}_{3}$ decomposition. ${ }^{26}$ On the other hand, the carbon framework is able to function as a charge-transfer mediator that induces the direct charge transport from the co-adsorbed organics (the electron donor) to oxidants (the electron acceptor) via the surface region of the carbocatalyst to achieve contaminant destruction. ${ }^{27}$ In addition, aromatic organics tend to be adsorbed or activated on the basal plane due to the $\pi-\pi$ interactions or electrostatic interactions, followed by an electrophilic attack by ROS. ${ }^{16}$ It is worth mentioning that the $\pi$ orbitals are perpendicular to the graphene layer in graphene, while in CNTs, the curvature structures induce a bent $\pi$ system and the redistributed electron density from the inner to the outer surface, thereby affecting the catalytic activity ${ }^{28}$

Engineering three-dimensional (3D) carbon catalysts with mesoporous and macroporous structures is a promising strategy to improve the catalytic activity by shortening the mass transport/diffusion length, increasing specific surface area (SSA) and the number of exposed active sites, and further accelerating the reaction kinetics. Nanoconfinement effects are also expected in the porous structure, which facilitate both mass and charge transfer (Fig. 2b). 3D hierarchical carbon structures further enhance electron mobility and facilitate the adsorption of reactants in water media. ${ }^{16}$ In the presence of metal catalysts at a high pyrolysis temperature, 3D hybrid nanostructures can be synthesized by intercalating onedimensional (1D) wirelike nanocarbons between the stacked two-dimensional (2D) sheets (Fig. 2a). ${ }^{29}$ The $3 \mathrm{D}$ ordered macroporous (3DOM) carbon architecture with an increased number of active sites and enlarged SSA also demonstrates a favorable application in environmental catalysis (Fig. 2c)..$^{30,31}$ (a)
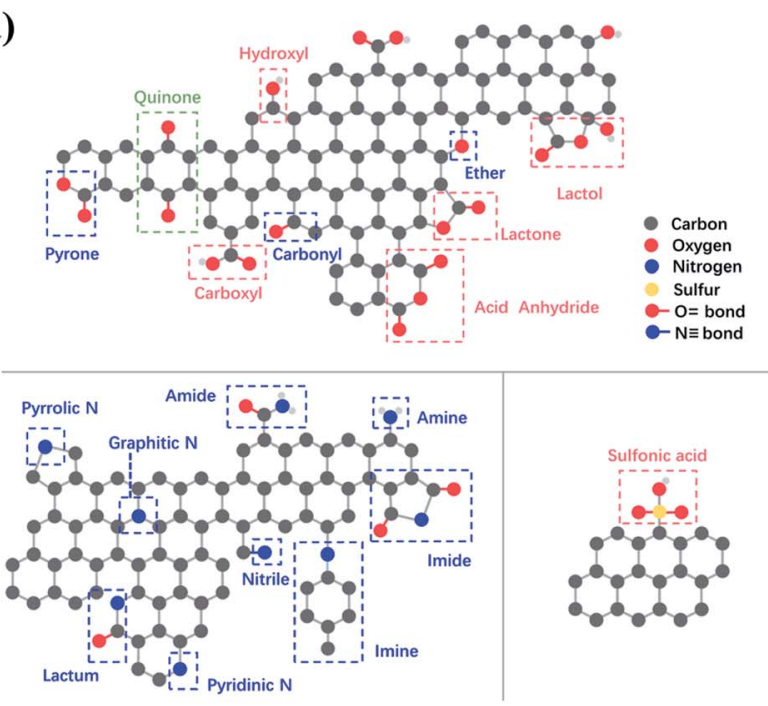

(b)

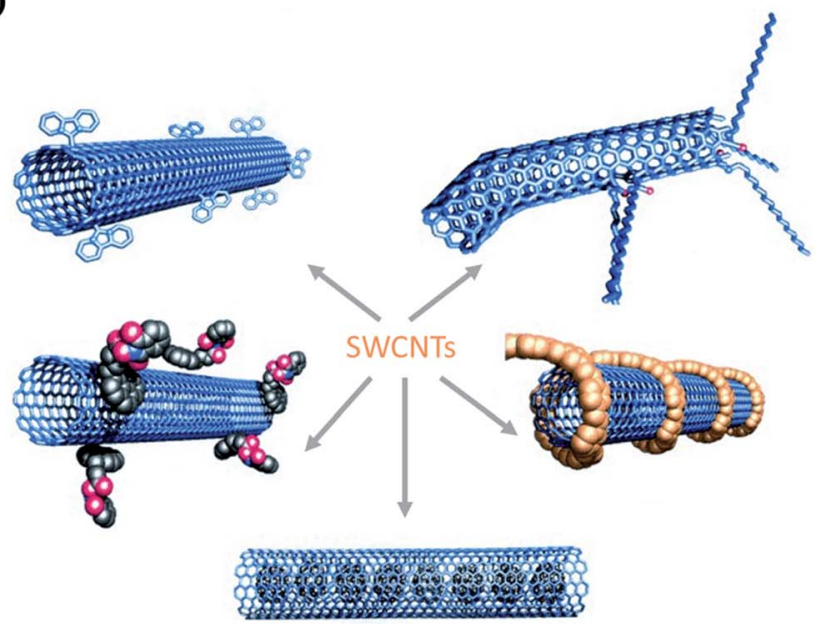

Fig. 3 (a) Possible oxygen-, nitrogen- and sulfur-containing functional groups on carbon surface. Reproduced with permission from ref. 49. Copyright 2013, Royal Society of Chemistry. (b) Functionalization strategies for CNTs. Adapted with permission from ref. 50. Copyright 2002, Wiley- $\mathrm{VCH}$. 


\subsection{Surface functionalization}

The surface chemistry such as surface charge and the electronic properties of the carbon materials is largely dependent on the surface functionalities, especially the surface oxygen functionalities, which have been proposed as the active sites in various carbon-based catalysts (Fig. 3a). Carbonyl groups $(-\mathrm{C}=\mathrm{O})$ with high basicity and nucleophilicity are catalytically active. It was found that reduced graphene oxide $(\mathrm{rGO}) / \mathrm{g}-\mathrm{C}_{3} \mathrm{~N}_{4}$ with a higher content of carbonyl groups exhibited better catalytic performance toward $\mathrm{O}_{3}$ activation. ${ }^{35,36}$ The electron-rich carbonyl groups with lone-pair electrons can act as Lewis basic sites to activate $\mathrm{O}_{3}$ by an electron-transfer process. Similarly, carbonyl groups are critical active sites in persulfate activation. It was reported that carbonyl groups located at the boundaries showed a high affinity to interact with peroxymonosulfate (PMS), leading to the significant elongation of the peroxide $\mathrm{O}-\mathrm{O}$ bond in PMS. ${ }^{37,38}$ Carboxyl groups $(-\mathrm{COOH})$ can act as Lewis basic sites to facilitate $\mathrm{O}_{3}$ activation due to its similar properties with $-\mathrm{C}=\mathrm{O}$ in catalytic ozonation systems. $\mathrm{Qu}$ et al. reported that carboxyl functionalized CNTs (CNTs-COOH) possessed a better activity compared with hydroxyl functionalized CNTs (CNTs$\mathrm{OH}$ ), because the high charge density of $-\mathrm{COOH}$ was beneficial for the direct oxidation of pollutants by $\mathrm{O}_{3} .{ }^{39}$ Moreover, the deprotonated carboxyl groups reacted with $\mathrm{O}_{3}$ to form electrophilic oxygen species, which served as radical promoters to

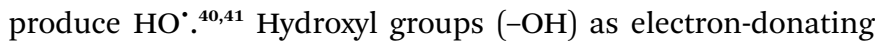
groups would reinforce the electron density of the conjugated $\pi$ system to facilitate the electron-transfer process. Ren and coworkers found that, as compared with carbonyl and carboxyl groups, hydroxyl groups on the CNTs surface were more conducive to persulfate adsorption and electron migration in the peroxodisulfate (PDS)/CNTs system..$^{42}$ In catalytic ozonation, $\mathrm{O}_{3}$ will electrophilically attack the surface $-\mathrm{OH}$ groups to generate ROS $\left(\mathrm{HO}^{\cdot}\right.$ and $\left.\mathrm{O}_{2}{ }^{\cdot-}\right) .^{43}$ Furthermore, $-\mathrm{OH}$ groups might be oxidized into $-\mathrm{C}=\mathrm{O}$ groups by $\mathrm{O}_{3}$, and the redox cycle of carbonyl-hydroxyl groups is beneficial to $\mathrm{O}_{3}$ activation. ${ }^{44}$

Tailoring the type and amount of the surface functionalities is a practical step to enhance the catalytic performance (Fig. 3b).
Thus, surface engineering is a crucial way to manipulate the surface functionalities, which can be categorized into surface oxidation and reduction modifications. ${ }^{45}$ Surface oxidative modification generally employs oxidants (e.g., $\mathrm{HNO}_{3}, \mathrm{KMnO}_{4}$, $\mathrm{H}_{2} \mathrm{SO}_{4}, \mathrm{H}_{2} \mathrm{O}_{2}$, and $\mathrm{O}_{3}$ ) to introduce a large number of oxygencontaining groups (e.g., $-\mathrm{COOH},-\mathrm{OH},-\mathrm{NO}_{2},-\mathrm{SO}_{3} \mathrm{H}$, etc.) on the carbon surface, thereby increasing the acidic property. During the surface reduction modification, carbon materials are treated at a high temperature in a reducing atmosphere or are reduced in alkaline solutions, leading to the formation of basic surface functionalities $\left(e . g\right.$., $-\mathrm{C}=\mathrm{O},-\mathrm{NH}_{2}$, etc.). Noteworthly, the carbon structure can be entirely damaged by $\mathrm{HNO}_{3}$ at its boiling point. ${ }^{46}$ For surface-oxidized multi-walled CNTs (MWCNTs), the increased oxygen-containing functionalities $(-\mathrm{C}=\mathrm{O})$ on MWCNTs facilitated the adsorption of reaction intermediates and thus accelerated the reaction via tuning the electronic structures of the adjacent carbon atoms. ${ }^{47}$ Graphene modified with amine groups $\left(-\mathrm{NH}_{2}\right)$ demonstrated better catalytic activity compared with unmodified graphene for persulfates activation. ${ }^{48}$ Nevertheless, excessive surface functionalities are not desirable. ${ }^{38}$ Overabundant surface oxygen groups hindered the catalytic activity due to increased electrostatic repulsions and stereo-hindrance effect. ${ }^{42}$ Moreover, the extra surface oxygen moieties decrease the reductive degree of the carbon lattice for charge transfer and occupy the defective sites or edges, which are also crucial active sites for oxidant activation. Therefore, fabricating carbon materials with optimized oxygen contents to enhance the catalytic performance is highly imperative for future studies. In addition, unveiling the roles of the individual oxygen-containing groups on carbocatalysts is challenging since it is hard to regulate single type of surface functional groups without influencing others.

\subsection{Defects engineering}

Defect engineering has been demonstrated as an effective strategy to tailor the electronic properties of carbon catalysts. Nanocarbons are inherently produced with edges and topological defects (Fig. 4a). These defective sites with unpaired (a)

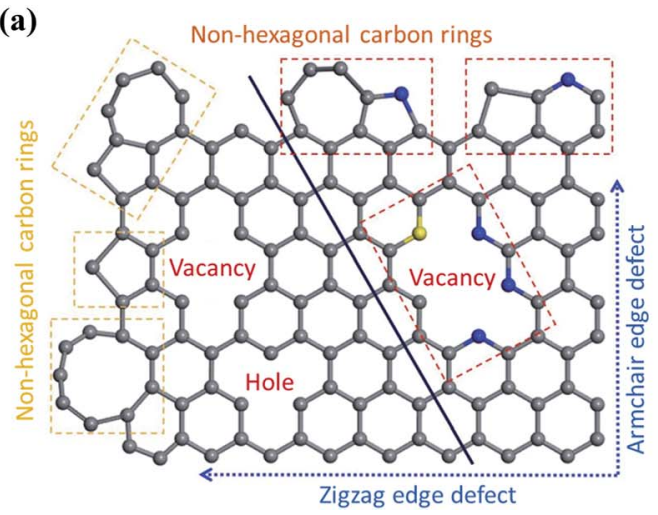

(b)

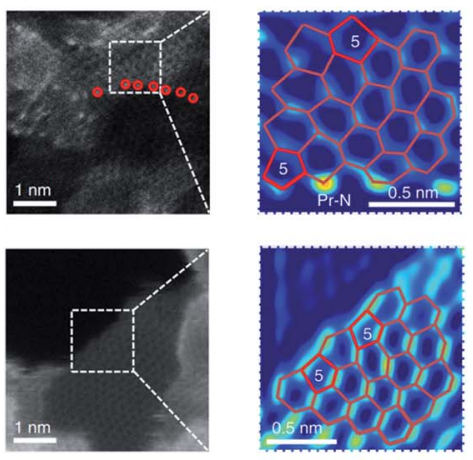

Fig. 4 (a) Defect-engineered nanocarbon. Adapted with permission from ref. 61. Copyright 2021, Springer. (b) The high-angle annular dark-field scanning transmission electron microscopy (HAADF-STEM) images of carbon defects. Reprinted with permission from ref. 62. Copyright 2019, Nature. 
electrons disturb the homogeneity of carbon skeleton and tune the electronic structures of basal planes (Fig. 4b). ${ }^{51}$ The catalytic activity of edges originates from the presence of dangling bonds, which are high-energy sites and possess high reactivity toward the reactants to promote the radical chain oxidations. The carbon atoms at the edging sites obtain unpaired electrons in a "localized state", which strongly interact with the small molecules to form an attached complex. ${ }^{52}$ It was revealed that the electron transfer at graphene edges was much faster than that on the honeycomb basal plane. ${ }^{53}$ With the merits, edge sites have been reported to promote $\mathrm{O}_{3}$ adsorption and subsequent activation. ${ }^{25,52,54,55}$ On the other hand, topological defects (e.g., vacancies and non-hexagonal carbon rings) can break the conjugated $\pi$ network and redistribute the electrons. ${ }^{53}$

Defects in a carbon framework can be further created either by downsizing carbons or by removal of the template materials. A novel catalyst for oxygen reduction reaction (ORR) based on graphene quantum dots (GQDs) supported on graphene nanoribbons (GNRs) was developed through a one-step reduction of methylbenzene and hexabromobenzene by $\mathrm{Na} .{ }^{56}$ Such a treatment resulted in abundant surface and edge defects on the GQD/GNR surfaces or at their interface, which served as active sites to promote charge transfer. During the synthesis of $\mathrm{N}$ doped graphene, both edge and topological defects can be produced by high-temperature pyrolysis for decomposition of the N-rich precursors. ${ }^{57}$ Meanwhile, topological defects can be created through the direct carbonization of carbon/nitrogen precursors on templates of $\mathrm{MgO} / \mathrm{Zn}$-metal-organic frameworks (MOFs).$^{58}$ Additionally, microwave reduction is an efficient method to synthesize rGO with abundant structural defects, attributed to the microwave absorbing property of graphene oxide (GO) and the severe and uniform heating ambience provided by microwave irradiation. ${ }^{59}$ Nevertheless, these carbocatalysts were fabricated under high temperatures or using template precursors, in which an accurate control of the generated defects was difficult. Plasma technology for etching the surface of nanocarbons has been proposed as an effective strategy to prepare defect-rich electrocatalysts in a controllable manner by altering treatment time and plasma power. ${ }^{60}$ It is worth mentioning that, although nanocarbons with high-defect levels obtained good reactivities in AOPs, they usually show poor stabilities, because the unsaturated dangling bond and long-paired electrons on defects would induce the electrophilic attack of the oxidants. Moreover, defects might also be changed or recombined under the working conditions. ${ }^{60}$ Hence, manipulating the defective level is required to balance the trade-off between reactivity and stability.

\subsection{Heteroatom doping}

Introduction of heteroatoms (e.g., $\mathrm{B}, \mathrm{N}, \mathrm{F}, \mathrm{P}$ or $\mathrm{S})$ to the carbon skeleton results in charge/spin redistribution and structural disorder because of the differences in electronegativities and atomic radius (Fig. 5a). ${ }^{\mathbf{1 0 6 3 , 6 4}}$ As a result, the heteroatom dopants and the $\mathrm{C}$ atoms adjacent to the dopants with variations in electronic properties are often regarded as the active sites favoring the interaction with $\mathrm{O}_{3} \cdot{ }^{65} \mathrm{~N}$-dopants alter the charge distribution and the density of states (DoS) of the doping area, owing to the great difference in electronegativity between $\mathrm{N}$ and $\mathrm{C}$ (3.07 vs. 2.55); $\mathrm{N}$ dopants also endow the

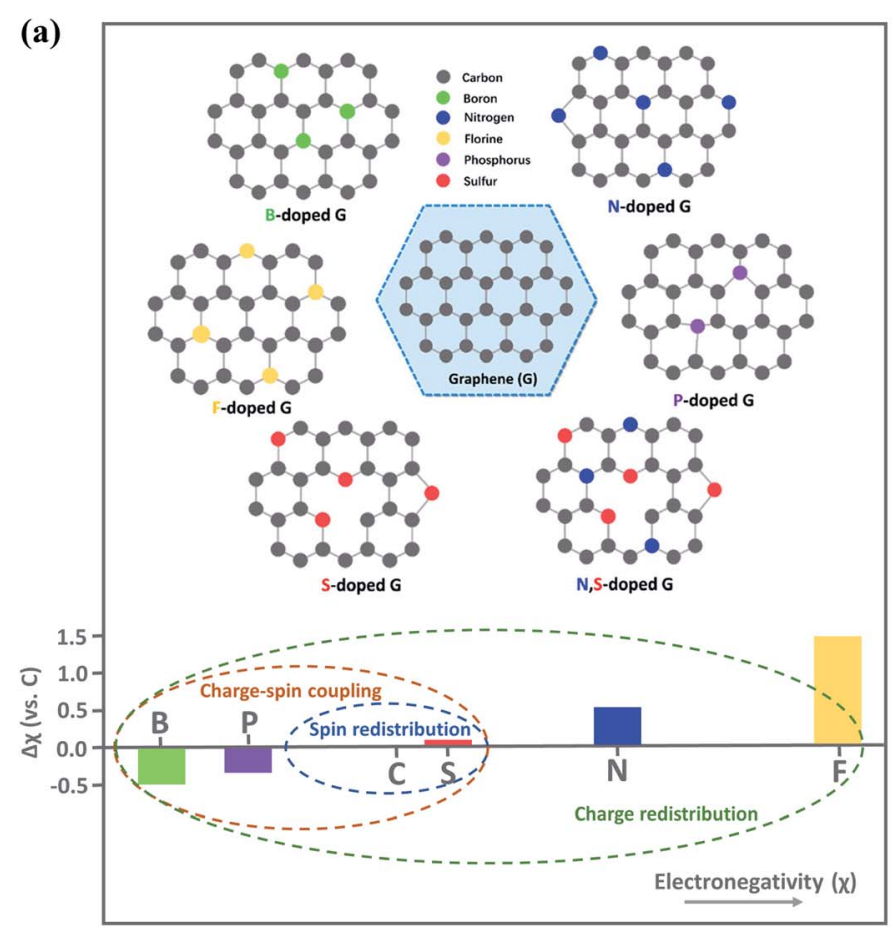

(b)

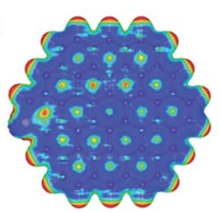

(c)

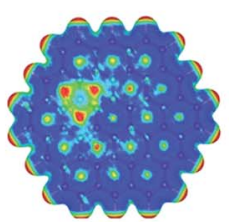

(d)

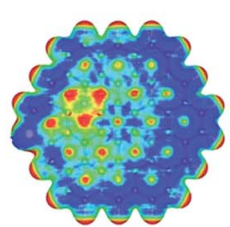

(e)

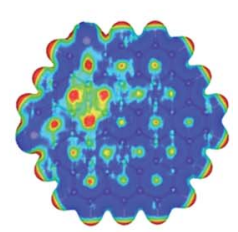

Fig. 5 (a) Illustration on heteroatom-doped carbon materials. Reproduced with permission from ref. 64. Copyright 2018, Wiley-VCH. Reprinted with permission from ref. 16. Copyright 2020, American Chemical Society. Electrostatic potential mapping from charge density matrix for (b) SrGO, (c) N-rGO, (d) S, N-rGO, and (e) S, S, N-rGO. Reprinted with permission from ref. 67. Copyright 2015, Wiley-VCH. 
adjacent $\mathrm{C}$ atoms with a highly positive charge density, facilitating the adsorption and activation of the reactants. Moreover, the intrinsic chemical and electronic coupling induced by $\mathrm{N}$ doping synergistically promoted proton adsorption and the reduction kinetics. ${ }^{66}$ Meanwhile, heteroatom doping results in the redistribution of spin density. ${ }^{64}$ Although the similar electronegativities of $\mathrm{S}$ to $\mathrm{C}$ weakened the intramolecular charge transfer, the higher spin density of S-doped graphene than that of pristine graphene (0.39 vs. 0) favored adsorption of reactants. ${ }^{67}$ Co-doping of the heteroatoms can further improve carbocatalysis due to the synergy between different dopants. The performances of binary (N, P-carbon), ternary (N, P, Fcarbon) and quaternary (S, N, B, P-carbon) doped carbon catalysts have well outperformed the single doping counterparts. ${ }^{68-70}$ In a N, F co-doped system, F dopants tailored the Ndoping-induced charge transfer and decreased the work function, which accelerated charge transfer for redox reactions. ${ }^{71}$ Meanwhile, in N, S co-doped graphene, $\mathrm{S}$ atoms could activate the $\mathrm{C}$ atoms adjacent to $\mathrm{N}$, which was advantageous for the interaction with PMS to lower the energy barrier for ROS generation. ${ }^{67,72}$ Additionally, the synergistic effect arising from co-doping dramatically enlarged the positively charged regions. Nevertheless, overloading of the $\mathrm{S}$ dopants restrained the synergistic effect due to the redistribution of electrons/spins and reduced active regions (Fig. $5 \mathrm{~b}-\mathrm{e}$ ) ${ }^{67}$ Therefore, the doping species, level and configuration need to be carefully controlled.

Typically, heteroatom doping could be achieved by two strategies, direct/in situ synthesis and post-treatment. ${ }^{11,73}$ Direct/in situ synthesis strategy starts from molecular carbon and dopant precursors; the formation of graphitic carbon framework and heteroatom doping occur concurrently at the elevated temperature by CVD, solvothermal, segregation growth, or arc-discharge approaches. ${ }^{73}$ Homogeneous doping could be attained by precisely controlling the direct/in situ synthesis parameters. The post-treatment method is to pyrolyze the derived carbon materials with heteroatom-rich resources by a hydrothermal treatment, pyrolysis, ball milling method or plasma treatment.

Multiple factors can affect the catalytic performances of heteroatom-doped carbon catalysts. First, the dopant types and the bonding configurations determine the catalytic activity. $\mathrm{N}$ doping introduces graphitic, pyridinic, and pyrrolic Ns in the carbon framework, among which the electron-donating graphitic $\mathrm{N}$ is more favorable for $\mathrm{O}_{3}$ adsorption. According to density functional theory (DFT) simulation, graphitic $\mathrm{N}$ showed a superior catalytic activity to pyridinic and pyrrolic Ns. ${ }^{74}$ Altering the annealing temperature and ambience could manipulate the types and compositions of the N-dopants because of the different thermal stability of $\mathrm{N}$ species. ${ }^{75,76}$ Second, the content of heteroatom dopants can also influence doping performance. Although increasing the $\mathrm{N}$ content in $\mathrm{N}$ doped CNTs was reported to enhance the electrocatalytic activity, ${ }^{77}$ the excessive doping amount might hinder the catalytic activity because of the resulted unfavorable electronic structure and poor structural robustness. ${ }^{78}$ Therefore, it is significant to optimize the doping content by tuning the amount of heteroatom-containing precursors, substrate structures and treatment parameters. Third, catalytic activity may vary with the dopant location even with the same doping element and configuration. It was suggested that $\mathrm{N}$ doping at graphene edges demonstrated the best catalytic activity because the edges obtained a much faster electron-migration rate than the basal plane in graphene. ${ }^{749}$ Employing the heteroatomcontaining precursors with well-controlled locations of heteroatom atoms is a promising strategy to control the location of the heteroatom dopants and to establish structure-property relationships in specific applications. ${ }^{19}$ Noteworthily, the type, content, and location of dopants in heteroatom-doped carbon (a)

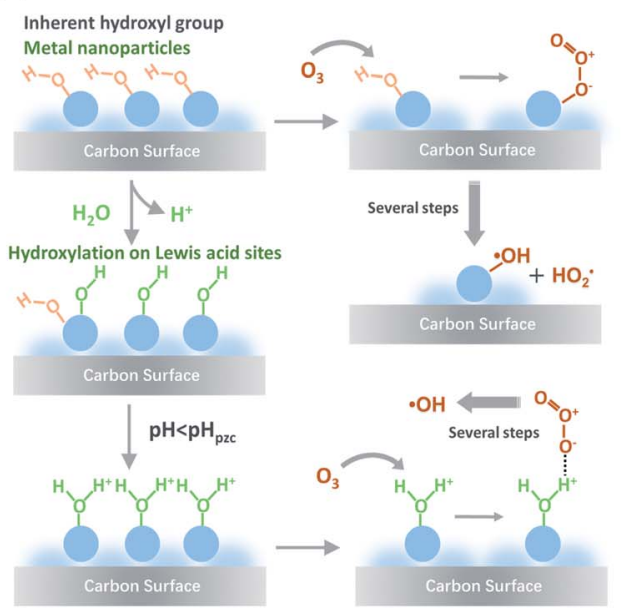

(b)

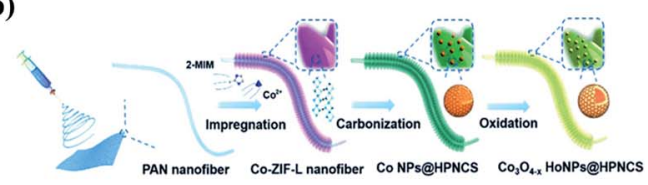

(c)

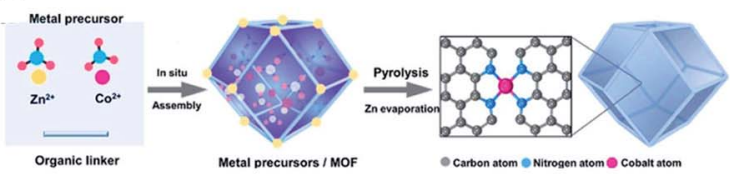

(d)

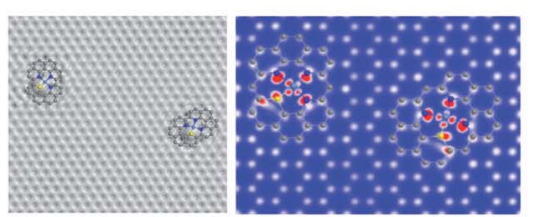

Fig. 6 (a) Schematic illustration of the interactions between $\mathrm{O}_{3}$ and the surface hydroxyl groups on the metal sites of carbon materials. Reproduced with permission from ref. 16. Copyright 2020, American Chemical Society. (b) Preparation process of Co nanoparticles embedded carbon nanoflakes. Reprinted with permission from ref. 106. Copyright 2019, Wiley-VCH. (c) The formation procedure of Co-SA. Reprinted with permission from ref. 107. Copyright 2021, Wiley-VCH. (d) Simulated HRTEM and STM images of TM- $\mathrm{N}_{x}$ architecture in atomically disperse S|NiN ${ }_{x}$ species embedded in porous carbon (PC) nanosheets. Reprinted with permission from ref. 108. Copyright 2019, Nature. 
catalysts are difficult to be precisely manipulated owing to the complexity of heteroatom dopants and the variety in the surface properties. Novel doping strategies need to be developed, and combined experimental and theoretical approaches will help unveil the chemical nature of the dopants.

\subsection{Compositing and doping with metals}

Compositing with metal species is another appealing strategy to enhance the performance of carbocatalysis because of the interfacial coupling and charge transfer between the dissimilar counterparts. The defects, heteroatom dopants, and surface oxygen functional groups on the carbon surface provide unique sites for anchoring the metal species owing to the strong binding strength and accelerated electron transfer. Metal species with electron-donating d-orbital electrons can improve electron conductivity and electron-transfer capacity of carbon materials by regulating their electronic properties such as spin density and work functions. ${ }^{80-82}$ Therefore, the strong couplings between the metal species and carbon support significantly change the interface charge density and the coordination environment of active sites, ultimately regulating the catalytic activity.

The redox couples of metal cations $\left(\mathrm{Me}^{n+} / \mathrm{Me}^{n+1}\right)$ facilitate $\mathrm{O}_{3}$ decomposition into ROS via creating the electron-transfer environment during catalytic ozonation. ${ }^{83}$ Moreover, the surface of metal oxides is commonly covered by hydroxyl groups, including the inherent hydroxyl groups and the hydroxyl groups arising from the surface hydroxylation process, which act as the Lewis acid sites to accelerate $\mathrm{O}_{3}$ decomposition or induce a substitution reaction with $\mathrm{O}_{3}$ to form surfaceadsorbed active species (Fig. 6a). ${ }^{16,84,85}$ Oxygen vacancies (OVs) are typical defects in metal oxides which contain unsaturated coordination sites and unpaired electrons. ${ }^{86}$ OVs can enhance the mobility of the surface oxygen and thus facilitate electron transfer in catalytic reactions. Electronic properties of metal/ carbon composites can be regulated with the existence of OVs. The abundant OVs within the surface in $\mathrm{NiCo}_{2} \mathrm{O}_{4}$-loaded hollow carbon spheres (HCS) increased DoS near the Fermi level and decreased work function and also optimized the valence state of active sites, resulting in a remarkable enhancement in ORR activity. ${ }^{87}$ Meanwhile, OVs of $\mathrm{TiO}_{2}$ resulted in inter-bandgap states and a lower flat band potential in a $\mathrm{CNT} / \mathrm{TiO}_{2}$ hybrid, promoting the photocatalytic activity. ${ }^{88}$ Recently, the generation of high-valent metal species has been successfully verified in various kinds of AOPs..$^{89-91}$ In the $\mathrm{Fe}(\mathrm{II}) / \mathrm{O}_{3}$ system, the involvement of high-valent iron-oxo species (Fe(Iv)-oxo) formed from the reaction of $\mathrm{Fe}(\mathrm{II})$ with $\mathrm{O}_{3}$ was identified by ${ }^{18} \mathrm{O}$ isotopelabeling technique. ${ }^{22}$ The generated high-valent metal-oxo species are highly reactive and capable of oxidizing the organic contaminants.

Impregnation has been widely employed for the synthesis of metal-loaded carbon catalysts, whereas the loading rate should be below the threshold of $30 \mathrm{wt} \%$ to attain the well-distributed metal particles. ${ }^{93}$ To achieve both high metal loading and optimal particle size distribution, MOFs can be utilized as templates. ${ }^{94,95}$ Compared with metal-loaded carbon composites, encapsulation of metal clusters/nanoparticles within carbon layers by forming a core@shell structure successfully avoid undesirable metal leaching (Fig. 6b). Meanwhile, the encapsulated metal species will modulate the electronic state of outer-sphere graphitic layers via an electron tunnelling effect at the carbon-metal interfaces and enhance electron-transfer capability. ${ }^{96,97}$ Additionally, the size of anchored transition metals (TM) can be downsized to an atomic level to form single-atom catalysts (SAC), which can be synthesized by a variety of approaches, such as CVD, atomic layer deposition, pyrolysis, wet chemical method, and electron/ion irradiation (Fig. 6c). ${ }^{98,99}$ Extensive attention has been given to single-atom transition metal (TM) species coordinated N-doped nanocarbons (TM- $\mathrm{N}_{x}-\mathrm{C}$ ) because of their high catalytic activities stemmed from the unique TM-N coordination (Fig. 6d). ${ }^{100-102}$ Such TM-N coordinations have been regarded as the principal active centers, because the hybridizations between the d-orbitals of TM and the 2p-orbitals of nitrogen increased the electron densities near the Fermi level and the work function of carbon basal plane. ${ }^{16}$ The inexpensive precursors, such as inorganic salts, carbon, and nitrogen sources, have been extensively employed for the preparation of $\mathrm{TM}-\mathrm{N}_{x}-\mathrm{C}$ catalysts. ${ }^{103-105}$

\section{Catalytic ozonation with different carbon allotropes}

\subsection{Bulky carbons}

By virtue of its high surface area, large porosity, plentiful surface functionalities and low costs, activated carbon (AC) has been widely used to remove micropollutants from water. Combined AC with ozonation was found to be an attractive method for wastewater decontamination owing to the synergistic effect between adsorption and catalytic oxidation (summarized in Table 1). The rich porosity and maneuverable surface functionalities expedite the interactions of both organic pollutants and $\mathrm{O}_{3}$ on the surface of AC. Moreover, it was reported that AC or carbon black could act as the initiator for radical chain reactions to accelerate $\mathrm{O}_{3}$ decomposition into $\mathrm{HO}^{*} .^{109,110} \mathrm{In}$ ACinitiated catalytic ozonation, variations in solution $\mathrm{pH}$ and surface chemistry of AC will exert a profound influence on the catalytic performance.

Solution $\mathrm{pH}$ can be a critical factor affecting the ozonation activation pathways, yet the mechanism is still controversial. Beltrán et al. applied AC in catalytic ozonation of oxalic acid $(\mathrm{OA})$ at acid $\mathrm{pH}$ and proved that catalytic degradation of $\mathrm{OA}$ at $\mathrm{pH} 2.5$ could be ascribed to a $\mathrm{HO}^{\circ}$-based radical pathway occurring in the bulk solution. ${ }^{111}$ In another study, $\mathrm{O}_{3}$ mainly adsorbed on the surface of $\mathrm{AC}$ without generating free radicals at acidic $\mathrm{pH}$ to near neutral $\mathrm{pH}$ ( $\mathrm{pH} 2$ to 6), while it tended to react with the surface hydroxyl groups on the AC to produce $\mathrm{HO}^{\circ}$ in bulk solution when solution $\mathrm{pH}>6 .{ }^{110}$ Faria et al. reported that surface oxidation was the dominant degradation route of $\mathrm{OA}$ at $\mathrm{pH} 3$ since the addition of $\mathrm{HO}^{*}$ scavenger resulted in a marginal inhibition on the destruction rate of OA. ${ }^{112}$ At alkaline $\mathrm{pH}$, both surface oxidations and bulk reactions relying on $\mathrm{HO}^{*}$ were responsible for $\mathrm{OA}$ destruction. Additionally, the greater degradation efficiency of $\mathrm{OA}$ was achieved at acidic $\mathrm{pH}$ 


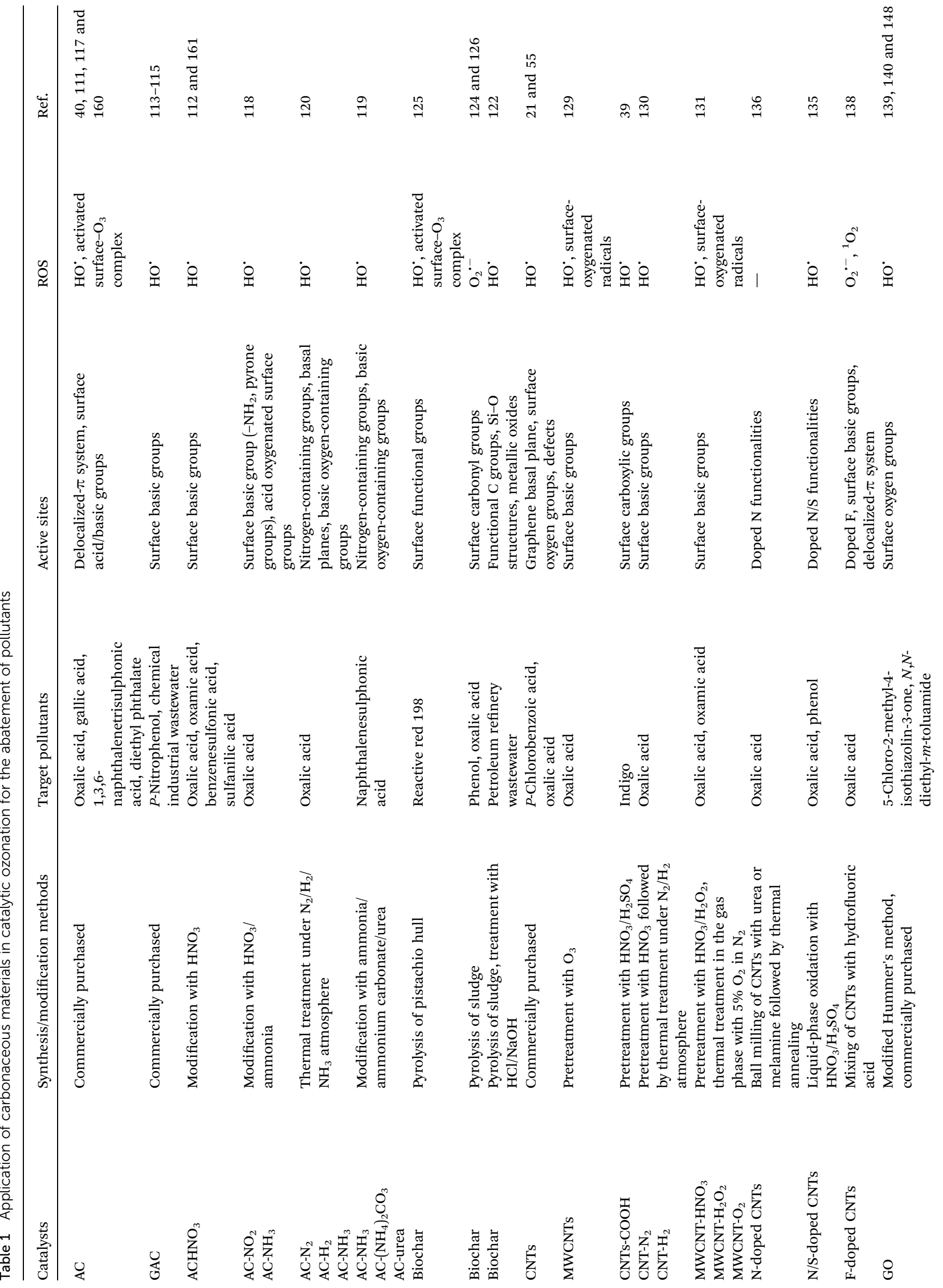




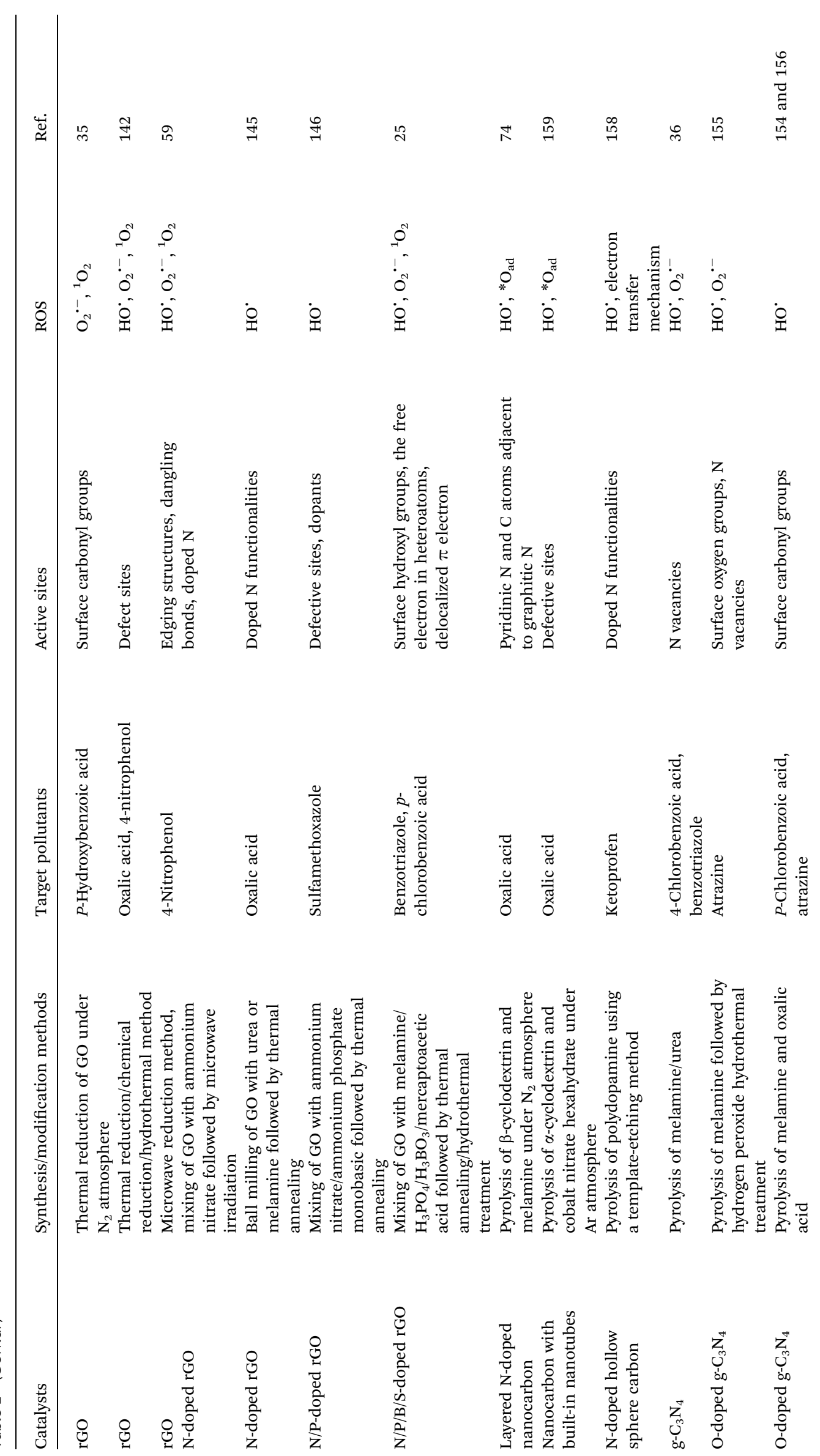


(a)

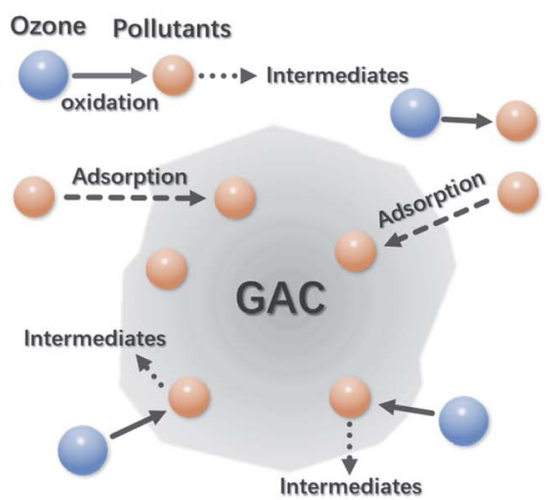

(b)

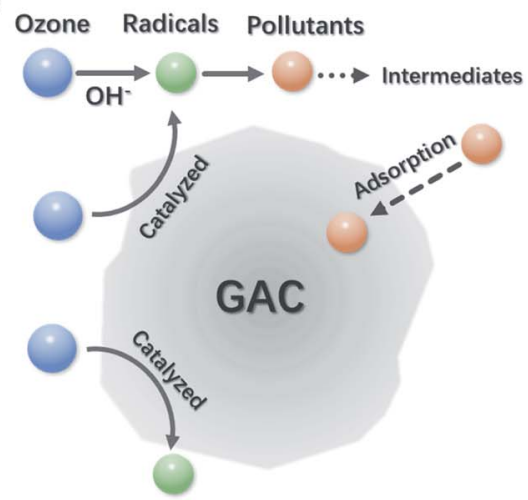

Fig. 7 Schematic illustrations of the main reactions on GAC surface under (a) acidic conditions and (b) basic conditions. Reproduced with permission from ref. 113. Copyright 2008, American Chemical Society.

than at basic $\mathrm{pH}$, though a higher $\mathrm{pH}$ promoted the decomposition of $\mathrm{O}_{3}$ into more reactive species.

Variations in solution $\mathrm{pH}$ not only affect the decomposition rate of $\mathrm{O}_{3}$, but also alter the surface charge of $\mathrm{AC}$ as well as the dissociation of organic molecules in aqueous solutions. Surface of AC is positively charged when solution $\mathrm{pH}$ is lower than $\mathrm{pH}$ at the point of zero charge $\left(\mathrm{pH}_{\mathrm{pzc}}\right)$ of $\mathrm{AC}$, and its surface becomes negatively charged vice versa. Meanwhile, the organic molecules could dissociate to anionic species at a solution $\mathrm{pH}$ higher than its $\mathrm{p} K_{\mathrm{a}}$. Hence, the resulted electrostatic forces (attraction or repulsion) between the surface of $\mathrm{AC}$ and the organic molecules at different solution pHs affect their interactions, which influence the catalytic performance and oxidation pathways. ${ }^{112}$ The principal reactions on $\mathrm{AC}$ at different $\mathrm{pH}$ conditions are schematically illustrated in Fig. $7 \mathrm{a}$ and $\mathrm{b} .{ }^{113}$

The activity of AC can also be correlated with the types and contents of surface functionalities. Increasing the amounts of acidic surface oxygen functionalities with electron-withdrawing ability can be accounted for the activity loss of AC after the catalytic ozonation reaction. ${ }^{114}$ The increased amount of acidic functionalities reduces the affinity to the electrophilic interaction with $\mathrm{O}_{3}$ molecules and prevents $\mathrm{O}_{3}$ decomposition in solution. Acid or alkali surface modifications are effective in optimizing the catalytic activity of AC. Faria and co-workers modified $\mathrm{AC}$ by nitric acid treatment $\left(\mathrm{ACHNO}_{3}\right)$, and the increased surface acidity by introducing carboxyl groups on $\mathrm{AC}$ surface led to the decrease in catalytic ozonation activity. ${ }^{112}$ The delocalized $\pi$ electron system of basic groups on AC surface favored $\mathrm{OH}^{-}$adsorption and acted as catalytic centers to catalyze $\mathrm{HO}^{\circ}$ generation. ${ }^{110,115,116}$ Also, pyrone-like and chromenelike surface oxygen functionalities react actively with $\mathrm{O}_{3}$ via Criegee mechanism to yield hydrogen peroxide $\left(\mathrm{H}_{2} \mathrm{O}_{2}\right)$, which reacts with the AC surface or with $\mathrm{O}_{3}$ itself for $\mathrm{HO}^{\circ}$ generation. ${ }^{113,114,117}$ It was also observed that the adsorption capacity of basic AC was superior to more acidic ones because of the increased electronic attraction resulted from the higher $\mathrm{pH}_{\mathrm{pzc}}$ of alkaline AC. ${ }^{112}$ In addition, surface basic oxygen functionalities facilitate the occurrence of surface-based oxidations. However, the generated $\mathrm{HO}^{*}$ around the high basicity active sites was difficult to diffuse into the bulk solution owing to its short lifetime and rapid reaction with surface-adsorbed organics. Additionally, the surface basic oxygen functionalities on $\mathrm{AC}$ tended to dissociate into cationic species with positive charges, which impeded the electrophilic attack of $\mathrm{O}_{3}$ for $\mathrm{HO}^{*}$ generation. Thus, the basicity of AC may indirectly weaken $\mathrm{HO}^{-}$dominated oxidation in bulk solution. ${ }^{118}$ Despite of its electronwithdrawing character, the deprotonated acid oxygenated surface groups can enhance the formation of $\mathrm{O}_{2}{ }^{-{ }^{-}}$and $\mathrm{O}_{3}{ }^{-{ }^{-}}$as a consequence of its reaction with $\mathrm{O}_{3}$, which function as radical initiators to generate $\mathrm{HO}^{\circ}$ through the radical chain reactions. ${ }^{40}$ Surface nitrogen-containing functionalities also influenced the catalytic activity of AC. ACs with various types and concentrations of nitrogenated functional groups were prepared, and urea-treated $\mathrm{AC}$ with enriched pyrrole groups and low concentrations of pyridine and pyridone groups demonstrated the best catalytic ozonation activity among ACs treated by different nitrogenating agents. ${ }^{119}$ The pyrrole groups extensively increased the electronic density of the graphitic layers in AC, which served as the catalytic active sites and promoted $\mathrm{O}_{3}$ decomposition into $\mathrm{HO}^{*}{ }^{120}$ On the contrary, the $\pi$-deficient pyridine groups diminished the electronic density of AC basal plane. This is in line with another study of Cao's group, where the pyrrole groups mainly accelerated $\mathrm{HO}^{\circ}$ generation in the bulk solution but the pyridine groups had a detrimental effect on the surface reaction. ${ }^{120}$

Biochar is a type of bulky carbon prepared from the pyrolysis of biomass or solid wastes, which possesses the merits such as abundant precursors with low costs, bulk level preparation and manipulatable surface chemistry. Thus, biochar as a highly modifiable green platform has drawn widespread attention in environmental remediation. ${ }^{121-124}$ The properties of biochar are highly dependent on different factors such as feedstock type and pyrolysis temperature. Moussavi and Khosravi converted pistachio hull into biochar via thermal pyrolysis $\left(500{ }^{\circ} \mathrm{C}\right.$ for 2 h). ${ }^{125}$ The pistachio hull-derived biochar had a strongly basic surface $\left(\mathrm{pH}_{\mathrm{pzc}}=11.5\right)$ and a macroporous structure in favor of adsorption of $\mathrm{O}_{3}$ and dye molecules. Therefore, a higher decolorization efficiency of reactive red 198 was observed in the 
catalytic ozonation process with pistachio hull-derived biochar than that with AC. Pyrolysis temperature has certain effects on the morphological, physicochemical, and catalytic capacity of biochar. For instance, Zhang et al. produced biochar using raw sludge obtained from coking wastewater at different pyrolysis temperatures $\left(300,500,700,900{ }^{\circ} \mathrm{C}\right)$ for catalytic ozonation of phenol. ${ }^{\mathbf{1 2 6}}$ Raising the pyrolysis temperature enhanced the graphitization level of the biochar and stabilized the carbon structure and the inherently integrated metal components. Substantial reduction in total organic carbon (TOC) releasing and metal ions (e.g., $\mathrm{Co}^{2+}, \mathrm{Fe}^{3+}, \mathrm{Ni}^{2+}, \mathrm{Cu}^{2+}$ and $\mathrm{Mn}^{2+}$ ) leaching were observed when pyrolysis temperature was $900{ }^{\circ} \mathrm{C}$. In addition, high-temperature pyrolysis also favored the formation of a porous structure with an increased surface area by promoting the evaporation of the volatile matters in biochar feedstock. The increasing amount of oxygen-bonded carbon groups formed at elevated pyrolysis temperature endows the biochar with the ability to remove contaminants, since the functionality will facilitate the adsorption of $\mathrm{O}_{3}$ within the surface region and participate in the electron-transfer process.

\subsection{Nanocarbons}

Although bulky carbonaceous materials are cost-effective and facile to prepare, their microporous structures limit the diffusion of both reactants and products in catalytic reactions. Thus, bulky carbons usually demonstrate poor activity and reusability in catalytic ozonation. The mixed mesoporous or microporous structures in nanocarbons such as carbon nanotubes (CNTs), graphene allotropes, carbon nitride $\left(\mathrm{g}-\mathrm{C}_{3} \mathrm{~N}_{4}\right)$, and $3 \mathrm{D}$ hierarchical carbons shorten the length of mass diffusion, facilitate the exposure of active sites, and accelerate the reaction kinetics. Additionally, the surface chemistry of nanocarbons can be easily regulated. The introduced defects or heteroatoms will further improve the catalytic activity. Herein, nanocarbons with well-defined structures and chemistry are promising platforms to gain insights into catalytic ozonation as well as other carbonbased AOPs. Table 1 summarizes carbonaceous materials in catalytic ozonation for the removal of organics.

3.2.1 Carbon nanotubes. CNTs belongs to the 1Dstructured allotrope of nanocarbons, which can be regarded as a tubular structure of rolled graphene layers. The mesoporous structure enables CNTs with a large external specific surface area which facilitates the dispersion of active components and promotes the interactions with reactants. Surfaceengineered CNTs have been widely used as heterogeneous catalysts for ozonation in aqueous solution to degrade organic pollutants. ${ }^{55,127,128}$ The highly graphitic degree of CNTs with limited structural topological defects favors grafting oxygen functional groups. Surface functionalization and heteroatom doping are two main strategies to modify the surface chemistry of CNTs, thereby enhancing the catalytic activity. The role of surface functional groups in the catalytic activity has been studied by Ma's group. ${ }^{\mathbf{1 2 9 , 1 3 0}}$ Compared with untreated MWCNTs, the catalytic activity of MWCNTs was significantly reduced after $\mathrm{O}_{3}$ oxidation pretreatment, which was ascribed to the remarkable decrease of surface basic groups and the increase of acidic groups, especially for carboxyl acid groups. ${ }^{129}$ $\mathrm{N}_{2}$ or $\mathrm{H}_{2}$ heat treatment of CNTs further increased the $\mathrm{pH}_{\mathrm{pzc}}$ value and afforded higher catalytic activity in OA degradation. ${ }^{\mathbf{1 3 0}}$ It was found that higher $\mathrm{pH}_{\mathrm{pzc}}$ of CNTs resulted in a greater rate constant for OA removal. Compared with $\mathrm{N}_{2}$ heat treatment, $\mathrm{H}_{2}$ heat treatment had a more significant effect in eliminating acidic groups because of the reducibility of $\mathrm{H}_{2}$. Gonçalves et al. also reported similar results that low acidity of MWCNTs promoted the catalytic ozonation of aliphatic acids. ${ }^{131}$ In these scenarios, surface basic functionalities stimulated the evolution of $\mathrm{O}_{3}$ or $\mathrm{H}_{2} \mathrm{O}_{2}$ via Criegee reactions into active species, such as $\mathrm{HO}^{\circ}$. Additionally, CNTs with a negative surface charge density were favorable to OA adsorption, which accelerated the surface reactions. ${ }^{\mathbf{1 2 9 , 1 3 0}}$ Confirmed by the quenching tests with the presence of tert-butanol (TBA), a typical HO ${ }^{*}$ scavenger, only minor inhibition on the activity of heat-treated CNTs was observed compared with CNTs. Therefore, similar to AC, CNTs with a higher basic character were more conducive to catalytic ozonation of OA through surface reaction.

The effects of oxidized surface of CNTs on the catalytic activity are debatable, which can be favorable, ${ }^{55}$ unfavorable ${ }^{\mathbf{1 2 9 , 1 3 0}}$ or marginal. ${ }^{\mathbf{1 3 1 , 1 3 2}}$ One obstacle in the clarification of this argument is that it is difficult to alter the surface chemistry without changing the morphology or dispersity of CNTs after a prolonged exposure in the highly oxidative environment during catalytic ozonation processes; additionally, it is challenging to directly correlate the catalytic activity with one or more surface properties. ${ }^{\mathbf{1 3 3 , 1 3 4}}$ To distinguish the influence of CNTs surface chemistry and CNTs aggregation on catalytic activity, Oulton et al. investigated the effects of MWCNTs surface properties and suspension stability on $\mathrm{HO}^{\circ}$ production in a catalytic ozonation system by functionalizing MWCNTs with $\mathrm{HNO}_{3} \cdot{ }^{55}$ It was found that the oxidized MWCNTs possessed a higher rate of $\mathrm{HO}^{*}$ formation compared with the pristine MWCNTs. Dynamic light scattering and sedimentation studies indicated that oxidized MWCNTs exhibited a lower degree of aggregation than pristine MWCNTs, and the better dispersion favored $\mathrm{O}_{3}$ decomposition and $\mathrm{HO}^{*}$ formation. Moreover, surface oxygen functionalities (e.g., $-\mathrm{COOH},-\mathrm{C}=\mathrm{O}$, and $-\mathrm{OH}$ ) resulting from $\mathrm{HNO}_{3}$-pretreatment were also responsible for $\mathrm{HO}^{\bullet}$ formation.

Tailoring the surface chemistry and the electrochemical properties of CNTs by substituting carbon atoms with metalfree heteroatoms (e.g., N, S, and F) can be an alternative strategy to promote catalytic activity. Restivo et al. reported that the introduction of $\mathrm{N}$ and $\mathrm{S}$ species led to improved catalytic efficiency of CNTs in catalytic ozonation. ${ }^{135}$ Soares et al. further prepared N-doped CNTs by a simple ball-milling method. ${ }^{\mathbf{1 3 6}}$ The elevated catalytic activity and the high stability were observed for as-prepared N-CNTs, which may be primarily attributed to the pyridine $\mathrm{N}$ groups. However, compared with non-doped ball-milled CNTs, no significant improvement in the mineralization degree of the organic contaminants was observed for $\mathrm{N}$ doped CNTs. ${ }^{136,137}$ It was suggested that ball milling led to the breakage of nanotubes and the decrease in the entanglement, thus resulting in the increase in surface area and more exposure of active sites; however, N-doping decreased the surface area. F 
(a)

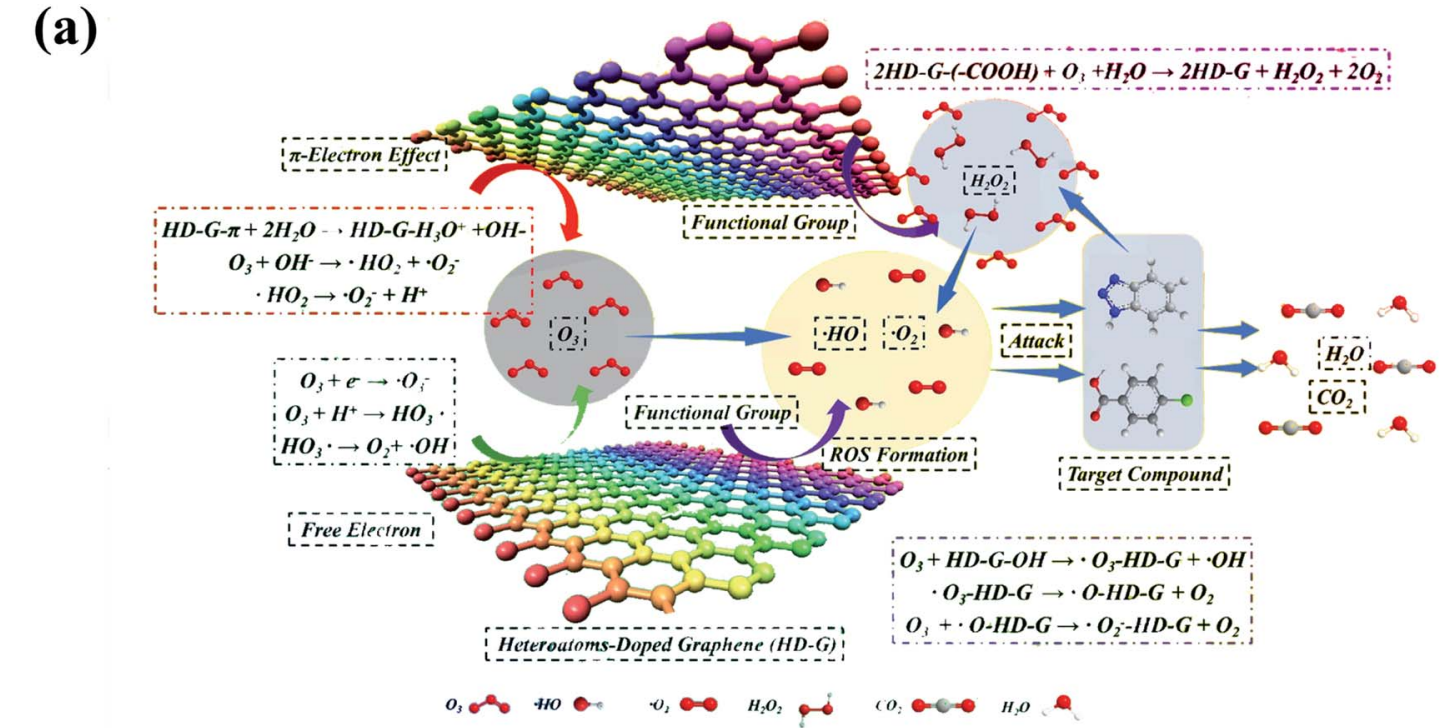

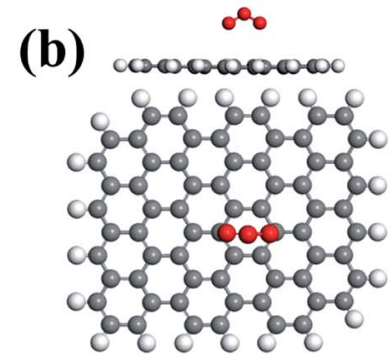

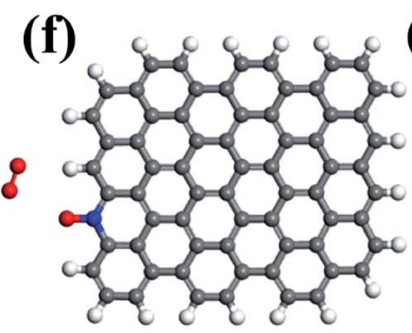

(c)

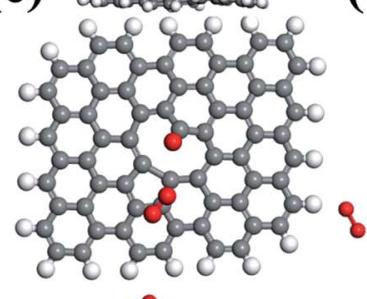

(d)

(g)
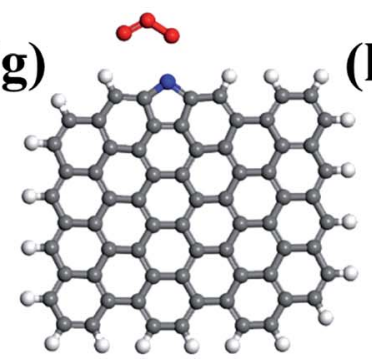

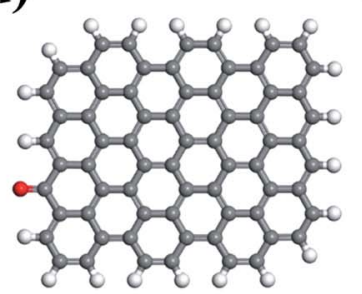

(e)

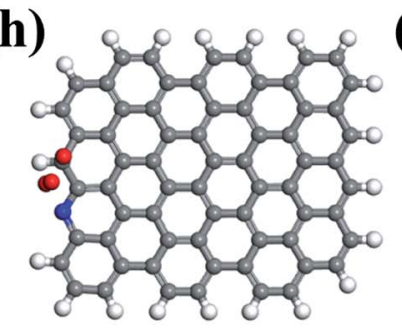

(i)

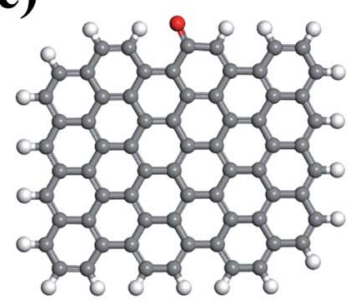

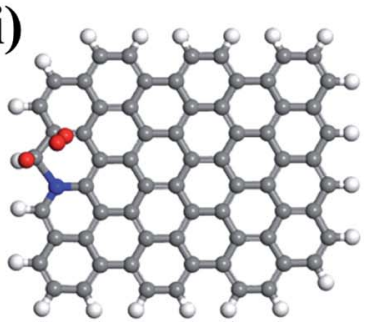

Fig. 8 (a) Mechanism of catalytic ozonation by heteroatom-doped graphene. Adapted with permission from ref. 25. Copyright 2019, American Chemical Society. DFT simulations of $\mathrm{O}_{3}$ adsorption on the (b) basal plane, (c) vacancy, (d) zigzag edge, and (e) armchair edge of graphene. Reprinted with permission from ref. 142. Copyright 2018, Elsevier. DFT simulations of $\mathrm{O}_{3}$ adsorption on (f) pyridinic N, (g) pyrrolic N, $\mathrm{C}$ with high charge density adjacent to (h) pyridinic N, and (i) edge graphitic N. Reprinted with permission from ref. 74. Copyright 2019, Elsevier.

atoms are the most electronegative elements with an extraordinary electron-withdrawing ability. Wang and co-workers found that F-doped CNTs obtained a significantly improved catalytic ozonation activity in OA destruction than the undoped CNTs, and outperformed N-CNTs and several metal oxides (e.g., $\mathrm{ZnO}, \mathrm{Al}_{2} \mathrm{O}_{3}, \mathrm{Fe}_{2} \mathrm{O}_{3}$, and $\mathrm{MnO}_{2}$ ). ${ }^{138}$ The covalent $\mathrm{C}-\mathrm{F}$ bonds in $\mathrm{F}$ CNTs formed in $\mathrm{sp}^{3}$ hybridization maintained the integrity of the delocalized $\pi$ networks, which were beneficial to $\mathrm{O}_{3}$ activation via an electron-transfer process.

3.2.2 Graphene and derivatives. Graphene is a promising 2D material consisting of honeycomb-like $\mathrm{sp}^{2}$ carbon layers. Graphene-based materials have attracted intensive research attention due to their unique chemical and electronic properties. Different from CNTs, topological defects can be introduced during the synthesis or post-treatment processes. The high surface area of graphene facilitates the adsorption of reactants and the exposure of active sites for $\mathrm{O}_{3}$ to decompose into ROS.

$\mathrm{GO}^{139-141}$ and $\mathrm{rGO}^{35,36,59,142}$ have been widely employed to activate $\mathrm{O}_{3}$ for the degradation of various contaminants. rGO displayed much higher catalytic performance than GO ascribed to the higher defective level and a proper amount of surface oxygen functionalities. By the purification of the graphite from the anode of waste lithium-ion battery (LIB), Wang et al. synthesized defects-rich rGO (LIB-rGO). ${ }^{142}$ The as-prepared LIBrGO outperformed rGO obtained from commercial graphite powder with a mediocre defective level in catalytic ozonation for 4-nitrophenol degradation. DFT simulations validated that the peroxide bond in $\mathrm{O}_{3}$ would be broken to generate surfaceadsorbed atomic oxygen $\left({ }^{*} \mathrm{O}_{\text {ad }}\right)$ and free peroxide species $\left({ }^{*} \mathrm{O}_{2}\right.$ free) when $\mathrm{O}_{3}$ molecules were placed on vacancies, zigzag, and 
armchair edges of rGO, giving rise to the adsorption energies of $-3.88,-5.69$, and $-4.64 \mathrm{eV}$, respectively (Fig. $8 \mathrm{c}-\mathrm{e}$ ). In contrast, the peroxide bond in $\mathrm{O}_{3}$ only slightly prolonged when placed above the graphene basal plane, resulting in adsorption energy of $-0.32 \mathrm{eV}$ (Fig. 8b). The more negative adsorption energy of $\mathrm{O}_{3}$ on defective sites than that on the basal plane demonstrated the vital role of structural defects, especially the edging sites. ${ }^{\mathbf{1 4 2}}$ Additionally, $\mathrm{O}_{3}$ interacting with different oxygen functional groups $(-\mathrm{OH},-\mathrm{C}=\mathrm{O},-\mathrm{COOH}$, and $\mathrm{C}-\mathrm{O}-\mathrm{C})$ of graphene were also performed by DFT calculations. Among different configurations, $-\mathrm{OH}$ groups on the zigzag edge of graphene exhibited the highest affinity toward $\mathrm{O}_{3}$ as it obtained the most negative adsorption energy with $\mathrm{O}_{3}(-1.00 \mathrm{eV})$. Moreover, the longest peroxide bond $\left(l_{\mathrm{O}-\mathrm{O}}\right)$ in $\mathrm{O}_{3}(1.360 \AA)$ also indicated the greatest possibility for $\mathrm{O}_{3}$ decomposition on surface hydroxyl groups. ${ }^{\mathbf{1 4 2}}$ However, as discussed above, the number of surface oxygen functionalities should be manipulated at a proper level, otherwise, the overabundant surface oxygen functionalities, such as the ones on GO, can impede the catalytic activity by affecting the electron-transfer process and inhibiting the adsorption of both $\mathrm{O}_{3}$ and organics due to the steric effect.

Doping of metal-free heteroatoms in the graphene structure can further improve the catalytic activity and stability by regulating the chemical and electronic properties of rGO. ${ }^{\mathbf{1 4 3 , 1 4 4}}$ $\mathrm{N}-\mathrm{rGO}$ was prepared by a simple ball milling method using urea (rGO-U) or melamine (rGO-M) as nitrogen precursors. ${ }^{\mathbf{1 4 5}}$ The higher SSA (102 vs. $47 \mathrm{~m}^{2} \mathrm{~g}^{-1}$ ) and a greater amount of doped $\mathrm{N}$ (9.3\% vs. $7.5 \%$ ) endowed rGO-M with higher catalytic activity than rGO-U. Furthermore, metal-free doping also created a large number of defective sites. ${ }^{\mathbf{1 4 6}}$ Song and co-workers prepared N-, P-, B-, and S-doped rGO and the catalytic ozonation activity for wastewater decontamination was in the order of N-rGO $>$ P-rGO $>\mathrm{B}-\mathrm{rGO}>\mathrm{rGO}>\mathrm{S}-\mathrm{rGO}{ }^{25}$ They suggested that the unpaired electron/free electrons and delocalized $\pi$ electrons from defective sites in heteroatom-doped rGO participated in the electrontransfer process, in which unpaired electrons were easily captured by $\mathrm{O}_{3}$ to generate $\mathrm{HO}^{\circ}$ and the delocalized $\pi$ electrons expedited $\mathrm{O}_{2}{ }^{--}$formation. Furthermore, surface $-\mathrm{OH}$ and -COOH groups also acted as the active centers for ROS evolution in this study (Fig. 8a). DFT simulations revealed insights into the activity improvement induced by heteroatom doping. ${ }^{74}$ It was found that $\mathrm{N}$-doping redistributed the charge density of the graphene basal plane and enabled the pyridinic and graphitic $\mathrm{N}$-doping sites as well as $\mathrm{C}$ atoms adjacent to graphitic $\mathrm{N}$ to be electron-rich zones, which acted as active sites for catalyzing $\mathrm{O}_{3}$ dissociation (Fig. 8f-i). The chemisorbed $\mathrm{O}_{3}$ molecules on the
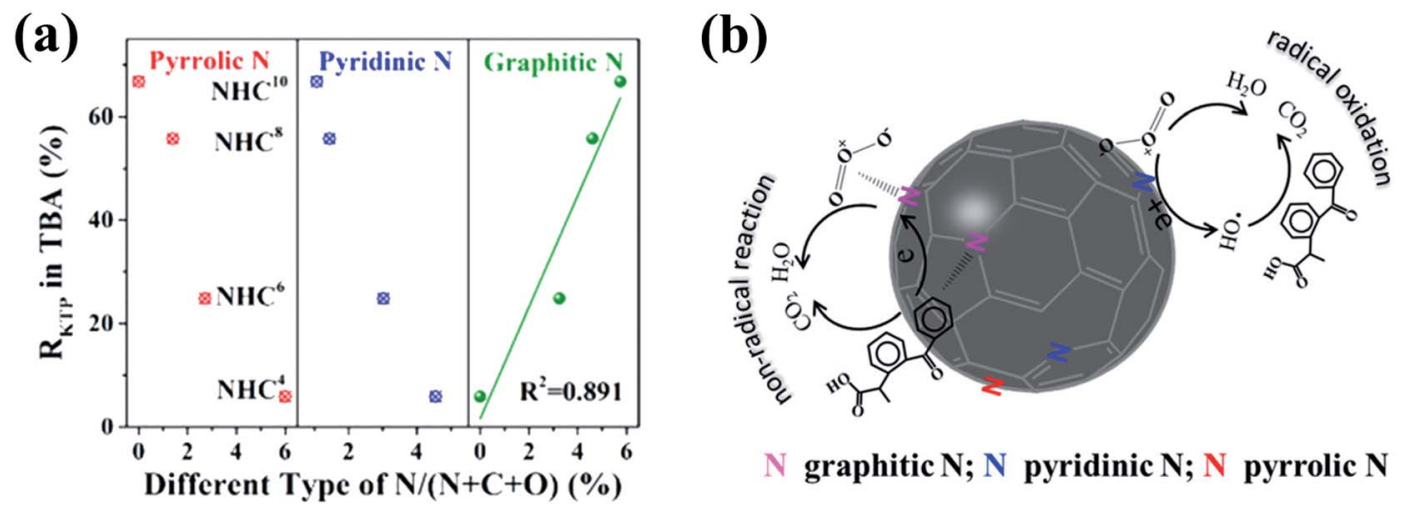

\section{$\mathrm{N}$ graphitic $\mathrm{N}$; $\mathrm{N}$ pyridinic $\mathrm{N}$; $\mathrm{N}$ pyrrolic $\mathrm{N}$}
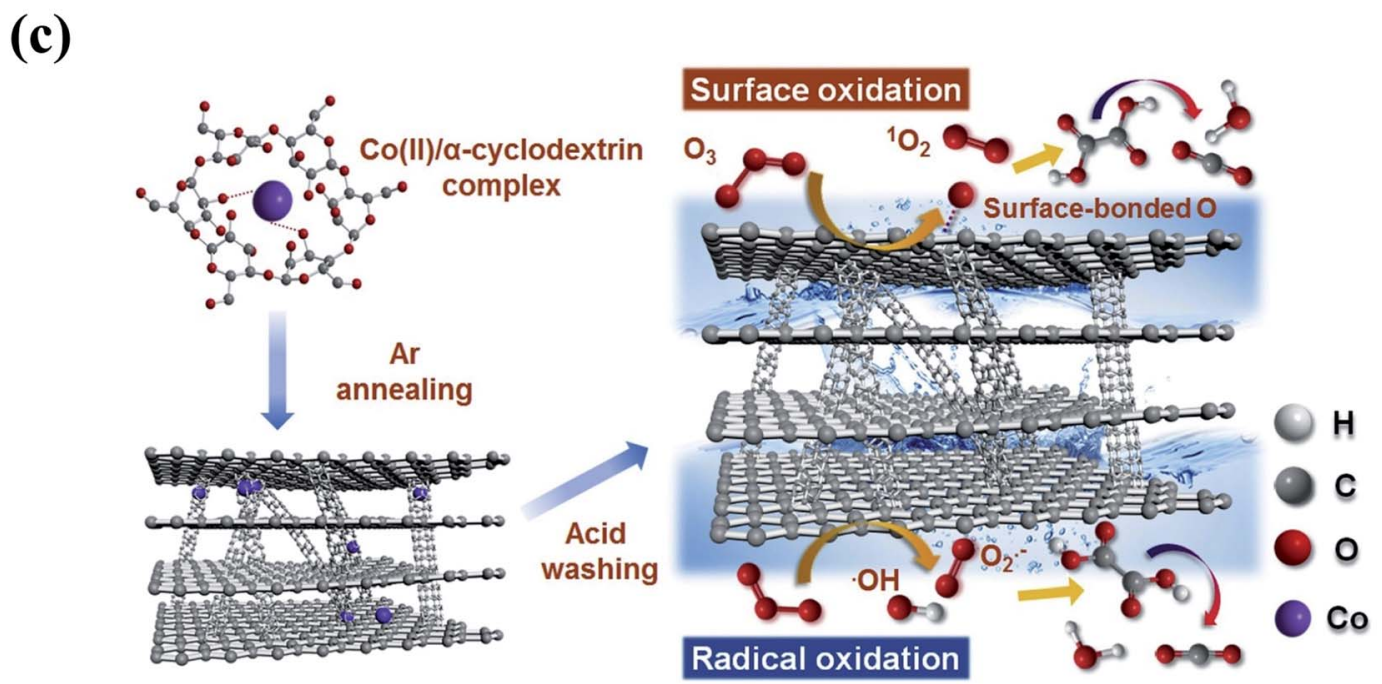

Fig. 9 (a) Relationships between the removal rates of ketoprofen and the content of different N species of NHCs. (b) Mechanism of ketoprofen degradation by catalytic ozonation on NHCs. Reprinted with permission from ref. 158. Copyright 2019, American Chemical Society. (c) Schematic diagram of catalytic ozonation of OA with CPGs. Reprinted with permission from ref. 159. Copyright 2020, Elsevier. 
active sites tended to dissociate into ${ }^{*} \mathrm{O}_{\mathrm{ad}}$ and ${ }^{*} \mathrm{O}_{2}$ free based on in situ Raman spectrum and DFT simulations. With a high oxidation potential of $2.43 \mathrm{~V},{ }^{*} \mathrm{O}_{\mathrm{ad}}$ could directly attack the adsorbed OA molecules via nonradical oxidation, and it was able to react with the ambient $\mathrm{H}_{2} \mathrm{O}$ to generate surface-adsorbed HO'.

Despite of their high catalytic activities, graphene-based materials in catalytic ozonation reactions often demonstrated poor stability and became passivated after the long-term operation. In Song's study, the increase of TOC was observed in both 4-chlorobenzoic acid and benzotriazole degradation using GO as the catalyst. ${ }^{36}$ The soluble GO would react with $\mathrm{O}_{3}$ and ROS during catalytic ozonation, leading to the destruction of its structure and the change in surface chemistry. $\mathrm{O}_{3}$ would attack GO first by oxidation and follow by decomposition. In the oxidation stage, oxygen-containing groups were generated on the surface of GO, and the decomposition stage would give rise to the decay of carbon framework and release of $\mathrm{CO}_{2} / \mathrm{CO}^{147} \mathrm{Du}$ et al. reported that $\mathrm{O}_{3}$ was only capable of oxidizing functionalized aromatic rings in $\mathrm{GO}$; the $\mathrm{C}-\mathrm{O}-\mathrm{C} / \mathrm{C}-\mathrm{OH}$ groups could be oxidized to $\mathrm{C}=\mathrm{O}$ and $\mathrm{O}-\mathrm{C}=\mathrm{O}$ by $\mathrm{O}_{3}$, which could lead to the opening of the aromatic ring. ${ }^{148}$ The combination of $\mathrm{HO}^{\circ}$ and $\mathrm{O}_{3}$ could oxidize both functionalized and unfunctionalized aromatic carbon rings. Previous studies on applications of GO in other oxidative systems, such as $\mathrm{UV} / \mathrm{H}_{2} \mathrm{O}_{2},{ }^{149} \mathrm{UV} / \mathrm{PS},{ }^{149}$ and photo-Fenton process ${ }^{150}$ also reported the similar observations, indicating that GO was not an appropriate candidate for AOPsbased technologies. Though rGO exhibited better structural robustness than GO in catalytic ozonation, ${ }^{36}$ it would still experience gradual deactivation with the increase of cyclic numbers, ${ }^{35,54,142}$ which was mainly ascribed to the change of surface chemistry and the blockage of active sites by the degradation intermediates. Herein, the stability and recyclability of graphene-based materials should be evaluated for applications in AOPs, and the treatment time needs to be optimized to avoid the increase of TOC caused by graphene decomposition.

3.2.3 Other nano-scale carbon-based materials. Apart from CNTs and graphene-based catalysts, graphitic carbon nitride (g$\mathrm{C}_{3} \mathrm{~N}_{4}$ ) with a 2D layered structure composed of intralayer heptazine units with $\mathrm{sp}^{2}$-hybridized $\mathrm{C}$ and $\mathrm{N}$ atoms has been employed in catalytic ozonation. Pristine $\mathrm{g}-\mathrm{C}_{3} \mathrm{~N}_{4}$ usually obtains insufficient activity for the degradation of oxalic acid, ${ }^{151,152}$ bisphenol A, ${ }^{151}$ and $p$-hydroxybenzoic acid. ${ }^{153}$ Modification of $\mathrm{g}$ $\mathrm{C}_{3} \mathrm{~N}_{4}$ with metal-free heteroatoms will disrupt the $\mathrm{sp}^{2}$-hybridized carbon network and induce new physicochemical and electronic properties for photocatalytic ozonation. ${ }^{\mathbf{1 2 1 5 4}}$ Yuan et al. found that oxygen functionalized $\mathrm{g}-\mathrm{C}_{3} \mathrm{~N}_{4}$ (O@g- $\mathrm{C}_{3} \mathrm{~N}_{4}$ ) composite could enhance the removal efficiency of atrazine in catalytic ozonation systems. ${ }^{155}$ The introduction of $\mathrm{O}$ atoms with lone electron pairs effectively regulated the electronic properties of surrounding atoms and facilitated their interactions with $\mathrm{O}_{3}$ to generate $\mathrm{HO}^{\circ}$ and $\mathrm{O}_{2}{ }^{--}$through radical chain reactions. Furthermore, compared with direct oxidation, pre-doping $\mathrm{O}$ atoms into g- $\mathrm{C}_{3} \mathrm{~N}_{4}$ followed by $\mathrm{HNO}_{3}$ oxidation generated extra attachment sites at which oxygen-containing groups could be anchored. ${ }^{156}$ The extensively grafted carboxyl groups at an apex angle in the heptazine unit of $\mathrm{g}-\mathrm{C}_{3} \mathrm{~N}_{4}$ were the principal active sites. Meanwhile, the construction of $\mathrm{N}$ vacancies on the $\mathrm{g}-\mathrm{C}_{3} \mathrm{~N}_{4}$ framework also enhanced the catalytic ozonation activity. As reported by Song et al., delocalized electrons generated by $\mathrm{N}$ vacancies and carbonyl groups in $\mathrm{g}-\mathrm{C}_{3} \mathrm{~N}_{4}$ facilitated the decomposition of $\mathrm{O}_{3}$ into $\mathrm{HO}^{*}$ for 4-chlorobenzoic acid and benzotriazole degradation as well as bromate elimination. ${ }^{36}$ However, the overabundant hydrogen bonds might hinder electron transfer and thus impact catalytic activity. It should be noted that the heptazine unit of $\mathrm{g}-\mathrm{C}_{3} \mathrm{~N}_{4}$ would be attacked by $\mathrm{HO}^{\cdot}$ into nitrates, while $\mathrm{g}-\mathrm{C}_{3} \mathrm{~N}_{4}$ could maintain structural stability under the attack of $\mathrm{O}_{2}{ }^{--}$and $\mathrm{O}_{3} \cdot{ }^{157}$ Due to the competitive reactions between organic pollutants and $g-\mathrm{C}_{3} \mathrm{~N}_{4}$ for $\mathrm{HO}^{*}$, the decomposition of $\mathrm{g}-\mathrm{C}_{3} \mathrm{~N}_{4}$ could be completely or partially impeded in the presence of organic pollutants with small molecular weights. On the contrary, in the case of pollutants with larger molecular weights, both $\mathrm{g}-\mathrm{C}_{3} \mathrm{~N}_{4}$ and pollutants were simultaneously oxidized by $\mathrm{HO}^{\circ}$.

3D nanocarbons with porous structures and large SSA are conducive to the maximum exposure of active sites and the mass transfer in heterogeneous catalytic processes. Ma's group prepared in situ N-doped hollow sphere carbons (NHCs) via the facile pyrolysis of polydopamine using a template-etching method, and principally figured out the specific role of three $\mathrm{N}$ species including pyrrolic, pyridinic, and graphitic Ns in catalytic ozonation (Fig. 9a). ${ }^{\mathbf{1 5 8}}$ The extraordinary catalytic ozonation activity of NHCs for ketoprofen destruction was attributed to the synergy between $\mathrm{HO}^{*}$ radical-based oxidation and a nonradical intra-electron-transfer pathway. Pyrrolic and pyridinic Ns at edges and structural vacancies functioned as the "radical-generation" region to initiate $\mathrm{HO}^{\circ}$-based oxidation, while the graphitic $\mathrm{N}$ served as the "electron-mobility" region to accelerate the electron transfer from the adsorbed organics to the activated $\mathrm{O}_{3}$ via a nonradical oxidation pathway (Fig. 9b). ${ }^{158}$ Metal-free 3D mesoporous graphitic carbons with built-in nanotubes (CPGs) were synthesized via a facile one-pot copyrolysis method using cost-efficient precursors (Fig. 9c). ${ }^{159}$ The CPGs showed superior catalytic ozonation activities in OA destruction compared with CNTs, rGO, and $\mathrm{LaMnO}_{3}$ perovskite catalysts, which could be ascribed to the nanoconfinement effect brought by the presence of few-layer (5-10) built-in nanotubes within the bulk structure of graphitic carbons.

\subsection{Carbon-based nanocomposites}

Heterogeneous metal-based catalysts show desirable activities, but generally suffer from poor stability due to metal leaching and agglomeration. Anchoring metal species on supports can significantly improve the stability and dispersion of metal species, thereby suppressing the metal leaching and facilitating the exposure of active metal sites (Fig. 10a). Moreover, the electron conductivity and electron-transfer capacity can be enhanced due to the synergistic effect between the metal species and the supports, which further contributes to the catalytic activity. Carbonaceous materials have been exploited as versatile catalyst supports because of their adjustable 
(a)

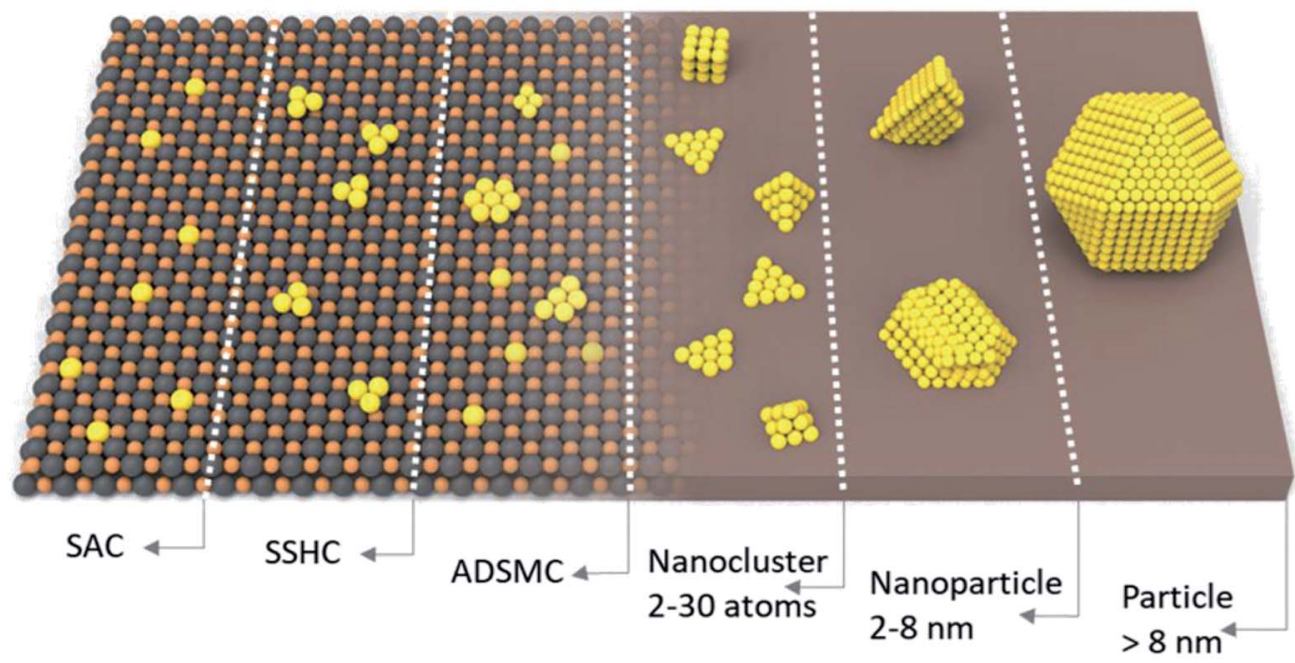

(b)

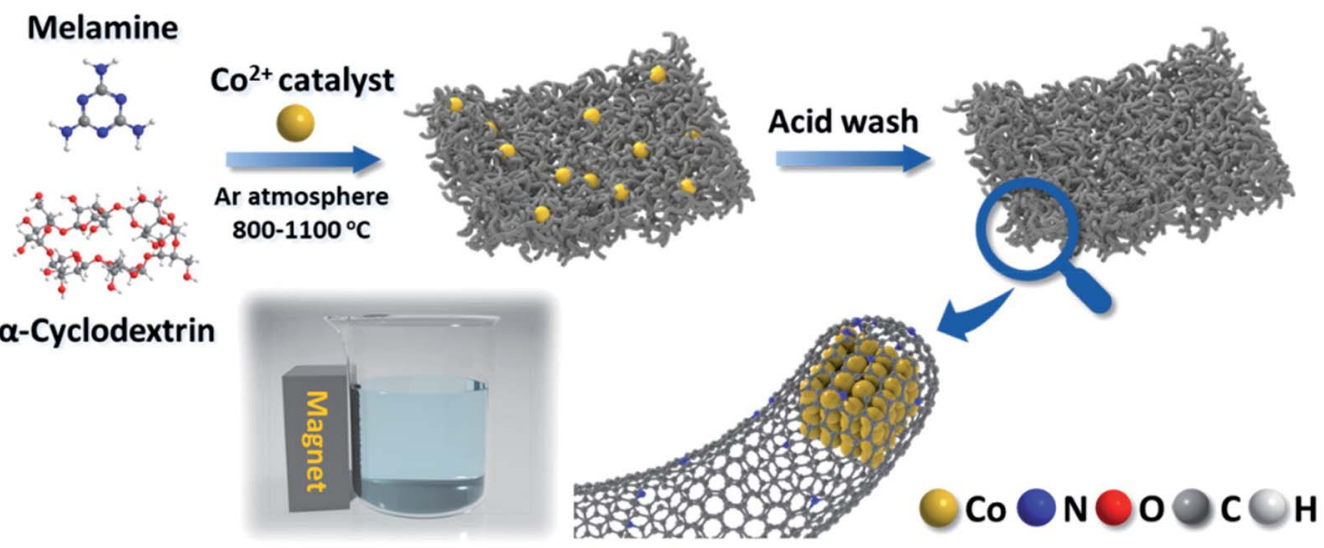

(c)
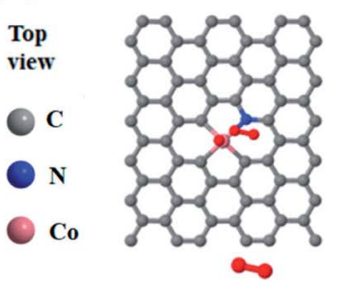

Side
view

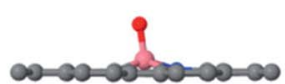

(d)

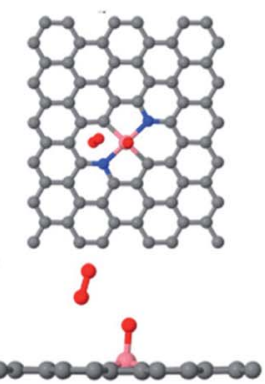

(e)

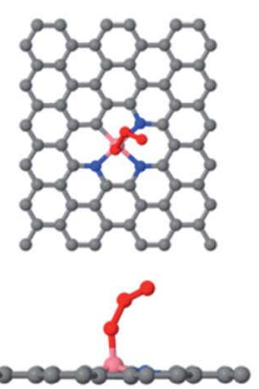

(f)

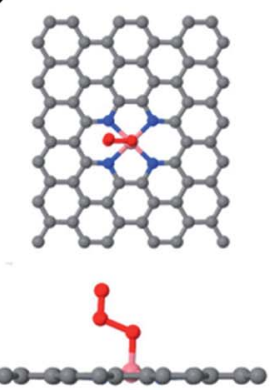

Fig. 10 (a) Schematic illustration of the various types of metal-carbon nanocomposites. (SSHC and ADSMC are defined as single site heterogeneous catalyst and atomically dispersed supported metal catalyst, respectively.) Reprinted with permission from ref. 195. Copyright 2019, Wiley-VCH. (b) Schematic illustration of the synthesis route for Co-NaCNTs. DFT simulations for mimicking the adsorption of $\mathrm{O}_{3}$ onto (c) Co$\mathrm{N}_{1}$, (d) Co $-\mathrm{N}_{2}$, (e) $\mathrm{Co}-\mathrm{N}_{3}$, and (f) Co-N . Reprinted with permission from ref. 96. Copyright 2021, American Chemical Society.

dimensional architecture, SSA, and surface chemistry which facilitate the anchoring and dispersion of metal species.

Transition metals have been recognized as the catalytic active sites in ozone activation owing to their multivalence states originated from their $3 \mathrm{~d}$ orbitals, which accelerate the electron-transfer process via redox reactions. Different transition metals have been applied to modify carbon materials, such as $\mathrm{Mn}, \mathrm{Fe}, \mathrm{Co}$, and $\mathrm{Zn}$, as well as their oxides (summarized in Table 2). Ma et al. anchored manganese oxides $\left(\mathrm{MnO}_{x}\right)$ on granular active carbon (GAC) to enhance the ozonation of nitrobenzene, and higher catalytic treatment efficiency was observed at low pH (2.74-3.52) than that at high pH (6.72-9.61) because the low $\mathrm{pH}$ condition benefited the adsorption of nitrobenzene on the catalyst. ${ }^{162}$ AC derived from sewage sludge (SBAC) was also used to load Mn. ${ }^{\mathbf{1 6 3 , 1 6 4}}$ The organic degradation pathways were different in these studies which were either attributed to $\mathrm{HO}^{\circ}$-based degradation or the surface electron transfer among the loaded metal oxides and the adsorbed 
Table 2 Application of carbon-based nanocomposites in catalytic ozonation for the abatement of pollutants

\begin{tabular}{|c|c|c|c|c|c|}
\hline Catalysts & $\begin{array}{l}\text { Synthesis/modification } \\
\text { methods }\end{array}$ & Target pollutants & Active sites & ROS & Ref. \\
\hline \multicolumn{6}{|c|}{ Supported manganese oxides } \\
\hline $\mathrm{MnO}_{x} / \mathrm{GAC}$ & Impregnation method & $\begin{array}{l}\text { Nitrobenzene, oxalic } \\
\text { acid }\end{array}$ & Mn species & $\begin{array}{l}\mathrm{HO}^{\circ}, \text { surface } \\
\text { adsorbed } \\
\text { ROS }\end{array}$ & 162 and 163 \\
\hline $\mathrm{MnO}_{2} /$ biochar & Impregnation method & $\begin{array}{l}\text { Piggery bio-treatment } \\
\text { effluents }\end{array}$ & Surface hydroxyl groups & $\mathrm{HO}^{\circ}$ & 196 \\
\hline $\mathrm{MnO}_{x} /$ biochar & Impregnation method & Atrazine & Lewis acid sites & $\mathrm{HO}^{*}, \mathrm{O}_{2}^{\cdot-}$ & 197 \\
\hline $\mathrm{MnO}_{x} / \mathrm{MWCNT}$ & Impregnation method & Ciprofloxacin & $\mathrm{Mn}^{n+} / \mathrm{Mn}^{n+2}$ & $\mathrm{HO}^{\circ}$ & 198 \\
\hline $\mathrm{MnO}_{2}-\mathrm{NH}_{2} / \mathrm{GO}$ & Hydrothermal method & Cephalexin & $\mathrm{Mn}^{3+} / \mathrm{Mn}^{4+}$ & $\mathrm{O}_{2}^{\cdot-}$ & 188 \\
\hline$\alpha-\mathrm{MnO}_{2} / \mathrm{rGO}$ & Hydrothermal method & Bisphenol-A & - & $\mathrm{HO}^{\circ}$ & 165 \\
\hline$\beta-\mathrm{MnO}_{2} / \mathrm{rGO}$ & Hydrothermal method & Dichloroacetic acid & - & $\mathrm{HO}^{*}$ & 166 \\
\hline$\gamma-\mathrm{MnO}_{2} / \mathrm{rGO}$ & Hydrothermal method & 4-Nitrophenol & $\mathrm{Mn}(\mathrm{III}) / \mathrm{Mn}(\mathrm{IV})$ & $\mathrm{O}_{2}{ }^{\cdot-},{ }^{1} \mathrm{O}_{2}$ & 83 \\
\hline \multicolumn{6}{|c|}{ Supported iron oxides } \\
\hline $\mathrm{Fe} / \mathrm{AC}$ & $\begin{array}{l}\text { Dipping method, } \\
\text { commercially } \\
\text { purchased }\end{array}$ & $\begin{array}{l}\text { Dibutyl phthalate, } \\
\text { formate }\end{array}$ & Fe species & $\mathrm{HO}^{\circ}$ & 169 and 172 \\
\hline $\mathrm{FeO}_{x} /$ biochar & Impregnation method & Atrazine & Lewis acid sites & $\mathrm{HO}^{\circ}, \mathrm{O}_{2}^{\cdot-}$ & 197 \\
\hline $\mathrm{Fe}^{0} / \mathrm{CNTs}$ & $\begin{array}{l}\text { Electrophoresis } \\
\text { deposition followed by } \\
\text { calcinations }\end{array}$ & Methylene blue & $\mathrm{Fe}(\mathrm{III}) / \mathrm{Fe}(\mathrm{IV})$ & $\mathrm{HO}^{\circ}$ & 199 \\
\hline $\mathrm{Fe}_{3} \mathrm{O}_{4} / \mathrm{MWCNTs}$ & Hydrothermal method & Bisphenol A & Surface oxygen groups & $\mathrm{HO}^{\circ}$ & 173 \\
\hline $\mathrm{Fe}_{3} \mathrm{O}_{4} / \mathrm{GO}$ & Precipitation method & $\begin{array}{l}p \text {-Chlorobenzoic acid, } \\
\text { ibuprofen }\end{array}$ & - & $\mathrm{HO}^{\circ}$ & 141 \\
\hline \multicolumn{6}{|c|}{ Supported cobalt oxides } \\
\hline $\mathrm{Co} / \mathrm{AC}$ & Impregnation method & Nitrobenzene & Co species & $\mathrm{HO}^{\bullet}$ & 200 \\
\hline Co-N@CNTs & $\begin{array}{l}\text { Two-step carbonization } \\
\text { method }\end{array}$ & Oxalic acid, phenol & $\begin{array}{l}\text { Two pyridinic N- } \\
\text { coordinated } \mathrm{Co}\left(\mathrm{Co}-\mathrm{N}_{2}\right)\end{array}$ & ${ }^{*} \mathrm{O}_{\mathrm{ad}},{ }^{1} \mathrm{O}_{2}$ & 96 \\
\hline \multicolumn{6}{|c|}{ Supported zinc oxides } \\
\hline GAC@ZnO & Deep-coating method & Metronidazole & Zn species & $\mathrm{HO}^{\bullet}$ & 201 \\
\hline Zn/CNTs & $\begin{array}{l}\text { Thermal solvent } \\
\text { treatment process using } \\
\text { zinc power, MWCNTs } \\
\text { and } 40 \% \text { polyethylene } \\
\text { glycol followed by } \\
\text { pyrolysis under } \mathrm{N}_{2} \\
\text { atmosphere }\end{array}$ & $\begin{array}{l}\text { 4-Chloro-3-methyl } \\
\text { phenol }\end{array}$ & Zinc oxide (hydroxide) & $\mathrm{HO}^{\circ}, \mathrm{O}_{2}^{\cdot-}$ & 174 \\
\hline $\mathrm{ZVZ} / \mathrm{g}-\mathrm{C}_{3} \mathrm{~N}_{4}$ & $\begin{array}{l}\text { Pyrolysis of zero-valent } \\
\text { zinc }(\mathrm{ZVZ}) \text { and } \mathrm{g}-\mathrm{C}_{3} \mathrm{~N}_{4}\end{array}$ & Atrazine & $\begin{array}{l}\text { Surface hydroxyl } \\
\text { groups, ZVZ/ZnO }\end{array}$ & $\begin{array}{l}\mathrm{HO}^{*}, \mathrm{O}_{2}{ }^{\cdot-}, \\
{ }^{1} \mathrm{O}_{2}\end{array}$ & 175 \\
\hline $\mathrm{ZnO} / \mathrm{g}-\mathrm{C}_{3} \mathrm{~N}_{4}$ & $\begin{array}{l}\text { Mixing and calcination } \\
\text { method }\end{array}$ & Atrazine & $\begin{array}{l}\text { Surface hydroxyl } \\
\text { groups, Zn species }\end{array}$ & $\begin{array}{l}\mathrm{HO}^{\cdot}, \mathrm{O}_{2}^{\cdot-}, \\
{ }^{1} \mathrm{O}_{2}\end{array}$ & 94 \\
\hline \multicolumn{6}{|c|}{ Supported copper oxides } \\
\hline $\mathrm{CuO} / \mathrm{AC}$ & Impregnation method & $\begin{array}{l}\text { Heavy oil refinery } \\
\text { wastewater }\end{array}$ & $\mathrm{Cu}$ species & $\mathrm{HO}^{*}$ & 202 \\
\hline $\mathrm{CuO} / \mathrm{g}-\mathrm{C}_{3} \mathrm{~N}_{4}$ & $\begin{array}{l}\text { Reflux condensation } \\
\text { method }\end{array}$ & Oxalic acid & $\begin{array}{l}\text { Oxygen vacancies, } \\
\text { surface hydroxyl groups }\end{array}$ & $\mathrm{HO}^{*}, \mathrm{O}_{2}{ }^{--}$ & 203 \\
\hline \multicolumn{6}{|c|}{ Supported platinum oxides } \\
\hline $\mathrm{Pt} / \mathrm{CNT}$ & $\begin{array}{l}\text { Incipient wetness } \\
\text { impregnation method }\end{array}$ & Oxalic acid & $\mathrm{Pt}_{\mathrm{red}} / \mathrm{Pt}_{\mathrm{ox}}$ & $\mathrm{HO}^{\circ}$ & 176 \\
\hline \multicolumn{6}{|c|}{ Supported cerium oxides } \\
\hline $\mathrm{Ce} / \mathrm{AC}$ & Precipitation method & $\begin{array}{l}\text { Textile dyes, dimethyl } \\
\text { phthalate, } p \text { - } \\
\text { toluenesulfonic acid }\end{array}$ & $\mathrm{Ce}^{3+}$ species & $\mathrm{HO}^{\circ}$ & $\begin{array}{l}177,178 \text { and } \\
180\end{array}$ \\
\hline
\end{tabular}


Table 2 (Contd.)

\begin{tabular}{|c|c|c|c|c|c|}
\hline Catalysts & $\begin{array}{l}\text { Synthesis/modification } \\
\text { methods }\end{array}$ & Target pollutants & Active sites & ROS & Ref. \\
\hline $\mathrm{CeO}_{2} / \mathrm{AC}$ & Impregnation method & Oxalic acid, aniline & $\mathrm{Ce}^{3+}$ species & $\mathrm{HO}^{\circ}$ & 179 and 181 \\
\hline $\begin{array}{l}\mathrm{CeO}_{2} / \mathrm{AC}, \mathrm{CeO}_{2} / \\
\text { MWCNT }\end{array}$ & Impregnation method & Erythromycin & $\mathrm{Ce}^{3+}$ species & $\begin{array}{l}\mathrm{HO}^{\circ}, \text { surface- } \\
\text { oxygenated } \\
\text { radicals }\end{array}$ & 182 \\
\hline $\mathrm{CeO}_{2} / \mathrm{rGO}$ & Hydrothermal method & $\begin{array}{l}N, N \text {-Diethyl- } m \text { - } \\
\text { toluamide }\end{array}$ & $\mathrm{Ce}^{3+} / \mathrm{Ce}^{4+}$ & $\mathrm{HO}^{\circ}$ & 205 \\
\hline \multicolumn{6}{|c|}{ Supported bimetallic oxides } \\
\hline $\mathrm{Fe}_{2} \mathrm{O}_{3}-\mathrm{CeO}_{2} / \mathrm{AC}$ & Impregnation method & Sulfamethoxazole & Metal oxides & $\mathrm{HO}^{\circ}$ & 206 \\
\hline $\mathrm{MnO}_{2}-\mathrm{Co}_{3} \mathrm{O}_{4} / \mathrm{AC}$ & $\begin{array}{l}\text { Impregnation- } \\
\text { precipitation method }\end{array}$ & Incineration leachate & - & $\mathrm{HO}^{\circ}$ & 192 \\
\hline $\mathrm{Fe}-\mathrm{Ni} / \mathrm{AC}$ & Impregnation method & $\begin{array}{l}2,4- \\
\text { Dichlorophenoxyacetic } \\
\text { acid }\end{array}$ & Iron-nickel & $\mathrm{HO}^{\circ}$ & 207 \\
\hline $\mathrm{Fe}-\mathrm{Mn} / \mathrm{GAC}$ & $\begin{array}{l}\text { Impregnation- } \\
\text { desiccation method }\end{array}$ & Methyl orange & Metal species & $\mathrm{HO}^{\circ}$ & 208 \\
\hline $\mathrm{MnFe}_{2} \mathrm{O}_{4} / \mathrm{rGO}$ & $\begin{array}{l}\text { Electrospinning } \\
\text { method }\end{array}$ & Di- $n$-butyl phthalate & $\begin{array}{l}\text { Surface hydroxyl } \\
\text { groups, } \mathrm{Mn}^{2+} / \mathrm{Mn}^{3+}\end{array}$ & $\mathrm{HO}^{\circ}$ & 193 and 194 \\
\hline
\end{tabular}

organics and $\mathrm{O}_{3} \cdot{ }^{163,164}$ However, the multivalence of Mn stimulated the electron-transfer in both processes. Great efforts have also been put into the hybridization of rGO and $\mathrm{MnO}_{2}$ for catalytic ozonation. ${ }^{\mathbf{8 3 , 1 6 5 , 1 6 6}} \quad 2 \mathrm{D} \quad \gamma-\mathrm{MnO}_{2} / \mathrm{rGO}$ nanohybrids $\left(\mathrm{MnO}_{2} / \mathrm{rGO}\right)$ were fabricated and used for catalytic ozonation by Wang and co-workers. ${ }^{83}$ The redox reactions between $\mathrm{Mn}^{3+}$ and $\mathrm{Mn}^{4+}$ via single electron transfer acted as the active sites for the catalytic reaction. The electron transfer process was further promoted by the tight interaction between $\mathrm{MnO}_{2}$ and rGO.

$\mathrm{Mn} / \mathrm{CNTs}$ composites were developed to intensify catalytic ozonation by uniting the merits of both homogeneous and heterogeneous reactions. ${ }^{\mathbf{1 6 7}}$ The reversible desorption and adsorption of $\mathrm{Mn}^{2+}$ on the surface of CNTs could be regulated by the spontaneous variations of solution $\mathrm{pH}$ during pollutant mineralization. At the first stage, organic acids as the degradation intermediates would gradually accumulate and lower the solution $\mathrm{pH}$. CNTs surface was positively charged when solution $\mathrm{pH}<\mathrm{pH}_{\mathrm{pzc}}$ of CNTs, leading to the desorption of $\mathrm{Mn}^{2+}$ by the electrostatic repelling forces. The dissolved $\mathrm{Mn}^{2+}$ in the solution allowed homogeneously catalytic ozonation. With the mineralization of organic acid intermediates, solution $\mathrm{pH}$ gradually increased and $\mathrm{Mn}^{2+}$ re-adsorbed on the electronegative CNTs surface when solution $\mathrm{pH}$ was higher than the $\mathrm{pH}_{\mathrm{pzc}}$ of the catalyst, thereby achieving the recovery of $\mathrm{Mn}^{2+}$. However, during this process, $\mathrm{Mn}^{2+}$ was inevitably oxidized into $\mathrm{MnO}_{2}$ during catalytic ozonation and resulted in the decrease of catalytic efficiency.

Iron-based catalysts have been widely employed because of their comparatively low price and high catalytic performance. In combination with Fe-loaded AC for catalytic ozonation, the treatment efficiency for various refractory pollutants such as crystal violet, ${ }^{\mathbf{1 6 8}}$ dibutyl phthalate, ${ }^{\mathbf{1 6 9}}$ and organic contaminants in heavy oil refining wastewater ${ }^{\mathbf{1 7 0}}$ and biologically pretreated coal gasification wastewater ${ }^{171}$ were greatly enhanced. In Yuan's study, an iron oxide-impregnated AC catalyst (JBX) was only effective to activate $\mathrm{O}_{3}$ for formate/oxalate degradation at $\mathrm{pH} 3$, while the alkaline environment $(\mathrm{pH} 7.3$ and 8.5) inhibited the catalytic activity. ${ }^{\mathbf{1 7 2}}$ As revealed, the positively charged protonated iron oxide surface sites at acidic $\mathrm{pH}$ obtained a higher affinity toward $\mathrm{O}_{3}$ than the deprotonated sites at basic $\mathrm{pH}$. $\mathrm{Fe}_{3} \mathrm{O}_{4} / \mathrm{MWCNTs}$ samples with the similar surface area but different surface oxygen functional groups were also fabricated to investigate the effect of oxygen-containing groups on catalytic ozonation activity. ${ }^{173} \mathrm{Fe}_{3} \mathrm{O}_{4}$ /MWCNTs with the maximum amount of surface oxygen-containing groups exhibited the highest adsorption capability and catalytic activity, because 
surface oxygen functionalities could combine with organics via hydrogen bonding and induce $\mathrm{O}_{3}$ decomposition.

The built-in electric field at the Zn-CNTs interface facilitated $\mathrm{O}_{3}$ adsorption and subsequent conversion into $\mathrm{H}_{2} \mathrm{O}_{2}$, which further evolved into $\mathrm{HO}^{*}$ for organics degradation. ${ }^{\mathbf{1 7 4}}$ Additionally, the formed zinc oxide and zinc hydroxide with small particle sizes and large SSA could also promote the decomposition of $\mathrm{O}_{3}$ to yield $\mathrm{HO}^{\circ}$. The introduction of zero-valent zinc $(\mathrm{ZVZ})$ modified the electronic structure of pristine $\mathrm{g}-\mathrm{C}_{3} \mathrm{~N}_{4}$, and the redox couple of $\mathrm{ZnO} / \mathrm{ZVZ}$ was favorable to the electrontransfer process. ${ }^{175}$ Loading $\mathrm{ZnO}$ on $\mathrm{g}-\mathrm{C}_{3} \mathrm{~N}_{4}$ also induced a higher density of defective sites. ${ }^{94}$ Meanwhile, the formed $\mathrm{Zn}$ $\mathrm{N}$ bonds between $\mathrm{ZnO}$ and $\mathrm{g}-\mathrm{C}_{3} \mathrm{~N}_{4}$ adjusted the electron density of the nanocomposites near the Fermi level and optimized the work function for promoting the generation of photoinduced electrons. Platinum (Pt) has also been loaded on the carbonaceous supports as the ozonation catalysts. ${ }^{176} \mathrm{CNTs}$ supported Pt catalyst (Pt/CNTs) was found to be more active than Pt/AC in the ozonation of $\mathrm{OA}$, because of the higher accessibility of $\mathrm{Pt}$ particles locating on the outer surface of CNTs. ${ }^{176}$ It was reported that the redox couple of $\mathrm{Pt}$ was decisive for $\mathrm{HO}^{\circ}$ generation.

As a typical rare earth oxide, cerium oxide $\left(\mathrm{CeO}_{2}\right)$ is more active than other rare earth oxides due to its special structure of 4f orbit and high oxygen mobility. ${ }^{177}$ A coupling effect of AC and $\mathrm{CeO}_{2}$ was reported to enhance the catalytic ozonation efficiency in the treatment of textile effluents, ${ }^{178}$ pharmaceutical wastewater $^{177}$ as well as the removal of individual or mixed micropollutants. ${ }^{\mathbf{1 7 9 , 1 8 0}}$ The free electrons on the basal plane of AC were beneficial for the formation of $\mathrm{Ce}^{3+}$ species and thus promoted the redox reactions involving the cerium redox pair $\left(\mathrm{Ce}^{3+} /\right.$ $\left.\mathrm{Ce}^{4+}\right) \cdot{ }^{178,181}$ The catalytic activity and selectivity of Ce/AC depend on the cerium precursors $\left(\mathrm{Ce}^{3+}\right.$ or $\left.\mathrm{Ce}^{4+}\right)$. For oxalic acid destruction, the catalysts obtained from the " $\mathrm{Ce}^{4+}$ " precursor possessed the highest mineralization efficiency, whereas aniline mineralization was favored by the catalysts prepared

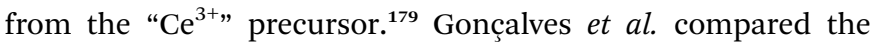
catalytic performance between $\mathrm{CeO}_{2} / \mathrm{MWCNTs}$ and $\mathrm{CeO}_{2} / \mathrm{AC}$ for the ozonation of erythromycin (ERY). ${ }^{182}$ The synergic effect between carbon materials and $\mathrm{CeO}_{2}$ was more evident in $\mathrm{CeO}_{2} /$ MWCNTs because of the higher dispersion of $\mathrm{CeO}_{2}$ on MWCNTs than that on AC. Additionally, ERY with large molecular weight tended to adsorb and react on the mesoporous surface of $\mathrm{CeO}_{2} / \mathrm{MWCNTs}$ rather than on the microporous surface of $\mathrm{CeO}_{2} / \mathrm{AC}$. The dispersion of $\mathrm{CeO}_{2}$ on CNTs can be regulated by chemical treatment to increase the surface functionalities of CNTs. The well-dispersed $\mathrm{CeO}_{2}$ was beneficial to the exposure of active sites and decrease the mass-transfer resistance. ${ }^{183}$ The abundant $\pi-\pi$ electrons on the surfacefunctionalized CNTs facilitated the mobility of electron and thus accelerated the redox cycle of $\mathrm{Ce}^{3+} / \mathrm{Ce}^{4+}$ for $\mathrm{O}_{3}$ activation.

The bonding strength between metal species and carbon supports is a decisive factor influencing the activity and stability of carbon-supported catalysts. Previous studies indicated that the presence of strong chemical bonds between graphene and active components could lead to the improvement of electrochemical performance as well as cyclic stability of constituents. ${ }^{\mathbf{1 8 4 , 1 8 5}}$ Therefore, reinforcing the interface bonding force can be a viable strategy to improve both the activity and the long-term stability of carbon-metal nanocomposites. The introduction of surface functionalities on the carbon supports provides strong binding sites for metal species and helps to stabilizing the structure of catalysts. ${ }^{\mathbf{1 8 6 , 1 8 7}}$ Given that the hybrid structure of $\mathrm{MnO}_{2}-\mathrm{GO}$ was not stable enough because of the weak physical adsorption and electrostatic interaction between $\mathrm{MnO}_{2}$ and $\mathrm{GO}, \mathrm{Xu}$ et al. synthesized a novel structured catalyst via amino-functionalizing the hybrids of $\mathrm{MnO}_{2}$ and $\mathrm{GO}\left(\mathrm{MnO}_{2}-\right.$ $\left.\mathrm{NH}_{2}-\mathrm{GO}\right){ }^{188}$ The amino-functionalization endowed $\mathrm{MnO}_{2}-$ $\mathrm{NH}_{2}$-GO higher stability than $\mathrm{MnO}_{2}-\mathrm{GO}$ via strengthening the covalent bonding between $\mathrm{MnO}_{2}$ and $\mathrm{GO}$ to prevent their decoupling. The formed strong covalent bonds bridged by $\mathrm{NH}_{2}$ would accelerate the charge transfer.

In addition to the surface functionalization, the introduction of heteroatoms into the carbon lattice alters the electronic and adsorption properties in the local region and increases the reactivity of adjacent carbon atoms, which possess efficient localized grounds for bonding with metal species. ${ }^{189,190}$ Taking advantage of $\mathrm{Co}_{3} \mathrm{O}_{4}$ and $\mathrm{N}$ modification, the $\mathrm{N}$-doped graphene (NG) supported $\mathrm{Co}_{3} \mathrm{O}_{4}$ nanocrystals $\left(\mathrm{Co}_{3} \mathrm{O}_{4} / \mathrm{NG}\right)$ showed outstanding catalytic activity and stability compared with its sole counterparts. ${ }^{191} \mathrm{Co}_{3} \mathrm{O}_{4} / \mathrm{NG}$ obtained a smaller particle size and better dispersion of $\mathrm{Co}_{3} \mathrm{O}_{4}$ compared with $\mathrm{Co}_{3} \mathrm{O}_{4} / \mathrm{G}$ because of $\mathrm{NH}_{3}-\mathrm{Co}$ coordination. The increased surface $\pi$ electronic density and the basic active centers (e.g., pyridinic-N and pyrrolic-N) brought by $\mathrm{N}$ dopants promoted electron transfer between the $\pi$ orbitals of graphene and the $\mathrm{d}$ orbitals of Co atoms, leading to the enhanced phenol adsorption and $\mathrm{O}_{3}$ activation. Recently, Wang et al. reported the remarkable catalytic activity and chemical stability of N-doped carbon nanotubes with encapsulated Co (Co-N@CNTs). ${ }^{96}$ The embedded Co nanoparticles endowed Co-N@CNTs with magneticity, which was favorable for magnetic separation and recycling (Fig. 10b). DFT calculations suggested that pyridinic $\mathrm{N}-\mathrm{Co}$ manifested more negative adsorption energy than other types of $\mathrm{N}-\mathrm{Co}$ coordination, and Co coordinated with two pyridinic $\mathrm{N}$ atoms $\left(\mathrm{Co}-\mathrm{N}_{2}\right)$ demonstrated the greatest affinity toward $\mathrm{O}_{3}$ adsorption to induce surface-based nonradical oxidation (Fig. 10c-f). Meanwhile, the high DoS of Co- $\mathrm{N}_{2}$ at the Fermi level facilitated the electron transfer from $\mathrm{Co}-\mathrm{N}_{2}$ to $\mathrm{O}_{3}$ and the redox cycle at the active sites.

Additionally, the activity and durability of carbocatalysts can also be improved through bimetallic loading. Li and co-workers used $\mathrm{MnO}_{2}-\mathrm{Co}_{3} \mathrm{O}_{4} / \mathrm{AC}$ in catalytic ozonation and observed the increased biodegradability $\left(\mathrm{BOD}_{5} / \mathrm{COD}\right)$ of incineration leachate containing abundantly refractory humic-like and fulvic-like components, compared with AC loaded with single metal. ${ }^{192}$ The relationship between the concentration of surface hydroxyl sites on $\mathrm{rGO}-\mathrm{MnFe}_{2} \mathrm{O}_{4}$ and the removal rate of di- $n$ butyl phthalate was in positive linearity. ${ }^{193,194}$ The hydroxyl groups on the surface of $\mathrm{rGO}-\mathrm{MnFe}_{2} \mathrm{O}_{4}$ hybrids bonded with $\mathrm{MnFe}_{2} \mathrm{O}_{4}$ and $\mathrm{C}$ atoms to form chemisorbed oxygen groups (Mn-O-H, C-O-H, or $\mathrm{C}-\mathrm{OOH}$ ), which acted as the active sites for catalytic ozonation. ${ }^{194}$ In a $\mathrm{LaCoO}_{3} / \mathrm{g}-\mathrm{C}_{3} \mathrm{~N}_{4}$ activated $\mathrm{O}_{3}$ system, the charge transfer between electron-rich centers 


$$
\text { Strong interaction }
$$

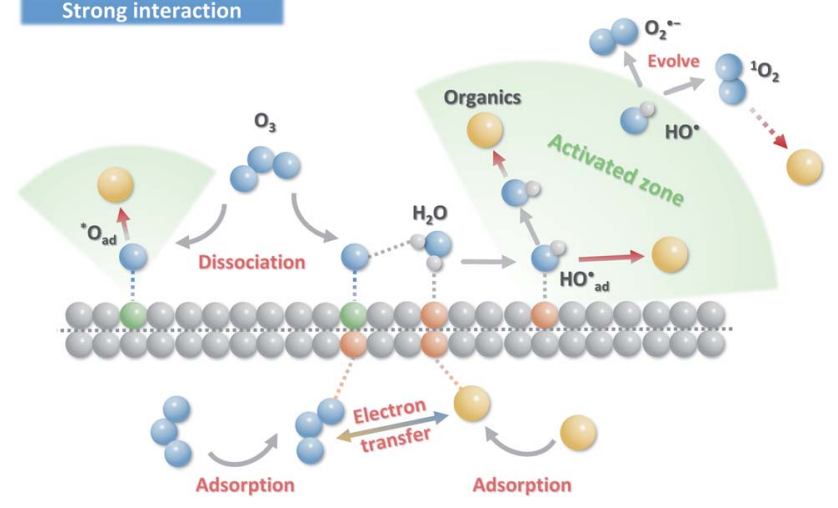

Weak interaction

Fig. 11 Schematic illustration of the interactions of $\mathrm{O}_{3}$ on carbon surface for ROS generation.

created by $-\mathrm{C}-\mathrm{O}-\mathrm{Co}$ or nitrogen vacancies and electron-poor centers promoted $\mathrm{HO}^{\circ}$ generation. ${ }^{97}$

\section{Catalytic mechanisms in carbon- driven ozonation}

\subsection{Correlations of $\mathrm{O}_{3} @$ @carbon interaction intensity and reaction pathways}

Carbon-based ozonation processes typically involve free radicals (such as $\mathrm{HO}^{\cdot}$ and $\mathrm{HO}_{2}{ }^{*} / \mathrm{O}_{2}{ }^{-}$) and nonradical (surfaceadsorbed activated species and singlet oxygen $\left({ }^{1} \mathrm{O}_{2}\right)$ ) oxidation pathways. ${ }^{15,16}$ The adsorption of $\mathrm{O}_{3}$ on the catalysts surface is a vital process for $\mathrm{O}_{3}$ activation and the subsequent ROS formation. The intensity of interactions between the active sites and the reactants $\left(\mathrm{O}_{3}\right.$ and organics $)$ governs the oxidation pathways (Fig. 11). Defects and active sites with high electron density could induce strong interactions with $\mathrm{O}_{3}$, resulting in the dissociation of $\mathrm{O}_{3}$ into surface-adsorbed atomic oxygen $\left({ }^{*} \mathrm{O}_{\mathrm{ad}}\right)$ and a free peroxide species $\left({ }^{*} \mathrm{O}_{2}\right.$ free $)$ (eqn (1)). ${ }^{*} \mathrm{O}_{\mathrm{ad}}$ with a high oxidation potential of $2.43 \mathrm{~V}$ will elevate the surface potential, which facilitates the activation of the ambient water molecules to generate $\mathrm{HO}^{\circ}$ and triggers the subsequent radical chain reactions (Fig. 11). ${ }^{74,96,142} * \mathrm{O}_{\text {ad }}$ also favors the hydrogen abstraction reaction with surrounding water molecules or $\mathrm{H}^{+}$, and such a process is governed by the solution $\mathrm{pH}$. The asformed ${ }^{*} \mathrm{O}_{\mathrm{ad}}-\mathrm{H}$ might further activate $\mathrm{O}_{3}$ molecules for $\mathrm{HO}{ }^{*}$ formation. In situ characterizations with the isotopic substitution of ${ }^{16} \mathrm{O}_{3}$ or $\mathrm{H}_{2}{ }^{16} \mathrm{O}$ by ${ }^{17} \mathrm{O}_{3}$ or $\mathrm{H}_{2}{ }^{17} \mathrm{O}^{209,210}$ and the DFT simulations on thermodynamics feasibility of the reactions between ${ }^{*} \mathrm{O}_{\text {ad }}$ and $\mathrm{H}_{2} \mathrm{O}$ via calculating the free energies of intermediates and the energy barriers of transition states can be performed in the future studies to unveil the origin of $\mathrm{HO}^{\circ}{ }^{211,212}$ The $\mathrm{HO}^{\circ}$-based ozonation obtains fast reaction rates toward almost all kinds of organics because of the high oxidizing capability and nonselectivity of $\mathrm{HO}^{\circ}$. Nevertheless, the short half-life of $\mathrm{HO}^{\circ}\left(t_{1 / 2} \leq 1 \mu \mathrm{s}\right)$ limits the effective mass transfer and long-range attack, making $\mathrm{HO}^{*}$ only effective around the surface region of catalysts. ${ }^{213}$ Additionally, ${ }^{*} \mathrm{O}_{\mathrm{ad}}$ can induce nonradical oxidation. The high oxidation potential makes it capable of mineralizing recalcitrant organics such as aliphatic acids. The strong interactions between the active sites and $\mathrm{O}_{3}$ could form a positively charged zone on catalyst surface. Even if organics cannot adsorb on the surface, organics within this activated zone can be captured and oxidized (Fig. 11).

During the radical chain reactions, $\mathrm{HO}_{2}{ }^{*} / \mathrm{O}_{2}{ }^{-}$and ${ }^{1} \mathrm{O}_{2}$ can be produced as side products (eqn (2)-(7)). With a mild oxidation potential of $0.89-1.7 \mathrm{~V}, \mathrm{HO}_{2}{ }^{-} / \mathrm{O}_{2}{ }^{--}$favors nucleophilic attack of certain organics (e.g., phenolics) via nucleophilic substitution. Singlet oxygen, as one of nonradical ROS, also possesses a mild oxidation potential $(0.81 \mathrm{~V})$. The reaction rates of ${ }^{1} \mathrm{O}_{2}$ with organic compounds range from $10^{4}$ to $10^{7} \mathrm{M}^{-1} \mathrm{~s}^{-1}$, which are much inferior to those with free radicals. ${ }^{2}$

$$
\begin{gathered}
\mathrm{O}_{3} \stackrel{\text { active sites }}{\longrightarrow}{ }^{*} \mathrm{O}_{\mathrm{ad}}+{ }^{*} \mathrm{O}_{2} \text { free } \\
\mathrm{O}_{3}+\mathrm{OH}^{-} \rightarrow \mathrm{HO}_{2}^{\cdot}+\mathrm{O}_{2}{ }^{-}, k=70 \mathrm{M}^{-1} \mathrm{~s}^{-1} \\
\mathrm{O}_{3}+\mathrm{HO}^{\cdot} \rightarrow \mathrm{O}_{2}+\mathrm{HO}_{2}^{\cdot} \\
\mathrm{HO}_{2}^{\cdot} \leftrightarrow \mathrm{O}_{2}{ }^{--}+\mathrm{H}^{+}, \mathrm{p} K_{\mathrm{a}}=4.8 \\
{ }^{*} \mathrm{O}_{2} \stackrel{\text { electron transfer }}{\longrightarrow} \mathrm{O}_{2} \\
\mathrm{O}_{2}{ }^{-}+\mathrm{HO}_{2}^{\cdot}+\mathrm{H}^{+} \rightarrow \mathrm{H}_{2} \mathrm{O}_{2}+{ }^{1} \mathrm{O}_{2} \\
\mathrm{O}_{2}{ }^{--}+\mathrm{HO}^{\cdot} \rightarrow{ }^{1} \mathrm{O}_{2}+\mathrm{OH}^{-}
\end{gathered}
$$

Surface active sites on carbon-based catalysts with moderate electron density would lead to weak interactions with $\mathrm{O}_{3}$, which is conducive to forming a surface- $\mathrm{O}_{3}$ complex. The activated complex would potentially elevate the redox potential of the carbon framework, making it capable of oxidizing the adsorbed organics via an intramolecular electron-transfer process (Fig. 11). ${ }^{158,214,215}$ In this process, the carbon substrate acts both as a catalyst and an electron tunnel for electron transport. A similar activated surface-oxidant complex was reported in persulfate/nanocarbon systems, where the formed carbon-persulfate complex demonstrated a mild oxidation potential $(<1.2$ V) with particular selectivity toward electron-rich organics. ${ }^{216,217}$ Although PDS obtains a similar oxidation potential to $\mathrm{O}_{3}(2.01$ vs. $2.05 \mathrm{~V}$ ), the more complicated molecular structure of PDS dissipates the energy transferred from the adsorption site to the $\mathrm{O}-\mathrm{O}$ bond and hinders its further activation to a higher-energy state. Moreover, $\mathrm{O}_{3}$ presents a higher oxidation potential than PMS (2.05 vs. $1.75 \mathrm{~V})$. Therefore, a greater oxidation ability of the activated surface- $\mathrm{O}_{3}$ complex is expected than that of activated persulfates (PDS and PMS) complex, which has been proved by higher efficiency of aliphatic acids mineralization. ${ }^{218,219}$

\subsection{Analytical approaches for ROS identification}

Tracing the occurrence of ROS and confirming their contributions during catalytic ozonation processes are indispensable for mechanistic studies. Due to the diversity of ROS generated from $\mathrm{O}_{3}$ activation, it is difficult to precisely evaluate the species, quantity, and roles of the reactive species by a single strategy. 
(a)

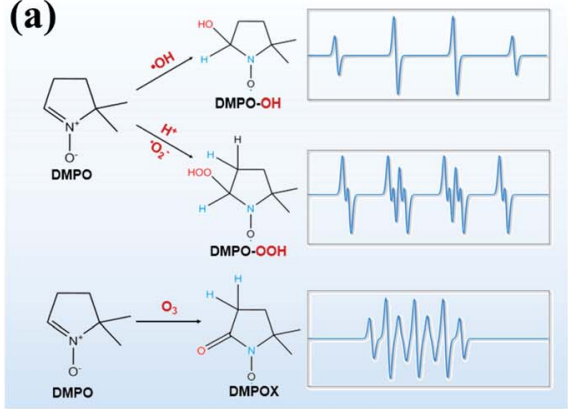

(b)

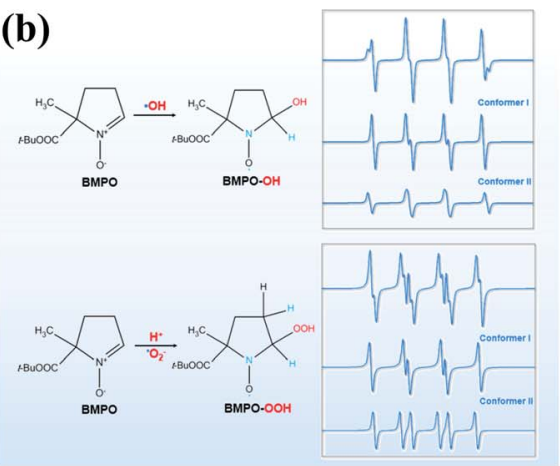

(c)
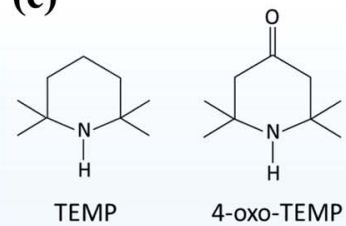<smiles>CC1(C)CC(O)CC(C)(C)N1</smiles>

4-hydroxy-TEMP

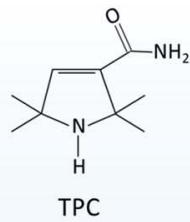

(d)

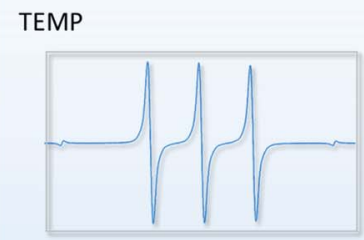

4-hydroxy-TEMP

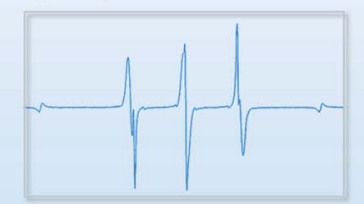

4-OXO-TEMP

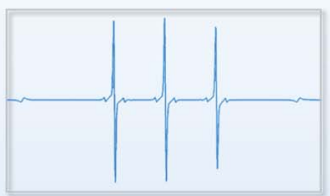

TPC

Fig. 12 (a) Structures and simulated EPR signals of DMPO-HO and DMPO-HOO adducts formed by trapping $\mathrm{HO}^{\cdot}$ and $\mathrm{O}_{2}{ }^{\cdot-}$ with $\mathrm{DMPO}$ and DMPOX formed by oxidation of DMPO with $\mathrm{O}_{3}$. (b) Structures and EPR signals of BMPO-HO' and BMPO-HOO adducts formed by trapping $\mathrm{HO}^{\circ}$ and $\mathrm{O}_{2}{ }^{--}$with BMPO. Adapted with permission from ref. 16. Copyright 2020, American Chemical Society. (c) Chemical structures of four sterically hindered amines. (d) EPR signals of nitroxide radicals formed by trapping ${ }^{1} \mathrm{O}_{2}$ with four sterically hindered amines. Reproduced with permission from ref. 230. Copyright 2017, Royal Society of Chemistry. Reproduced with permission from ref. 231. Copyright 2011, Royal Society of Chemistry.

Therefore, multi-strategies would be encouraged to obtain an in-depth understanding of their generation and contributions.

4.2.1 Electron spin resonance/paramagnetic resonance. Electron spin/paramagnetic resonance (ESR/EPR) spectroscopy provides an efficient way to identify the types of radicals based on the characteristic signals of the spin adducts from the reactions between ROS and their corresponding spin trapping agents. 5,5-Dimethylpyrroline-N-oxide (DMPO) and 5-tertbutoxycarbonyl-5-methyl-1-pyrroline-N-oxide (BMPO) are the most prevailing spin trapping agents for $\mathrm{HO}^{\cdot}$ and $\mathrm{O}_{2}{ }^{\cdot-}$, respectively, due to their good solubility and stability (Fig. 12a and $b$ ). The signal of DMPO-HO' adducts (peak intensity ratio: $1: 2: 2: 1$, hyperfine splitting constants: $\left.a_{\mathrm{N}}=a_{\mathrm{H}}^{\beta}=14.9 \mathrm{G}\right)$ can be easily discriminated by EPR, while the identification of $\mathrm{HO}_{2}^{\circ} / \mathrm{O}_{2}{ }^{-}$is challenging in catalytic ozonation. This is because the oxidation potential of $\mathrm{HO}_{2}^{*} / \mathrm{O}_{2}{ }^{-}-$is relatively weak and their production often accompany by other ROS such as $\mathrm{HO}^{\circ}$ and ${ }^{1} \mathrm{O}_{2} \cdot{ }^{35,220}$ Additionally, the reaction rate of DMPO with $\mathrm{O}_{2}{ }^{\cdot-}$ is extremely lower than that with $\mathrm{HO}^{*}\left(2-170 \mathrm{M}^{-1} \mathrm{~s}^{-1}\right.$ vs. $1.9-4.3 \times$ $\left.10^{9} \mathrm{M}^{-1} \mathrm{~s}^{-1}\right),{ }^{221}$ and the characteristic signals for DMPO-HOO' adducts $\left(a_{\mathrm{N}}=14.2 \mathrm{G}, a_{\mathrm{H}}{ }^{\beta}=11.4 \mathrm{G}\right.$, and $\left.a_{\mathrm{H}}^{\gamma 1}=1.2 \mathrm{G}\right)$ and DMPO$\mathrm{HO}^{*}$ adducts normally overlap. In order to identify the DMPO$\mathrm{HOO}^{\circ}$ adducts, adopting absolute ethanol as the reaction medium instead of ultrapure water can prolong the half-life time $\left(t_{1 / 2}\right)$ of $\mathrm{O}_{2}{ }^{-}$and scavenge $\mathrm{HO}^{-}$in the meantime. ${ }^{35}$ However, carbon-centered radicals, as the byproducts of the quenching reaction, can also be captured by DMPO, which interfere with the distinguish of $\mathrm{O}_{2}{ }^{\cdot-} .^{222}$ Spin-fittings can thus be performed for the further differentiation. Furthermore, DMPO-HOO ${ }^{\circ}$ adducts are unstable $\left(t_{1 / 2}=45 \mathrm{~s}\right)$ and tend to convert into DMPO-HO` adducts. ${ }^{222}$ In some cases, the characteristic signal of 5,5-dimethyl-2-oxo-pyrroline-1-oxyl (DMPOX) with the peak intensity ratio of $1: 2: 1: 2: 1: 2: 1\left(a_{\mathrm{N}}=7.3 \pm\right.$ $\left.0.1 \mathrm{G}, a_{\mathrm{H}}=3.9 \pm 0.1 \mathrm{G}\right)$ is observed, which is attributed to the oxidation of DMPO by $\mathrm{O}_{3}$ or surface-activated species (Fig. 12a). ${ }^{223}$ DMPO-HO' can also be oxidized into DMPOX via electron extraction by $\mathrm{HO}^{*} .^{224}$ Compared with DMPO, BMPO is a better candidate for $\mathrm{O}_{2}{ }^{-}-$spin trapping. The higher stability and longer half-life of BMPO-HOO adducts $\left(t_{1 / 2}=23 \mathrm{~min}\right)$ facilitate the identification of $\mathrm{HO}_{2}^{\cdot} / \mathrm{O}_{2}{ }^{-}$against $\mathrm{HO}^{\cdot}{ }^{\cdot 25}$

Singlet oxygen can be detected by EPR in aqueous solution by four different sterically hindered amines as trapping reagents, including 2,2,6,6-tetramethylpiperidine (TEMP), 2,2,6,6tetramethyl-4-piperidone (4-oxo-TEMP), 2,2,6,6-tetramethyl-4piperidinol (4-hydroxy-TEMP) and 2,2,5,5-tetramethyl-3pyrroline-3-carboxamide (TPC) (Fig. 12c), which can be oxidized by ${ }^{1} \mathrm{O}_{2}$ to generate nitroxide radicals. ${ }^{226}$ The EPR signals of nitroxide radicals generated from each amine demonstrate distinctive triplet peaks (Fig. 12d). Interestingly, 4hydroxy-TEMP can be oxidized into two different EPR signals: 4hydroxy-2,2,6,6-tetramethylpiperidine- $N$-oxyl (TEMPOL) and 4oxo-2,2,6,6-tetramethyl-1-piperidinyloxy

(4-oxo-TEMPO). Among the four sterically hindered amines, 4-hydroxy-TEMP and TPC have a proper sensitivity and a wide detectable range 
for the yield of ${ }^{1} \mathrm{O}_{2} \cdot{ }^{226}$ It is noteworthy that other reactive species (e.g., $\mathrm{HO}^{\cdot}, \mathrm{HO}_{2}{ }^{*} / \mathrm{O}_{2}{ }^{-}$) can also oxidize TEMP to produce similar 3-line characterization signals as ${ }^{1} \mathrm{O}_{2} \cdot{ }^{221,227-229}$ Introducing radical scavengers to minimize the effects of other radicals would cause the competitive reactions and further mislead the results. Additionally, TEMP-based spin trapping agents are alkaline and might induce the base activation of $\mathrm{O}_{3}$. Therefore, the dosage of TEMP and solution $\mathrm{pH}$ should be precisely controlled.

4.2.2 Selective ROS scavenging tests. Quenching tests are based on the differences in the reactivity and rates of the reactions between the scavengers and the active species, which can be performed to differentiate the generated ROS and identify their contributions in removing target pollutants. Considering the co-existence of various oxidants, the ideal scavengers should have high selectivity toward the target ROS; otherwise the competitive reactions between the target ROS and other oxidative species (e.g., $\mathrm{O}_{3}$ and other ROS) would mislead the differentiation of dominant ROS. For instance, on account of the high oxidation potential of $\mathrm{HO}^{\circ}$, it can react rapidly with most of the quenchers, such as tert-butanol (TBA), para-benzoquinone ( $p$ BQ), furfuryl alcohol (FFA), and sodium azide $\left(\mathrm{NaN}_{3}\right)$. Thus, the corresponding scavengers are required to exclude the contribution of $\mathrm{HO}^{\circ}$. When TBA is employed as the $\mathrm{HO}^{\circ}$ quenching agent $\left(k=6 \times 10^{8} \mathrm{M}^{-1} \mathrm{~s}^{-1}\right)$, it is only effective for scavenging $\mathrm{HO}^{*}$ in the bulk solution rather than the surface-adsorbed $\mathrm{HO}^{\circ},{ }^{232}$ because of the low affinity of TBA toward the catalyst surface. ${ }^{\mathbf{2 3 3 , 2 3 4}}$ Meanwhile, fine bubbles might be produced with the presence of TBA which would enhance the mass transfer. ${ }^{235}$ Alternatively, methanol is capable of quenching $\mathrm{HO}^{\circ}$ both in bulk solution and on the catalyst surface, as well as preventing the generation of fine bubbles. However, quenching tests using radical scavengers are hard to distinguish the weak-oxidative ROS from high-oxidative ROS because of their differences in reactivities. Furthermore, the organics or reductive agents might attain fast reaction rates with $\mathrm{O}_{3}$, resulting in competitive consumption. $p$-BQ can react rapidly with $\mathrm{HO}_{2} \cdot / \mathrm{O}_{2}{ }^{-}-\mathrm{HO}^{\circ}$ and $\mathrm{O}_{3},\left(9.8 \times 10^{8}, 1.2 \times 10^{9}\right.$ and $2.5 \times 10^{8} \mathrm{M}^{-1} \mathrm{~s}^{-1}$, respectively $) .{ }^{236}$ Meanwhile, the low solubility of $p$-BQ hinder its contact with $\mathrm{O}_{2}{ }^{\cdot-}$. $\mathrm{NaN}_{3}$ is a strong reductant which would only quench ${ }^{1} \mathrm{O}_{2}$ $\left(2 \times 10^{9} \mathrm{M}^{-1} \mathrm{~s}^{-1}\right)$, but react with $\mathrm{O}_{3}$ with a mediocre constant $\left(2.5 \times 10^{6} \mathrm{M}^{-1} \mathrm{~s}^{-1}\right) .{ }^{237}$ Moreover, $\mathrm{N}_{3}{ }^{-}$is a strong alkaline agent, which would influence solution $\mathrm{pH}$ and cause base activation of $\mathrm{O}_{3}$. Taking advantage of the kinetic solvent isotope effect (KSIE), the contribution of ${ }^{1} \mathrm{O}_{2}$ can be better evaluated via using $\mathrm{D}_{2} \mathrm{O}$ instead of $\mathrm{H}_{2} \mathrm{O}$ as the solvent, because the lifetime and steadystate concentration of ${ }^{1} \mathrm{O}_{2}$ would increase in $\mathrm{D}_{2} \mathrm{O}$ owing to the lower reaction rate of ${ }^{1} \mathrm{O}_{2}$ in $\mathrm{D}_{2} \mathrm{O}$ than that in $\mathrm{H}_{2} \mathrm{O}\left(k_{\mathrm{d}}\left(\mathrm{H}_{2} \mathrm{O}\right)=\right.$ $\left.2.4-3.2 \times 10^{5} \mathrm{~s}^{-1} ; k_{\mathrm{d}}\left(\mathrm{D}_{2} \mathrm{O}\right)=1.4-2.3 \times 10^{4} \mathrm{~s}^{-1}\right) .{ }^{238-240}$ The KSIE effect using $\mathrm{D}_{2} \mathrm{O}$ as the reaction medium can also be employed in EPR technique for ${ }^{1} \mathrm{O}_{2}$ identification, and augmented signal intensity is expected for a ${ }^{1} \mathrm{O}_{2}$-based system. Nevertheless, similar effects can also be caused by other ROS because of their reduced reaction rates in $\mathrm{D}_{2} \mathrm{O}$ prolonged the life time. ${ }^{\mathbf{2 4 1}}$ Therefore, careful attention should be paid to the explanation of the experimental results. Potassium iodine (KI) and dimethyl sulfoxide (DMSO) have been used as scavengers for surfaceadsorbed ROS in other AOPs systems. ${ }^{\mathbf{9 6 , 2 4 2}}$ However, KI can react with $\mathrm{O}_{3}\left(1 \times 10^{8} \mathrm{M}^{-1} \mathrm{~s}^{-1}\right)$ and other oxidative species with high reaction rates, leading to the depletion of both the quenchers and dissolved $\mathrm{O}_{3}$. DMSO obtains an inferior reaction rate with $\mathrm{O}_{3}\left(0.4162 \mathrm{M}^{-1} \mathrm{~s}^{-1}\right)$, whereas it can fast react with both $\mathrm{HO}^{\circ}$ and surface-adsorbed ROS. Hence, the type and concentration of the scavengers should be carefully selected, in view of the undesired competition reactions with ozone and other ROS as well as the impact on solution properties. In a complex system involving various types of ROS, the scavenger might become unspecific to the desired ROS; thus comparing the reaction rates between scavengers and different oxidants is essential to determine the contribution of the specific ROS. In addition, the combination of scavengers with higher selectivity (a)

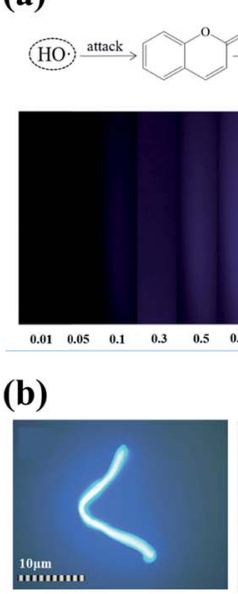

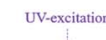

$\longrightarrow$
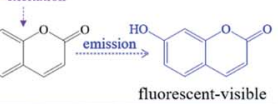
fluorescent-visible
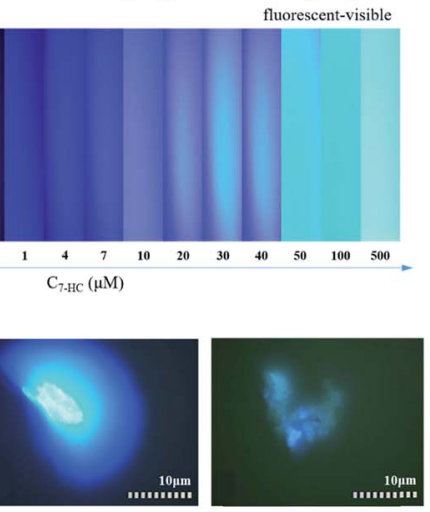

(c)

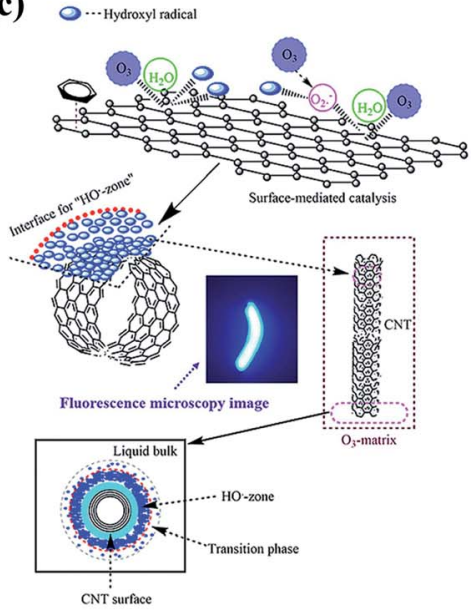

Fig. 13 (a) Colorimetric references of 7-hydroxycoumarin solutions with the changes to the 7-hydroxycoumarin concentration for FMI. (b) Fluorescence microscopy images of the produced $\mathrm{HO}^{*}$ during the catalytic ozonation on the surface of the carbonaceous materials. (c) Schematic illustration for the generation of interphase "HO' zone" on the surface of CNTs. Reprinted with permission from ref. 259. Copyright 2017, Elsevier. 
is necessary to comprehensively evaluate the contribution of each ROS during pollutants degradation.

4.2.3 Molecular probes. Chemical probes can be employed for ROS identification via detecting the byproducts formed from the reactions between target ROS and chemical probes. In addition, the amount of ROS can be semi-quantified by measuring the degradation reaction constants of chemical probes and the concentration of the generated byproducts. Probes such as $p$-chlorobenzoic acid, ${ }^{243-245}$ benzoic acid, ${ }^{246,247}$ salicylic acid, $,^{248,249} N, N$-dimethyl- $p$-nitrosoaniline, ${ }^{250}$ dimethyl sulfoxide, ${ }^{251,252}$ terephthalic acid ${ }^{253,254}$ and 1,5-diphenylcarbohydrazide $^{255}$ can be employed for $\mathrm{HO}^{\circ}$ detection. For example, $\mathrm{HO}^{*}$ can convert the non-fluorescent salicylic acid to the fluorescent 2,3-dihydroxybenzoic acid. ${ }^{248,249} \mathrm{HO}^{\circ}$ will react with DMSO to generate formaldehyde ( $\mathrm{HCHO}$ ). The concentration of the produced HCHO could be measured by 2,4-dinitrophenylhydrazine (DNPH) derivatization method, in which hydrazone (HCHO-DNPH) is formed and its concentration can be facilely quantified by chromatography analysis. ${ }^{252}$ Guo et al. employed $p$-chlorobenzoic acid ( $p$-CBA) and tetrachloromethane $\left(\mathrm{CCl}_{4}\right)$ as the probes for $\mathrm{HO}^{\cdot}$ and $\mathrm{O}_{2}{ }^{-}$in ozonation processes, respectively. ${ }^{\mathbf{2 4 4 , 2 4 5}}$ Based on the measured ROS exposures, the evolution of $\mathrm{HO}^{\circ}$ and $\mathrm{O}_{2}{ }^{--}$concentrations were simulated using chemical kinetic models. ${ }^{245}$ Moreover, nitro blue tetrazolium (NBT) is also efficient to estimate the concentration of $\mathrm{O}_{2}{ }^{--}$ based upon the absorbance intensity of the corresponding byproduct at $560 \mathrm{~nm} .{ }^{256}$ For ${ }^{1} \mathrm{O}_{2}$ identification, diphenylanthracene (DPA) has been considered as the preferably chemical probe besides furfuryl alcohol (FFA). Formation of the characterized dibenzanthracene peroxides $\left(\mathrm{DAPO}_{2}\right)$ from DAP indicates the direct singlet oxygenation. ${ }^{257}$ Also, chemical probes can be utilized to locate the area where ROS would be generated. As a probe for $\mathrm{HO}^{\circ}$, coumarin could be oxidized by $\mathrm{HO}^{\circ}$ via hydroxylation, forming the stable compound 7-hydroxycoumarin, which is photoluminescence with the UV characteristic absorption peak at $456 \mathrm{~nm} .^{258}$ Using fluorescence microscopy image (FMI), the region that $\mathrm{HO}^{\circ}$ produced on CNTs was visualized (Fig. 13a-c). ${ }^{259}$ However, careful consideration is required when interpreting the results of chemical probes, because $\mathrm{O}_{3}$ has a strong oxidation capability and might directly oxidize the added chemical probes during the reaction. Furthermore, the added probes might not be "chemically selective" to the target ROS. In persulfate-based AOPs, methyl phenyl sulfoxide (PMSO) is used as a chemical probe to distinct the high-valent metal species from $\mathrm{HO}^{\circ}$ or $\mathrm{SO}_{4}{ }^{-}{ }^{-}$, because PMSO can be oxidized by high-valent metal species to methyl phenyl sulfone $\left(\mathrm{PMSO}_{2}\right)$ via an oxygen-transfer reaction, while the reactions of $\mathrm{PMSO}$ with $\mathrm{HO}^{\circ}$ and $\mathrm{SO}_{4}{ }^{-}$lead to the formation of hydroxylated products and biphenyl compounds, respectively. ${ }^{89,212}$ Inspired by this method, it is promising to seek for certain chemical probes that obtain different reactivities toward ROS to yield characteristic products, which can be differentiated by chromatography or spectrum analysis.

4.2.4 Intermediates-directed prediction of oxidation pathways. With different oxidation potentials and electronic properties, the generated ROS obtain quite dissimilar mechanisms for organics oxidation, giving rise to featured degradation intermediates and pathways. Therefore, the contribution of a certain ROS can be determined. $\mathrm{HO}^{\circ}$ with a high oxidation potential tends to attack the aromatic ring to generate polyhydroxylated products; this is usually the very first step during the oxidation. ${ }^{\mathbf{2 6 0 , 2 6 1}}$ Additionally, $\mathrm{HO}^{\circ}$ also favors the attack of phenolics by hydrogen abstraction and hydroxylation reactions, resulting in the formation of hydroquinone and catechol, which might be further converted to $p$-benzoquinone and $o$-benzoquinone as a result of the extraction of hydrogen from the $\mathrm{O}-\mathrm{H}$ bond. ${ }^{262,263}$ Similarly, $\mathrm{O}_{2}{ }^{\cdot-}$ also favors the hydrogen abstraction reactions but the process will produce carbon-based radicals rather than hydroquinones in $\mathrm{O}_{2}{ }^{-}$-based oxidation..$^{264,265}$ Subsequently, the formed carbon-based radicals can further react with $\mathrm{O}_{2}$ to generate peroxy intermediates. ${ }^{266}$ In a ${ }^{1} \mathrm{O}_{2}$ driven process, the unsaturated organic compounds generally suffer from electrophilic attack and electron abstraction. ${ }^{267,268}$ Meanwhile, ${ }^{1} \mathrm{O}_{2}$ tends to attack phenolic compounds to form corresponding phenolic radicals, which further evolves into quinone-like and ring-opening products. ${ }^{269}$ So far, few studies have been focused on differentiating the reaction pathways and intermediates of specific pollutants degraded by different ROS in catalytic ozonation. Excavating the relationships between the characteristic intermediates and ROS can be an indirect way to verify the role(s) of potential ROS during ozonation.

\subsection{Selectivity of the ROS toward organic pollutants}

The free and surface-confined $\mathrm{HO}^{*}$ can non-selectively destroy most of organic contaminants at a high reaction rate $\left(10^{8}\right.$ to $10^{10}$ $\mathrm{M}^{-1} \mathrm{~s}^{-1}$ ) because of its strong oxidizing capability, while it might not be the dominant ROS responsible for the abatement of some certain electrophilic organic compounds such as $\mathrm{CCl}_{4}$ $\left(k_{\mathrm{HO}}<2 \times 10^{6} \mathrm{M}^{-1} \mathrm{~s}^{-1}\right)$, perfluorooctanesulfonic acid (PFOS, $k_{\mathrm{HO}}<10^{4} \mathrm{M}^{-1} \mathrm{~s}^{-1}$ ), and perfluorooctanoic acid (PFOA, $k_{\mathrm{HO}}<$ $\left.10^{4} \mathrm{M}^{-1} \mathrm{~s}^{-1}\right) .{ }^{270,271} \mathrm{O}_{2}{ }^{\cdot-}$ with a mild oxidation potential of $0.89-$ $1.7 \mathrm{~V}$ can oxidize less recalcitrant organics. Particularly, $\mathrm{O}_{2}{ }^{--}$ exhibits higher reaction rates with some halogenated hydrocarbons such as $\mathrm{CCl}_{4}$, PFOS, and PFOA $\left(k_{\mathrm{O}_{2}{ }^{-}}=10^{7}-10^{8} \mathrm{M}^{-1} \mathrm{~s}^{-1}\right)$ than $\mathrm{HO}^{\cdot}$ due to its strong nucleophilicity. ${ }^{244,245}$ Additionally, the halogenated hydrocarbons are recalcitrant for $\mathrm{O}_{3}$ attack $\left(k_{\mathrm{O}_{3}}\right.$ $<0.1 \mathrm{M}^{-1} \mathrm{~s}^{-1}$ ), which have been used as the chemical probes for quantifying the concentrations of $\mathrm{HO}^{\circ}$ and $\mathrm{HO}_{2}^{\circ} / \mathrm{O}_{2}{ }^{-}$generated in catalytic ozonation systems. ${ }^{244,245}$ Nonradical-based oxidations in catalytic ozonation reactions also demonstrated a substrate-dependent behavior. ${ }^{\mathbf{9 6 , 1 4 2}}$ The surface-confined nonradical species (including activated surface- $\mathrm{O}_{3}$ complex and ${ }^{*} \mathrm{O}_{\mathrm{ad}}$ ) with high oxidation potentials tend to attack aliphatic compounds with saturated carbon bonds rather than organics with unsaturated carbon bonds. Similar to $\mathrm{O}_{2}{ }^{\cdot-},{ }^{1} \mathrm{O}_{2}$ obtains a moderate oxidation capacity $\left(E^{0}=0.81 \mathrm{~V}, \mathrm{NHE}\right)$, which exhibits high selectivity in the decomposition of organics with unsaturated carbon bonds and electron-rich functionalities (e.g., phenols, sulfides, and anilines) via electrophilic addition and electron abstraction, but not reactive to saturated alcohols (e.g., methanol, ethanol and tertiary butanol). ${ }^{272}$ Some studies revealed that $\mathrm{O}_{2}{ }^{-}$or ${ }^{1} \mathrm{O}_{2}$ played a predominant role in the degradation of phenolic compounds during the catalytic 
ozonation processes, even though the existence of $\mathrm{HO}^{\bullet}$ was confirmed by EPR spectra and quenching tests. ${ }^{142,220,273}$ It is worth noting that, although studies have reported that $\mathrm{O}_{2}{ }^{--}$or ${ }^{1} \mathrm{O}_{2}$ were primarily responsible for the TOC abatement, $\mathrm{O}_{2}{ }^{\cdot-}$ and ${ }^{1} \mathrm{O}_{2}$ with mild oxidation potentials are substrate-dependent and cannot completely mineralize saturated compounds. ${ }^{274-276}$ Therefore, these conclusions are questionable and require a careful reevaluation. In addition, it is also quite challenging to justify the contribution of $\mathrm{O}_{2}{ }^{-} /{ }^{1} \mathrm{O}_{2}$ in the carbon-catalyzed ozonation system since the formation of $\mathrm{O}_{2}^{\cdot-} /{ }^{1} \mathrm{O}_{2}$ is often accompanied by other ROS.

\section{Impacts of water matrix}

\subsection{Solution pH}

Solution $\mathrm{pH}$ is a crucial factor in catalytic ozonation processes, affecting the surface properties of catalysts, the nature of organic contaminants, and the generation and transformation of ROS, thereby influencing the catalytic performances. The surface charge of the catalyst can be affected by solution $\mathrm{pH}$. The catalyst surface will be negatively charged when the solution $\mathrm{pH}$ is greater than $\mathrm{pH}_{\mathrm{pzc}}$ of the catalysts, which favors the electrophilic adsorption of $\mathrm{O}_{3}$. In contrast, the interaction of $\mathrm{O}_{3}$ with the positively charged surface is weak. Additionally, the charge and molecular states of organics are closely related to their $\mathrm{p} K_{\mathrm{a}}$ values, which are also affected by solution $\mathrm{pH}$. The states of organics will subsequently influence the electrostatic interactions with the surface of the catalysts and the affinities toward ROS. The opposite charge between the catalysts surface and the organics will induce electrostatic attraction and facilitate surface reactions, ${ }^{277,278}$ while the deprotonated organics are more likely to be electrophilically attacked by ROS. ${ }^{279}$ Additionally, the electrochemical parameters of organics, such as ionization potential, half-wave potential, and Hammett constant, will vary with solution $\mathrm{pH}$ and closely relate with the redox capacity of the oxidation system..$^{23,159,280,281}$ For example, the half-wave potential of phenol declined with the increased $\mathrm{pH}$, leading to a higher degradation rate. However, when solution $\mathrm{pH}$ was further elevated beyond the $\mathrm{p} K_{\mathrm{a}}$ of phenol, the phenolate would form and demonstrate strong recalcitrance for degradation. ${ }^{216}$ The variations in surface interactions and affinities toward ROS at different pHs might result in different reaction mechanisms. Altering solution $\mathrm{pH}$ might change the adsorption capacity of organics and alter the reaction pathway from a nonradical pathway to radical-dominated oxidation. ${ }^{\mathbf{1 1 2}}$

Solution $\mathrm{pH}$ can also influence the conversion of reactive species and their redox potentials. $\mathrm{O}_{3}$ molecules can be activated by alkaline solution into $\mathrm{HO}^{\circ}\left(k=70 \mathrm{M}^{-1} \mathrm{~s}^{-1}\right)$ (eqn (2)). ${ }^{282}$ However, deprotonation of $\mathrm{HO}^{\circ}$ takes place at $\mathrm{pH}>11.9$, and the formed conjugate base radical $\left(\mathrm{O}^{-}\right)$is less reactive than $\mathrm{HO}^{\circ}$

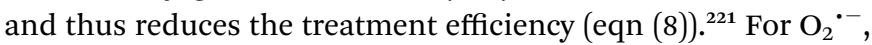
it can be oxidized with $\mathrm{HO}_{2}^{\cdot}$ in acidic solutions to generate ${ }^{1} \mathrm{O}_{2}$ (eqn (6)), while $\mathrm{HO}_{2}{ }^{-}$- will deprotonate into $\mathrm{O}_{2}{ }^{--}$when solution $\mathrm{pH}$ is over 4.8, thereby changing from electrophilic attack to nucleophilic attack (eqn (4)). ${ }^{6}$ The reduction potentials of ROS are $\mathrm{pH}$-dependent, because the concentrations of $\mathrm{H}^{+} / \mathrm{OH}^{-}$affect the activity of the generated ROS and their conjugated reductive pairs. ${ }^{283}$ Generally, an increased $\mathrm{H}^{+}$concentration demonstrates an improved activity of ROS, resulting in an increase in reductive potential as the solution $\mathrm{pH}$ decreases. ${ }^{\mathbf{2 2 1 , 2 8 3}}$

$$
\mathrm{HO}^{\bullet}+\mathrm{OH}^{-} \rightarrow \mathrm{O}^{\cdot-}+\mathrm{H}_{2} \mathrm{O}, \mathrm{p} K_{\mathrm{a}}=11.9
$$

\subsection{Inorganic anions}

Inorganic anions such as $\mathrm{Cl}^{-}, \mathrm{CO}_{3}{ }^{2-}, \mathrm{HCO}_{3}{ }^{-}$, and $\mathrm{SO}_{4}{ }^{2-}$ ubiquitously exist in practical wastewater and natural water systems, which can potentially affect $\mathrm{O}_{3}$ activation even at low concentrations. Inorganic anions are commonly considered as radical scavengers to consume ROS and generate less reactive radicals (eqn (9)-(14)), resulting in the decrease in the overall degradation efficiency. ${ }^{272,284}$ The scavenging capacity can be affected by solution $\mathrm{pH}$. For instance, $\mathrm{Cl}^{-}$can scavenge $\mathrm{HO}^{*}$ to produce $\mathrm{Cl}^{\circ}$. However, the scavenging effect was only effective within an acidic $\mathrm{pH}$ range and was limited under neutral conditions, because the intermediate of the radical chain reaction $\left(\mathrm{ClOH}^{\cdot-}\right)$ would rapidly revert to $\mathrm{HO}^{\circ}$ rather than forming $\mathrm{Cl}^{*}$ (eqn (9) and (10)). ${ }^{285}$ A similar effect was observed when $\mathrm{HCO}_{3}{ }^{-}$was involved. The elevated solution $\mathrm{pH}$ would deprotonate $\mathrm{HCO}_{3}{ }^{-}$into $\mathrm{CO}_{3}{ }^{2-}$, resulting in an increased scavenging effect because of the higher reaction rate of $\mathrm{HO}^{\circ}$ with $\mathrm{CO}_{3}{ }^{2-}\left(3.9 \times 10^{8} \mathrm{M}^{-1} \mathrm{~s}^{-1}\right)$ than that with $\mathrm{HCO}_{3}^{-}\left(8.5 \times 10^{6} \mathrm{M}^{-1} \mathrm{~s}^{-1}\right)$ (eqn (11) and (12)). ${ }^{232,286} \mathrm{CO}_{3}{ }^{2-}$ also increases the stability of $\mathrm{O}_{3}$ by removing the dominant chain carrier radicals, such as $\mathrm{O}_{3}{ }^{-1},{ }^{287}$ while $\mathrm{SO}_{4}{ }^{2-}$ and $\mathrm{NO}_{3}{ }^{-}$showed negligible effects on $\mathrm{O}_{3}$ decomposition. ${ }^{288}$ The presence of inorganic anions might also result in the improved selectivity of oxidative systems, because the generated reactive halogen species or $\mathrm{CO}_{3}{ }^{--}$are more selective than $\mathrm{HO}^{\circ}$ and favor the attack of electron-rich organics. ${ }^{2,289}$

$$
\begin{gathered}
\mathrm{Cl}^{-}+\mathrm{HO}^{\bullet} \leftrightarrow \mathrm{ClOH}^{\cdot-}, k=4.3 \times 10^{9} \mathrm{M}^{-1} \mathrm{~s}^{-1} \\
\mathrm{ClOH}^{--}+\mathrm{H}^{+} \leftrightarrow \mathrm{Cl}^{\bullet}+\mathrm{H}_{2} \mathrm{O}, k=2.1 \times 10^{10} \mathrm{M}^{-1} \mathrm{~s}^{-1} \\
\mathrm{CO}_{3}^{2-}+\mathrm{HO}^{\cdot} \rightarrow \mathrm{CO}_{3}^{\cdot-}+\mathrm{OH}^{-}, k=3.9 \times 10^{8} \mathrm{M}^{-1} \mathrm{~s}^{-1} \\
\mathrm{HCO}_{3}{ }^{-}+\mathrm{HO}^{\cdot} \rightarrow \mathrm{CO}_{3}^{\cdot-}+\mathrm{H}_{2} \mathrm{O}, k=8.5 \times 10^{6} \mathrm{M}^{-1} \mathrm{~s}^{-1} \\
\mathrm{HCO}_{3}{ }^{-}+\mathrm{O}_{2}^{\cdot-} \rightarrow \mathrm{CO}_{3}^{\cdot-}+\mathrm{HO}_{2}^{-}, k=1.5 \times 10^{6} \mathrm{M}^{-1} \mathrm{~s}^{-1} \\
\mathrm{PO}_{4}{ }^{3-}+\mathrm{HO}^{\cdot} \rightarrow \mathrm{PO}_{4}^{\cdot 2-}+\mathrm{OH}^{-}, k=1.1 \times 10^{9} \mathrm{M}^{-1} \mathrm{~s}^{-1}
\end{gathered}
$$

The effect of inorganic anions on catalytic ozonation processes also depends on their concentrations. It was reported that the $\mathrm{Cl}^{-}$concentration can influence the scavenging products and thus affect the catalytic ozonation efficiency. ${ }^{35,159}$ At low concentrations, $\mathrm{Cl}^{-}$would quench $\mathrm{HO}^{*}\left(E^{0}=2.7 \mathrm{~V}, \mathrm{NHE}\right)$ to form the less reactive $\mathrm{Cl}^{\circ}\left(E^{0}=2.4 \mathrm{~V}, \mathrm{NHE}\right)$. In contrast, a high concentration of $\mathrm{Cl}^{-}$favored the transformation of $\mathrm{Cl}^{\circ}$ into reactive chlorine species $\left(\mathrm{Cl}_{2}\right.$ and $\left.\mathrm{HClO}\right)$, which could couple with $\mathrm{HO}^{*}$ for organics degradation. However, opposite conclusions were derived in another study. ${ }^{\mathbf{2 9 0}}$ The discrepancies in these studies might be explained by the combined effects of ionic strength, which influences the solubility and mass transfer of $\mathrm{O}_{3}$, the reaction rates of ROS, and the interactions of $\mathrm{O}_{3}$ 
and organics on catalyst surface. It was reported that the solubility and mass transfer of $\mathrm{O}_{3}$ decrease as ionic strength grows, especially when $\mathrm{Cl}^{-}, \mathrm{CO}_{3}{ }^{2-}$ and $\mathrm{PO}_{4}{ }^{3-}$ are present, while $\mathrm{SO}_{4}{ }^{2-}$ gives rise to an insignificant effect. ${ }^{291}$ Moreover, positive effects of ionic strength on reaction rates were observed in various reaction systems. ${ }^{\mathbf{2 9 2}-294}$ Studies suggested that the reaction rates between oxidants and organics raised with the increase in ionic strength. ${ }^{295}$ The ionic strength created by different ions might also influence reaction rates. The reaction rate between $\mathrm{O}_{3}$ and $\mathrm{Cl}^{-}$improved with the increase in the ionic strength caused by $\mathrm{NaClO}_{4}$ or $\mathrm{KNO}_{3}$, whereas simply increasing the concentration of $\mathrm{Cl}^{-}$resulted in the decrease of the corresponding reaction rate. ${ }^{296}$ Additionally, increasing the ionic strength reduces the zeta potential of catalyst surface via compressing the thickness of the electric double layer and therefore affects the weak interactions (via electrostatic bonding) of $\mathrm{O}_{3}$ and organics on catalyst surface, such as the activated surface- $\mathrm{O}_{3}$ complex. ${ }^{297}$ However, marginal influence occurs to strong interactions, i.e., the ${ }^{*} \mathrm{O}_{\mathrm{ad}}$-induced oxidation model. Therefore, variations in ionic strength can be utilized to distinguish the different interaction models of $\mathrm{O}_{3}$ on the catalyst surface. Ionic strength also affects the adsorption capacity of the organics on catalysts. As ionic strength increases, the adsorption capacity decreases when the electrostatic forces between the catalyst surface and organics are attractive. ${ }^{298}$

Inorganic anions may compete on the surface-active sites of catalysts with $\mathrm{O}_{3}$ or organics, thus inhibiting the oxidation performance. The positively charged catalysts can provide suitable adsorption sites for inorganic anions. $\mathrm{PO}_{4}{ }^{3-}$ as a strong Lewis base shows the strong inhibitory effect by occupying surface Lewis acid sites and impeding $\mathrm{O}_{3}$ activation. ${ }^{299,300}$ Notably, the induced alkalinity with the presence of $\mathrm{CO}_{3}{ }^{2-}$ and $\mathrm{PO}_{4}{ }^{3-}$ as basic anions would promote the base activation of $\mathrm{O}_{3}$ and affect the surface charge of the catalyst. ${ }^{287,290}$ Therefore, special attention should be paid to the variation in solution $\mathrm{pH}$ with the presence of basic anions. In the most of current studies, individual effects of inorganic anions on the activation of $\mathrm{O}_{3}$ have been well evaluated. Nevertheless, considering the complexity in compositions of the practical wastewater, the synergistic effects of various inorganic anions cannot be overlooked.

\subsection{Natural organic matters}

NOMs are pervasive constituents in natural water, and are known to decrease the efficiency of AOPs-based treatments by competing with organic contaminants for $\mathrm{HO}^{*}$ consumption (1.6-3.3 $\left.\times 10^{8} \mathrm{M}^{-1} \mathrm{~s}^{-1}\right) .{ }^{301}$ NOMs with electron-rich sites could also deplete the dissolved $\mathrm{O}_{3}$ via direct $\mathrm{O}_{3}$ attack, thus lowering the utilization efficiency of $\mathrm{O}_{3} \cdot{ }^{302}$ Furthermore, NOMs containing carboxyl and phenolic hydroxyl groups would adsorb on the surface of carbonaceous materials and block the active sites, giving rise to inhibited interactions between the carbocatalysts and $\mathrm{O}_{3}$ /organics. ${ }^{303}$ For $\mathrm{HO}^{\circ}$-dominant oxidation pathway in catalytic ozonation, the inhibitory effects would continue until most of NOMs are mineralized because of the non-selectivity of $\mathrm{HO}^{*} .^{304}$ The nonradical pathways based on the surface oxidations are highly selective to the aliphatic acids with small molecular weight; therefore, NOMs may have a less impact on nonradical-based oxidation. ${ }^{159}$ Nevertheless, debates on the effect of NOMs on catalytic ozonation still exist. Some studies reported that NOMs could act as initiators and promotors for radical chain reactions of $\mathrm{O}_{3}$ decomposition to $\mathrm{HO}^{\circ}$, which enhanced the degradation rate. ${ }^{305,306}$ Specific moieties, such as aromatic and aliphatic unsaturated constituents in NOMs, could directly activate $\mathrm{O}_{3}$ and accelerate the radical chain reactions to generate more $\mathrm{HO}^{\cdot{ }^{307}}$ Moreover, the presence of humic acid (HA), a major constituent of NOMs, could introduce oxygen functional groups on $\mathrm{Fe}_{3} \mathrm{O}_{4}$ /MWCNTs and thus accelerate $\mathrm{HO}^{*}$ production. ${ }^{173}$

\section{Conclusions and future perspectives}

In summary, this review presents the current application of carbon-based catalysts for $\mathrm{O}_{3}$ activation and degradation of organic pollutants. The engineering principles for regulating the active sites and electronic structures of carbocatalysts have been discussed, which will provide directions and general guidelines for developing high-performance carbocatalysts. This review also puts forward new insights into ROS generation and the reaction pathways based on the interaction intensity model between $\mathrm{O}_{3}$ and catalyst surface. In addition, the effect of the water matrix factors, including $\mathrm{pH}$, inorganic anions and NOMs, on catalytic ozonation processes are highlighted. Based on our review, future directions to material design, ROS identification and mechanism regulation aiming at enhancing the application potential of carbon-based catalytic ozonation in real wastewaters are proposed as follows:

(1) Encapsulating metal species beneath graphitic carbons (metal@C) has been proven as an effective strategy to increase both the reactivity and stability of the composites. Additionally, the magneticity endowed by the encapsulated metal species facilitates the separation of the nano-scaled catalysts. Apart from the dimensional effects, surface properties of the graphitic carbons and the types of the encapsulated metals are critical factors governing the electron-transfer ability and the catalytic activity of the nanocomposites. Therefore, it is promising to design metal@C catalysts with various numbers of coated graphitic shells, defective levels, and heteroatom dopants and manage the types and exposed crystal facets of the encapsulated metal species. The electron hybridizing, distribution, and transfer process at the metal-carbon heterojunctions can be evaluated by the DFT simulations which guide the theoretical design and screening the metal@C catalysts.

(2) In the current stage, intensive research attentions have been paid to identifying the types of ROS and elucidating ROS evolution mechanisms. However, the interactions of reactants on the active sites of the carbocatalysts are normally transient and thus hinder the unravelling of the in-depth insights. Future mechanistic studies require combined theoretical and experimental methodologies. The development of in situ, cryo-, or 
time-resolved characterization techniques with the isotopic substitutions will help unravel the interactions of the $\mathrm{O}_{3}$ and/or ambient molecules on catalyst surface and differentiate the types of generated ROS. Additionally, evaluating the existence and effects of other ROS apart from $\mathrm{HO}^{\circ}$ in catalytic ozonation is challenging because of the high oxidation capacity and nonselectivity of $\mathrm{HO}^{\circ}$. Therefore, it is crucial to develop probes or sensors that selectively react with targeted ROS, especially those with mild oxidation potentials.

(3) Water matrix parameters such as $\mathrm{pH}$, inorganic anions and NOMs can significantly affect the interactions of $\mathrm{O}_{3}$ and organics on the catalyst surface and the reactivities of the generated ROS. $\mathrm{HO}^{\circ}$-based radical pathway demonstrates a highly oxidative and nonselective behavior, yet the treatment efficiency would be decreased in the presence of inorganics anions and NOMs as radical scavengers. Nonradical pathways arising from the weak interactions between $\mathrm{O}_{3}$ and catalyst surface is vulnerable to be influenced by solution $\mathrm{pH}$ and ionic strength. Nonradical oxidation induced by strong interactions are typically recalcitrant toward the ionic strength and NOMs, while solution $\mathrm{pH}$ might influence the catalytic performance by affecting the surface charges. Therefore, developing reactionoriented carbonaceous materials that can precisely regulate the reaction pathways based on the characters of different types of wastewater is highly desirable. DFT calculations of the interactions and electron properties at the atomic level can be employed to guide the design of on-demand active sites on carbocatalysts to trigger specific reaction pathways for different application scenarios.

\section{Conflicts of interest}

There are no conflicts to declare.

\section{Acknowledgements}

The authors greatly appreciate the financial supports from the National Natural Science Foundation of China (No. 21978324), Beijing Natural Science Foundation (No. 8192039), and Science Foundation of China University of Petroleum, Beijing (No. 2462020YXZZ034). Partial support from the Australian Research Council (DE210100253) is also acknowledged.

\section{References}

1 B. C. Hodges, E. L. Cates and J.-H. Kim, Nat. Nanotechnol., 2018, 13, 642-650.

2 J. Lee, U. Von Gunten and J.-H. Kim, Environ. Sci. Technol., 2020, 54, 3064-3081.

3 H. G. Kjaergaard, T. Kurtén, L. B. Nielsen, S. Jørgensen and P. O. Wennberg, J. Phys. Chem. Lett., 2013, 4, 2525-2529.

4 R. Criegee, Angew. Chem., Int. Ed., 1975, 14, 745-752.

5 J. Nawrocki and B. Kasprzyk-Hordern, Appl. Catal., B, 2010, 99, 27-42.

6 B. Kasprzyk-Hordern, M. Ziółek and J. Nawrocki, Appl. Catal., B, 2003, 46, 639-669.

7 J. Nawrocki, Appl. Catal., B, 2013, 142, 465-471.
8 D. S. Su, S. Perathoner and G. Centi, Chem. Rev., 2013, 113, 5782-5816.

9 J. Wang and H. Chen, Sci. Total Environ., 2020, 704, 135249.

10 L. Zhang, C.-Y. Lin, D. Zhang, L. Gong, Y. Zhu, Z. Zhao, Q. Xu, H. Li and Z. Xia, Adv. Mater., 2019, 31, 1805252.

11 L.-H. Zhang, Y. Shi, Y. Wang and N. R. Shiju, Adv. Sci., 2020, 7, 1902126.

12 J. Xiao, Y. Xie, J. Rabeah, A. Brückner and H. Cao, Acc. Chem. Res., 2020, 53, 1024-1033.

13 X. Duan, H. Sun and S. Wang, Acc. Chem. Res., 2018, 51, 678-687.

14 D. T. Oyekunle, X. Zhou, A. Shahzad and Z. Chen, J. Mater. Chem. A, 2021, 9, 8012-8050.

15 G. Yu, Y. Wang, H. Cao, H. Zhao and Y. Xie, Environ. Sci. Technol., 2020, 54, 5931-5946.

16 Y. Wang, X. Duan, Y. Xie, H. Sun and S. Wang, ACS Catal., 2020, 10, 13383-13414.

17 D. S. Su, G. Wen, S. Wu, F. Peng and R. Schlögl, Angew. Chem., Int. Ed., 2017, 56, 936-964.

18 Q. Ma, Y. Yu, M. Sindoro, A. G. Fane, R. Wang and H. Zhang, Adv. Mater., 2017, 29, 1605361.

19 X. Liu and L. Dai, Nat. Rev. Mater., 2016, 1, 1-12.

20 C. Hu, Y. Xiao, Y. Zou and L. Dai, Electrochem. Energy Rev., 2018, 1, 84-112.

21 S. Zhang, X. Quan, J.-F. Zheng and D. Wang, Water Res., 2017, 122, 86-95.

22 H. Li, X. Miao, J. Zhang, J. Du, S. Xu, J. Tang and Y. Zhang, Chem. Eng. J., 2020, 381, 122680.

23 J. Xiao, Y. Xie, Q. Han, H. Cao, Y. Wang, F. Nawaz and F. Duan, J. Hazard. Mater., 2016, 304, 126-133.

24 Y. Yao, Y. Xie, B. Zhao, L. Zhou, Y. Shi, Y. Wang, Y. Sheng, H. Zhao, J. Sun and H. Cao, Chem. Eng. J., 2020, 382, 122708.

25 Z. Song, M. Wang, Z. Wang, Y. Wang, R. Li, Y. Zhang, C. Liu, Y. Liu, B. Xu and F. Qi, Environ. Sci. Technol., 2019, 53, 53375348.

26 J. Xiao, J. Rabeah, J. Yang, Y. Xie, H. Cao and A. Brückner, ACS Catal., 2017, 7, 6198-6206.

27 H. Lee, H.-i. Kim, S. Weon, W. Choi, Y. S. Hwang, J. Seo, C. Lee and J.-H. Kim, Environ. Sci. Technol., 2016, 50, 10134-10142.

28 I. C. Gerber and P. Serp, Chem. Rev., 2019, 120, 1250-1349.

29 G. K. Dimitrakakis, E. Tylianakis and G. E. Froudakis, Nano Lett., 2008, 8, 3166-3170.

30 H. Arandiyan, Y. Wang, H. Sun, M. Rezaei and H. Dai, Chem. Commun., 2018, 54, 6484-6502.

31 Y.-z. Liu, R.-t. Guo, C.-p. Duan, G.-l. Wu, Y.-f. Miao, J.-w. Gu and W.-g. Pan, Chemosphere, 2021, 262, 127886.

32 X. Wan, Y. Huang and Y. Chen, Acc. Chem. Res., 2012, 45, 598-607.

33 S. Sihn, V. Varshney, A. K. Roy and B. L. Farmer, Carbon, 2012, 50, 603-611.

34 H. Arandiyan, H. Dai, K. Ji, H. Sun, Y. Zhao and J. Li, Small, 2015, 11, 2366-2371.

35 Y. Wang, Y. Xie, H. Sun, J. Xiao, H. Cao and S. Wang, ACS Appl. Mater. Interfaces, 2016, 8, 9710-9720.

36 Z. Song, Y. Zhang, C. Liu, B. Xu, F. Qi, D. Yuan and S. Pu, Chem. Eng. J., 2019, 357, 655-666. 
37 X. Duan, H. Sun, Z. Ao, L. Zhou, G. Wang and S. Wang, Carbon, 2016, 107, 371-378.

38 Y. Wang, Z. Ao, H. Sun, X. Duan and S. Wang, Appl. Catal., $B, 2016,198,295-302$.

39 R. Qu, B. Xu, L. Meng, L. Wang and Z. Wang, Water Res., 2015, 68, 316-327.

40 T. F. de Oliveira, O. Chedeville, H. Fauduet and B. Cagnon, Desalination, 2011, 276, 359-365.

41 C. D. Vecitis, T. Lesko, A. J. Colussi and M. R. Hoffmann, J. Phys. Chem. A, 2010, 114, 4968-4980.

42 W. Ren, L. Xiong, G. Nie, H. Zhang, X. Duan and S. Wang, Environ. Sci. Technol., 2019, 54, 1267-1275.

43 Y. Pi, J. Schumacher and M. Jekel, Water Res., 2005, 39, 8388.

44 F. Bernat-Quesada, J. C. Espinosa, V. Barbera, M. Álvaro, M. Galimberti, S. Navalon and H. García, ACS Sustainable Chem. Eng., 2019, 7, 17443-17452.

45 A. Bhatnagar, W. Hogland, M. Marques and M. Sillanpää, Chem. Eng. J., 2013, 219, 499-511.

46 I. Gerber, M. Oubenali, R. Bacsa, J. Durand, A. Gonçalves, M. F. R. Pereira, F. Jolibois, L. Perrin, R. Poteau and P. Serp, Chem.-Eur. J., 2011, 17, 11467-11477.

47 X. Lu, W.-L. Yim, B. H. Suryanto and C. Zhao, J. Am. Chem. Soc., 2015, 137, 2901-2907.

48 H. Chen and K. C. Carroll, Environ. Pollut., 2016, 215, 96102.

49 F. de Clippel, M. Dusselier, S. Van de Vyver, L. Peng, P. A. Jacobs and B. F. Sels, Green Chem., 2013, 15, 13981430.

50 A. Hirsch, Angew. Chem., Int. Ed., 2002, 41, 1853-1859.

51 Y. Jiang, L. Yang, T. Sun, J. Zhao, Z. Lyu, O. Zhuo, X. Wang, Q. Wu, J. Ma and Z. Hu, ACS Catal., 2015, 5, 6707-6712.

52 X. Duan, Z. Ao, L. Zhou, H. Sun, G. Wang and S. Wang, Appl. Catal., B, 2016, 188, 98-105.

53 W. Yuan, Y. Zhou, Y. Li, C. Li, H. Peng, J. Zhang, Z. Liu, L. Dai and G. Shi, Sci. Rep., 2013, 3, 1-7.

54 X. Duan, H. Sun, J. Kang, Y. Wang, S. Indrawirawan and S. Wang, ACS Catal., 2015, 5, 4629-4636.

55 R. Oulton, J. P. Haase, S. Kaalberg, C. T. Redmond, M. J. Nalbandian and D. M. Cwiertny, Environ. Sci. Technol., 2015, 49, 3687-3697.

56 H. Jin, H. Huang, Y. He, X. Feng, S. Wang, L. Dai and J. Wang, J. Am. Chem. Soc., 2015, 137, 7588-7591.

57 Y. Jia, L. Zhang, A. Du, G. Gao, J. Chen, X. Yan, C. L. Brown and X. Yao, Adv. Mater., 2016, 28, 9532-9538.

58 X. Zhao, X. Zou, X. Yan, C. L. Brown, Z. Chen, G. Zhu and X. Yao, Inorg. Chem. Front., 2016, 3, 417-421.

59 Y. Wang, H. Cao, C. Chen, Y. Xie, H. Sun, X. Duan and S. Wang, Chem. Eng. J., 2019, 355, 118-129.

60 D. Yan, Y. Li, J. Huo, R. Chen, L. Dai and S. Wang, Adv. Mater., 2017, 29, 1606459.

61 J. Zhang, J. Zhang, F. He, Y. Chen, J. Zhu, D. Wang, S. Mu and H.-Y. Yang, Nano-Micro Lett., 2021, 13, 65.

62 Y. Jia, L. Zhang, L. Zhuang, H. Liu, X. Yan, X. Wang, J. Liu, J. Wang, Y. Zheng, Z. Xiao, E. Taran, J. Chen, D. Yang, Z. Zhu, S. Wang, L. Dai and X. Yao, Nat. Catal., 2019, 2, 688-695.
63 Z. Zhao, M. Li, L. Zhang, L. Dai and Z. Xia, Adv. Mater., 2015, 27, 6834-6840.

64 K. Gao, B. Wang, L. Tao, B. V. Cunning, Z. Zhang, S. Wang, R. S. Ruoff and L. Qu, Adv. Mater., 2019, 31, 1805121.

65 L. Zhang and Z. Xia, J. Phys. Chem. C, 2011, 115, 1117011176.

66 K. Qu, Y. Zheng, X. Zhang, K. Davey, S. Dai and S. Z. Qiao, ACS Nano, 2017, 11, 7293-7300.

67 X. Duan, K. O'Donnell, H. Sun, Y. Wang and S. Wang, Small, 2015, 11, 3036-3044.

68 J. Zhang, L. Qu, G. Shi, J. Liu, J. Chen and L. Dai, Angew. Chem., 2016, 128, 2270-2274.

69 J. Zhang and L. Dai, Angew. Chem., Int. Ed., 2016, 55, 1329613300.

70 P. Huang, H. Li, X. Huang and D. Chen, ACS Appl. Mater. Interfaces, 2017, 9, 21083-21088.

71 J. Zhou, J. Lian, L. Hou, J. Zhang, H. Gou, M. Xia, Y. Zhao, T. A. Strobel, L. Tao and F. Gao, Nat. Commun., 2015, 6, 1-8.

72 J. Liang, Y. Jiao, M. Jaroniec and S. Z. Qiao, Angew. Chem., Int. Ed., 2012, 51, 11496-11500.

73 H. Wang, T. Maiyalagan and X. Wang, ACS Catal., 2012, 2, 781-794.

74 Y. Wang, L. Chen, C. Chen, J. Xi, H. Cao, X. Duan, Y. Xie, W. Song and S. Wang, Appl. Catal., B, 2019, 254, 283-291.

75 S. Indrawirawan, H. Sun, X. Duan and S. Wang, J. Mater. Chem. A, 2015, 3, 3432-3440.

76 D. Li, X. Duan, H. Sun, J. Kang, H. Zhang, M. O. Tade and S. Wang, Carbon, 2017, 115, 649-658.

77 Z. Mo, S. Liao, Y. Zheng and Z. Fu, Carbon, 2012, 50, 26202627.

78 L. Lai, J. R. Potts, D. Zhan, L. Wang, C. K. Poh, C. Tang, H. Gong, Z. Shen, J. Lin and R. S. Ruoff, Energy Environ. Sci., 2012, 5, 7936-7942.

79 A. Shen, Y. Zou, Q. Wang, R. A. Dryfe, X. Huang, S. Dou, L. Dai and S. Wang, Angew. Chem., 2014, 126, 10980-10984.

80 G. Pacchioni and H.-J. Freund, Chem. Soc. Rev., 2018, 47, 8474-8502.

81 G. Pacchioni, Phys. Chem. Chem. Phys., 2013, 15, 1737-1757. 82 T. Binninger, T. J. Schmidt and D. Kramer, Phys. Rev. B, 2017, 96, 165405.

83 Y. Wang, Y. Xie, H. Sun, J. Xiao, H. Cao and S. Wang, J. Hazard. Mater., 2016, 301, 56-64.

84 L. Zhao, Z. Sun and J. Ma, Environ. Sci. Technol., 2009, 43, 4157-4163.

85 J. Bing, C. Hu, Y. Nie, M. Yang and J. Qu, Environ. Sci. Technol., 2015, 49, 1690-1697.

86 A. Ruiz Puigdollers, P. Schlexer, S. Tosoni and G. Pacchioni, ACS Catal., 2017, 7, 6493-6513.

87 H. Yuan, J. Li, W. Yang, Z. Zhuang, Y. Zhao, L. He, L. Xu, X. Liao, R. Zhu and L. Mai, ACS Appl. Mater. Interfaces, 2018, 10, 16410-16417.

88 A. Moya, A. Cherevan, S. Marchesan, P. Gebhardt, M. Prato, D. Eder and J. J. Vilatela, Appl. Catal., B, 2015, 179, 574-582.

89 Z. Wang, J. Jiang, S. Pang, Y. Zhou, C. Guan, Y. Gao, J. Li, Y. Yang, W. Qiu and C. Jiang, Environ. Sci. Technol., 2018, 52, 11276-11284. 
90 S. Liang, L. Zhu, J. Hua, W. Duan, P.-T. Yang, S.-L. Wang, C. Wei, C. Liu and C. Feng, Environ. Sci. Technol., 2020, 54, 6406-6414.

91 Y. Zong, Y. Shao, Y. Zeng, B. Shao, L. Xu, Z. Zhao, W. Liu and D. Wu, Environ. Sci. Technol., 2021, 55, 7634-7642.

92 O. Pestovsky, S. Stoian, E. L. Bominaar, X. Shan, E. Münck, L. Que, Jr and A. Bakac, Angew. Chem., Int. Ed., 2005, 44, 6871-6874.

93 Y. Chen, J. Wei, M. S. Duyar, V. V. Ordomsky, A. Y. Khodakov and J. Liu, Chem. Soc. Rev., 2021, 50, 2337-2366.

94 C. Zhang, X. Guo, Q. Yuan, R. Zhang, Q. Chang, K. Li, B. Xiao, S. Liu, C. Ma and X. Liu, ACS Catal., 2018, 8, 7120-7130.

95 X. Sun, A. I. O. Suarez, M. Meijerink, T. Van Deelen, S. OuldChikh, J. Zečević, K. P. De Jong, F. Kapteijn and J. Gascon, Nat. Commun., 2017, 8, 1-8.

96 Y. Wang, N. Ren, J. Xi, Y. Liu, T. Kong, C. Chen, Y. Xie, X. Duan and S. Wang, ACS ES\&T Engg, 2021, 1, 32-45.

97 X. Duan, J. Kang, W. Tian, H. Zhang, S.-H. Ho, Y.-A. Zhu, Z. Ao, H. Sun and S. Wang, Appl. Catal., B, 2019, 256, 117795.

98 S. Weon, D. Huang, K. Rigby, C. Chu, X. Wu and J.-H. Kim, ACS ES\&T Engg, 2021, 1, 157-172.

99 M. B. Gawande, P. Fornasiero and R. Zbořil, ACS Catal., 2020, 10, 2231-2259.

100 C. Chu, J. Yang, X. Zhou, D. Huang, H. Qi, S. Weon, J. Li, M. Elimelech, A. Wang and J.-H. Kim, Environ. Sci. Technol., 2021, 55, 1242-1250.

101 H. Fei, J. Dong, M. J. Arellano-Jiménez, G. Ye, N. D. Kim, E. L. Samuel, Z. Peng, Z. Zhu, F. Qin and J. Bao, Nat. Commun., 2015, 6, 1-8.

102 P. Yin, T. Yao, Y. Wu, L. Zheng, Y. Lin, W. Liu, H. Ju, J. Zhu, X. Hong and Z. Deng, Angew. Chem., 2016, 128, 1095810963.

103 X. Chen, D.-D. Ma, B. Chen, K. Zhang, R. Zou, X.-T. Wu and Q.-L. Zhu, Appl. Catal., B, 2020, 267, 118720.

104 H. Yang, L. Shang, Q. Zhang, R. Shi, G. I. N. Waterhouse, L. Gu and T. Zhang, Nat. Commun., 2019, 10, 4585.

105 X. Zhang, S. Zhang, Y. Yang, L. Wang, Z. Mu, H. Zhu, X. Zhu, H. Xing, H. Xia, B. Huang, J. Li, S. Guo and E. Wang, Adv. Mater., 2020, 32, 1906905.

106 D. Ji, L. Fan, L. Tao, Y. Sun, M. Li, G. Yang, T. Q. Tran, S. Ramakrishna and S. Guo, Angew. Chem., Int. Ed., 2019, 58, 13840-13844.

107 X. Mi, P. Wang, S. Xu, L. Su, H. Zhong, H. Wang, Y. Li and S. Zhan, Angew. Chem., Int. Ed., 2021, 60, 4588-4593.

108 Y. Hou, M. Qiu, M. G. Kim, P. Liu, G. Nam, T. Zhang, X. Zhuang, B. Yang, J. Cho, M. Chen, C. Yuan, L. Lei and X. Feng, Nat. Commun., 2019, 10, 1392.

109 U. Jans and J. Hoigné, Ozone: Sci. Eng., 1998, 20, 67-90.

110 F. J. Beltrán, J. Rivas, P. Álvarez and R. Montero-deEspinosa, Ozone: Sci. Eng., 2002, 24, 227-237.

111 F. J. Beltrán, F. J. Rivas, L. A. Fernández, P. M. Álvarez and R. Montero-de-Espinosa, Ind. Eng. Chem. Res., 2002, 41, 6510-6517.
112 P. Faria, J. Órfão and M. Pereira, Appl. Catal., B, 2008, 79, 237-243.

113 L. Gu, X. Zhang and L. Lei, Ind. Eng. Chem. Res., 2008, 47, 6809-6815.

114 P. M. Alvarez, J. F. Garcia-Araya, F. J. Beltrán, I. Giráldez, J. Jaramillo and V. Gómez-Serrano, Carbon, 2006, 44, 3102-3112.

115 L. Lei, L. Gu, X. Zhang and Y. Su, Appl. Catal., A, 2007, 327, 287-294.

116 P. C. Faria, J. J. Órfão and M. F. R. Pereira, Ind. Eng. Chem. Res., 2006, 45, 2715-2721.

117 J. Rivera-Utrilla and M. Sánchez-Polo, Appl. Catal., B, 2002, 39, 319-329.

118 H. Cao, L. Xing, G. Wu, Y. Xie, S. Shi, Y. Zhang, D. Minakata and J. C. Crittenden, Appl. Catal., B, 2014, 146, 169-176.

119 J. Rivera-Utrilla and M. Sánchez-Polo, Langmuir, 2004, 20, 9217-9222.

120 L. Xing, Y. Xie, H. Cao, D. Minakata, Y. Zhang and J. C. Crittenden, Chem. Eng. J., 2014, 245, 71-79.

121 Y.-d. Chen, R. Wang, X. Duan, S. Wang, N.-q. Ren and S.-H. Ho, Water Res., 2020, 187, 116390.

122 C. Chen, X. Yan, Y. Xu, B. A. Yoza, X. Wang, Y. Kou, H. Ye, Q. Wang and Q. X. Li, Sci. Total Environ., 2019, 651, 26312640.

123 C. Zhao, B. Shao, M. Yan, Z. Liu, Q. Liang, Q. He, T. Wu, Y. Liu, Y. Pan and J. Huang, Chem. Eng. J., 2021, 416, 128829.

124 G. Wen, Z.-H. Pan, J. Ma, Z.-Q. Liu, L. Zhao and J.-J. Li, J. Hazard. Mater., 2012, 239, 381-388.

125 G. Moussavi and R. Khosravi, Bioresour. Technol., 2012, 119, 66-71.

126 F. Zhang, K. Wu, H. Zhou, Y. Hu, P. Sergei, H. Wu and C. Wei, J. Environ. Manage., 2018, 224, 376-386.

127 A. Gonçalves, J. J. Órfão and M. F. R. Pereira, Appl. Catal., B, 2013, 140, 82-91.

128 X. Fan, J. Restivo, J. J. Órfão, M. F. R. Pereira and A. A. Lapkin, Chem. Eng. J., 2014, 241, 66-76.

129 Z.-Q. Liu, J. Ma, Y.-H. Cui and B.-P. Zhang, Appl. Catal., B, 2009, 92, 301-306.

130 Z.-Q. Liu, J. Ma, Y.-H. Cui, L. Zhao and B.-P. Zhang, Appl. Catal., B, 2010, 101, 74-80.

131 A. G. Gonçalves, J. L. Figueiredo, J. J. Órfão and M. F. Pereira, Carbon, 2010, 48, 4369-4381.

132 A. G. Gonçalves, J. J. Órfão and M. F. Pereira, Catal. Commun., 2013, 35, 82-87.

133 I. D. Rosca, F. Watari, M. Uo and T. Akasaka, Carbon, 2005, 43, 3124-3131.

134 B. Smith, K. Wepasnick, K. E. Schrote, H.-H. Cho, W. P. Ball and D. H. Fairbrother, Langmuir, 2009, 25, 9767-9776.

135 J. Restivo, R. P. Rocha, A. M. Silva, J. J. Órfão, M. F. Pereira and J. L. Figueiredo, Chin. J. Catal., 2014, 35, 896-905.

136 O. Soares, R. Rocha, A. Gonçalves, J. Figueiredo, J. Órfão and M. Pereira, Appl. Catal., B, 2016, 192, 296-303.

137 A. S. G. Santos, C. A. Orge, O. S. G. Soares and M. F. R. Pereira, J. Water Process. Eng., 2020, 38, 101573.

138 J. Wang, S. Chen, X. Quan and H. Yu, Chemosphere, 2018, 190, 135-143. 
139 J.-N. Liu, Z. Chen, Q.-Y. Wu, A. Li, H.-Y. Hu and C. Yang, Sci. Rep., 2016, 6, 1-9.

140 B. Ye, M.-Y. Lee, W.-L. Wang, A. Li, Z.-Y. Liu, Q.-Y. Wu and H.-Y. Hu, J. Hazard. Mater., 2020, 394, 122563.

141 L. Jothinathan and J. Hu, Water Res., 2018, 134, 63-73.

142 Y. Wang, H. Cao, L. Chen, C. Chen, X. Duan, Y. Xie, W. Song, H. Sun and S. Wang, Appl. Catal., B, 2018, 229, 71-80.

143 X.-K. Kong, C.-L. Chen and Q.-W. Chen, Chem. Soc. Rev., 2014, 43, 2841-2857.

144 S. Osumi, S. Saito, C. Dou, K. Matsuo, K. Kume, H. Yoshikawa, K. Awaga and S. Yamaguchi, Chem. Sci., 2016, 7, 219-227.

145 R. P. Rocha, A. Gonçalves, L. Pastrana-Martínez, B. Bordoni, O. Soares, J. Órfão, J. L. Faria, J. L. Figueiredo, A. Silva and M. F. R. Pereira, Catal. Today, 2015, 249, 192-198.

146 R. Yin, W. Guo, J. Du, X. Zhou, H. Zheng, Q. Wu, J. Chang and N. Ren, Chem. Eng. J., 2017, 317, 632-639.

147 F. Yang, M. Zhao, Z. Wang, H. Ji, B. Zheng, D. Xiao, L. Wu and Y. Guo, RSC Adv., 2014, 4, 58325-58328.

148 T. Du, A. S. Adeleye, T. Zhang, N. Yang, R. Hao, Y. Li, W. Song and W. Chen, Environ. Sci.: Nano, 2019, 6, 24842494.

149 Z. Wang, L. Sun, X. Lou, F. Yang, M. Feng and J. Liu, J. Colloid Interface Sci., 2017, 507, 51-58.

150 C.-Z. Zhang, T. Li, Y. Yuan and J. Xu, Chemosphere, 2016, 153, 531-540.

151 G. Liao, D. Zhu, L. Li and B. Lan, J. Hazard. Mater., 2014, 280, 531-535.

152 J. Xiao, Y. Xie, F. Nawaz, S. Jin, F. Duan, M. Li and H. Cao, Appl. Catal., B, 2016, 181, 420-428.

153 J. Xiao, Y. Xie, F. Nawaz, Y. Wang, P. Du and H. Cao, Appl. Catal., B, 2016, 183, 417-425.

154 J. Zhang, B. Xin, C. Shan, W. Zhang, D. D. Dionysiou and B. Pan, Appl. Catal., B, 2021, 292, 120155.

155 X. Yuan, R. Xie, Q. Zhang, L. Sun, X. Long and D. Xia, Sep. Purif. Technol., 2019, 211, 823-831.

156 F. Zhang, J. Liao, J. Lu and J. Niu, Sep. Purif. Technol., 2021, 256, 117806.

157 J. Xiao, Q. Han, Y. Xie, J. Yang, Q. Su, Y. Chen and H. Cao, Environ. Sci. Technol., 2017, 51, 13380-13387.

158 Z. Sun, L. Zhao, C. Liu, Y. Zhen and J. Ma, Environ. Sci. Technol., 2019, 53, 10342-10351.

159 Y. Wang, J. Xi, X. Duan, W. Lv, H. Cao, C. Chen, Z. Guo, Y. Xie and S. Wang, J. Hazard. Mater., 2020, 384, 121486.

160 F. J. Beltrán, J. F. García-Araya and I. Giráldez, Appl. Catal., $B, 2006,63,249-259$.

161 P. Faria, J. Órfão and M. Pereira, Appl. Catal., B, 2008, 83, 150-159.

162 J. Ma, M. Sui, T. Zhang and C. Guan, Water Res., 2005, 39, 779-786.

163 Y. Huang, Y. Sun, Z. Xu, M. Luo, C. Zhu and L. Li, Sci. Total Environ., 2017, 575, 50-57.

164 H. Zhuang, H. Han, B. Hou, S. Jia and Q. Zhao, Bioresour. Technol., 2014, 166, 178-186.

165 G. Li, Y. Lu, C. Lu, M. Zhu, C. Zhai, Y. Du and P. Yang, J. Hazard. Mater., 2015, 294, 201-208.
166 G. Li, K. Li, A. Liu, P. Yang, Y. Du and M. Zhu, Sci. Rep., 2017, 7, 1-7.

167 J. Wang, X. Quan, S. Chen, H. Yu and Y. Chen, Environ. Sci.: Nano, 2019, 6, 1932-1940.

168 J. Wu, H. Gao, S. Yao, L. Chen, Y. Gao and H. Zhang, Sep. Purif. Technol., 2015, 147, 179-185.

169 Y. Huang, C. Cui, D. Zhang, L. Li and D. Pan, Chemosphere, 2015, 119, 295-301.

170 C. Chen, H. Chen, X. Guo, S. Guo and G. Yan, J. Ind. Eng. Chem., 2014, 20, 2782-2791.

171 S. Hou, S. Jia, J. Jia, Z. He, G. Li, Q. Zuo and H. Zhuang, J. Environ. Manage., 2020, 267, 110615.

172 Y. Yuan, G. Xing, S. Garg, J. Ma, X. Kong, P. Dai and T. D. Waite, Water Res., 2020, 177, 115785.

173 Y. Huang, W. Xu, L. Hu, J. Zeng, C. He, X. Tan, Z. He, Q. Zhang and D. Shu, Catal. Today, 2017, 297, 143-150.

174 Y. Liu, A. Zhou, Y. Liu and J. Wang, Chemosphere, 2018, 191, 54-63.

175 X. Yuan, W. Qin, X. Lei, L. Sun, Q. Li, D. Li, H. Xu and D. Xia, Chemosphere, 2018, 205, 369-379.

176 Z.-Q. Liu, J. Ma and Y.-H. Cui, Carbon, 2008, 46, 890-897.

177 Q. Dai, J. Wang, J. Chen and J. Chen, Sep. Purif. Technol., 2014, 127, 112-120.

178 P. Faria, J. Órfão and M. Pereira, Appl. Catal., B, 2009, 88, 341-350.

179 A. Gonçalves, J. Silvestre-Albero, E. V. Ramos-Fernandez, J. C. Serrano-Ruiz, J. J. Órfão, A. Sepúlveda-Escribano and M. F. R. Pereira, Appl. Catal., B, 2012, 113, 308-317.

180 L. Li, W. Ye, Q. Zhang, F. Sun, P. Lu and X. Li, J. Hazard. Mater., 2009, 170, 411-416.

181 P. Faria, J. Órfão and M. Pereira, Catal. Commun., 2008, 9, 2121-2126.

182 A. G. Gonçalves, J. J. Órfão and M. F. R. Pereira, Chem. Eng. J., 2014, 250, 366-376.

183 J. Wang, X. Quan, S. Chen, H. Yu and G. Liu, J. Hazard. Mater., 2019, 368, 621-629.

184 Y. Jiang, M. Wei, J. Feng, Y. Ma and S. Xiong, Energy Environ. Sci., 2016, 9, 1430-1438.

185 X. Meng, C. Yu, X. Song, J. Iocozzia, J. Hong, M. Rager, H. Jin, S. Wang, L. Huang and J. Qiu, Angew. Chem., 2018, 130, 4772-4776.

186 S. Shrestha, Y. Liu and W. E. Mustain, Catal. Rev., 2011, 53, 256-336.

187 B. Zhang and D. S. Su, ChemCatChem, 2015, 7, 3639-3645. 188 J. Xu, Y. Li, M. Qian, J. Pan, J. Ding and B. Guan, Appl. Catal., B, 2019, 256, 117797.

189 Y. Cao, S. Mao, M. Li, Y. Chen and Y. Wang, ACS Catal., 2017, 7, 8090-8112.

190 S. Campisi, C. E. Chan-Thaw and A. Villa, Appl. Sci., 2018, 8, 1159.

191 Q. Bao, K. San Hui and J. G. Duh, J. Environ. Sci., 2016, 50, 38-48.

192 C. Li, F. Jiang, D. Sun and B. Qiu, Chem. Eng. J., 2017, 325, 624-631.

193 Y. Yu, H. An, Y. Zhao, J. Feng, T. Wei, S. Yu, Y. Ren and Y. Chen, Sep. Purif. Technol., 2021, 259, 118097. 
194 Y. Ren, H. Zhang, H. An, Y. Zhao, J. Feng, L. Xue, T. Luan and Z. Fan, J. Colloid Interface Sci., 2018, 526, 347-355.

195 J. Wu, L. Xiong, B. Zhao, M. Liu and L. Huang, Small Methods, 2020, 4, 1900540.

196 Z. Luo, D. Wang, W. Zeng and J. Yang, Sci. Total Environ., 2020, 734, 139448.

197 S.-Q. Tian, J.-Y. Qi, Y.-P. Wang, Y.-L. Liu, L. Wang and J. Ma, Water Res., 2021, 193, 116860.

198 M. Sui, S. Xing, L. Sheng, S. Huang and H. Guo, J. Hazard. Mater., 2012, 227, 227-236.

199 S. Zhang, D. Wang, X. Quan, L. Zhou and X. Zhang, Sep. Purif. Technol., 2013, 116, 351-359.

200 A. Abdedayem, M. Guiza, F. J. R. Toledo and A. Ouederni, Sep. Purif. Technol., 2017, 184, 308-318.

201 N. Nasseh, F. S. Arghavan, S. Rodriguez-Couto, A. H. Panahi, M. Esmati and T. J. A-Musawi, Adv. Powder Technol., 2020, 31, 875-885.

202 W. Wang, H. Yao and L. Yue, Environ. Sci. Pollut. Res., 2020, 27, 7199-7210.

203 J. Liu, J. Li, S. He, L. Sun, X. Yuan and D. Xia, Sep. Purif. Technol., 2020, 234, 116120.

204 J. Feng, X. Zhang, J. Fu and H. Chen, Catal. Commun., 2018, 110, 28-32.

205 B. Ye, Z. Chen, X. Li, J. Liu, Q. Wu, C. Yang, H. Hu and R. Wang, Front. Environ. Sci. Eng., 2019, 13, 1-9.

206 J. Akhtar, N. S. Amin and A. Aris, Chem. Eng. J., 2011, 170, 136-144.

207 X. Lü, Q. Zhang, W. Yang, X. Li, L. Zeng and L. Li, RSC Adv., 2015, 5, 10537-10545.

208 S. Tang, D. Yuan, Q. Zhang, Y. Liu, Z. Liu and H. Huang, Environ. Sci. Pollut. Res., 2016, 23, 18800-18808.

209 L. Khachatryan, C. A. McFerrin, R. W. Hall and B. Dellinger, Environ. Sci. Technol., 2014, 48, 9220-9226.

210 R. J. Singh, H. Karoui, M. R. Gunther, J. S. Beckman, R. P. Mason and B. Kalyanaraman, Proc. Natl. Acad. Sci. U. S. A., 1998, 95, 6675-6680.

211 K. Qian, H. Chen, W. Li, Z. Ao, Y.-n. Wu and X. Guan, Environ. Sci. Technol., 2021, 55, 7034-7043.

212 Y. Zong, X. Guan, J. Xu, Y. Feng, Y. Mao, L. Xu, H. Chu and D. Wu, Environ. Sci. Technol., 2020, 54, 16231-16239.

213 T. Olmez-Hanci and I. Arslan-Alaton, Chem. Eng. J., 2013, 224, 10-16.

214 Q. Dai, J. Wang, J. Yu, J. Chen and J. Chen, Appl. Catal., B, 2014, 144, 686-693.

215 R. C. Martins and R. M. Quinta-Ferreira, Appl. Catal., B, 2009, 90, 268-277.

216 W. Ren, L. Xiong, X. Yuan, Z. Yu, H. Zhang, X. Duan and S. Wang, Environ. Sci. Technol., 2019, 53, 14595-14603.

217 W. Ren, G. Nie, P. Zhou, H. Zhang, X. Duan and S. Wang, Environ. Sci. Technol., 2020, 54, 6438-6447.

218 R. Andreozzi, A. Insola, V. Caprio, R. Marotta and V. Tufano, Appl. Catal., A, 1996, 138, 75-81.

219 F. J. Beltrán, F. J. Rivas and R. Montero-de-Espinosa, Water Res., 2005, 39, 3553-3564.

220 F. Nawaz, H. Cao, Y. Xie, J. Xiao, Y. Chen and Z. A. Ghazi, Chemosphere, 2017, 168, 1457-1466.
221 Y. Nosaka and A. Y. Nosaka, Chem. Rev., 2017, 117, 1130211336.

222 H. Zhao, J. Joseph, H. Zhang, H. Karoui and B. Kalyanaraman, Free Radical Biol. Med., 2001, 31, 599606.

223 J. Xiao, Q. Han, H. Cao, J. Rabeah, J. Yang, Z. Guo, L. Zhou, Y. Xie and A. Brückner, ACS Catal., 2019, 9, 8852-8861.

224 M. J. Davies, B. C. Gilbert, J. K. Stell and A. C. Whitwood, J. Chem. Soc., Perkin Trans. 2, 1992, (3), 333-335.

225 X. Chen, W.-D. Oh and T.-T. Lim, Chem. Eng. J., 2018, 354, 941-976.

226 K. Nakamura, K. Ishiyama, H. Ikai, T. Kanno, K. Sasaki, Y. Niwano and M. Kohno, J. Clin. Biochem. Nutr., 2011, 49, 87-95.

227 P. Bilski, K. Reszka, M. Bilska and C. Chignell, J. Am. Chem. Soc., 1996, 118, 1330-1338.

228 R. Poupko and I. Rosenthal, J. Phys. Chem., 1973, 77, 17221724.

229 T. A. Konovalova, J. Lawrence and L. D. Kispert, J. Photochem. Photobiol., A, 2004, 162, 1-8.

230 J. Cattani, V. Subramaniam and M. Drescher, Phys. Chem. Chem. Phys., 2017, 19, 18147-18151.

231 D. L. Marshall, M. L. Christian, G. Gryn'ova, M. L. Coote, P. J. Barker and S. J. Blanksby, Org. Biomol. Chem., 2011, 9, 4936-4947.

232 G. V. Buxton, C. L. Greenstock, W. P. Helman and A. B. Ross, J. Phys. Chem. Ref. Data, 1988, 17, 513-886.

233 J. Xiao, Y. Xie, H. Cao, Y. Wang, Z. Guo and Y. Chen, Carbon, 2016, 107, 658-666.

234 T. Turan-Ertas and M. D. Gurol, Chemosphere, 2002, 47, 293-301.

235 Y. Wang, L. Chen, H. Cao, Z. Chi, C. Chen, X. Duan, Y. Xie, F. Qi, W. Song and J. Liu, Appl. Catal., B, 2019, 245, 546-554.

236 E. Mvula and C. Von Sonntag, Org. Biomol. Chem., 2003, 1, 1749-1756.

237 A. Jawad, X. Lu, Z. Chen and G. Yin, J. Phys. Chem. A, 2014, 118, 10028-10035.

238 F. Wilkinson, W. P. Helman and A. B. Ross, J. Phys. Chem. Ref. Data, 1995, 24, 663-677.

239 C. A. Davis, K. McNeill and E. M.-L. Janssen, Environ. Sci. Technol., 2018, 52, 9908-9916.

240 C. Schweitzer and R. Schmidt, Chem. Rev., 2003, 103, 16851758.

241 O. Núñez, L. Madriz, D. Carvajal, J. Tatá and R. Vargas, J. Phys. Org. Chem., 2019, 32, e3952.

242 S. Zhu, X. Huang, F. Ma, L. Wang, X. Duan and S. Wang, Environ. Sci. Technol., 2018, 52, 8649-8658.

243 Y. Pi, J. Schumacher and M. Jekel, Ozone: Sci. Eng., 2005, 27, 431-436.

244 Y. Guo, J. Zhan, G. Yu and Y. Wang, Water Res., 2021, 194, 116927.

245 Y. Guo, Y. Zhang, G. Yu and Y. Wang, Appl. Catal., B, 2021, 280, 119418.

246 G.-X. Huang, J.-Y. Si, C. Qian, W.-K. Wang, S.-C. Mei, C.-Y. Wang and H.-Q. Yu, Anal. Chem., 2018, 90, 1443914446. 
247 L. Zhu, J. Ji, J. Liu, S. Mine, M. Matsuoka, J. Zhang and M. Xing, Angew. Chem., Int. Ed., 2020, 59, 13968-13976.

248 J.-F. Jen, M.-F. Leu and T. C. Yang, J. Chromatogr. A, 1998, 796, 283-288.

249 D. Wu, M. Liu, D. Dong and X. Zhou, Microchem. J., 2007, 85, 250-256.

250 C. A. Martínez-Huitle, M. A. Quiroz, C. Comninellis, S. Ferro and A. De Battisti, Electrochim. Acta, 2004, 50, 949-956.

251 C. Tai, J.-F. Peng, J.-F. Liu, G.-B. Jiang and H. Zou, Anal. Chim. Acta, 2004, 527, 73-80.

252 P. L. Gai and E. D. Boyes, Microsc. Res. Tech., 2009, 72, 153164.

253 L. Linxiang, Y. Abe, Y. Nagasawa, R. Kudo, N. Usui, K. Imai, T. Mashino, M. Mochizuki and N. Miyata, Biomed. Chromatogr., 2004, 18, 470-474.

254 P. Zhou, F. Cheng, G. Nie, Y. Yang, K. Hu, X. Duan, Y. Zhang and S. Wang, Green Energy Environ., 2020, 5, 414-422.

255 J. Wang, Y. Guo, B. Liu, X. Jin, L. Liu, R. Xu, Y. Kong and B. Wang, Ultrason. Sonochem., 2011, 18, 177-183.

256 F. Auchère and F. Rusnak, J. Biol. Inorg Chem., 2002, 7, 664667.

257 S. Miyamoto, G. R. Martinez, M. H. Medeiros and P. Di Mascio, J. Am. Chem. Soc., 2003, 125, 6172-6179.

258 G. Louit, S. Foley, J. Cabillic, H. Coffigny, F. Taran, A. Valleix, J. P. Renault and S. Pin, Radiat. Phys. Chem., 2005, 72, 119-124.

259 S. Zhang, X. Quan, J. Zheng and D. Wang, Water Res., 2017, 122, 86-95.

260 K. Zhang, P. Sun, M. C. A. Faye and Y. Zhang, Carbon, 2018, 130, 730-740.

261 H. Wang, W. Guo, R. Yin, J. Du, Q. Wu, H. Luo, B. Liu, F. Sseguya and N. Ren, Chem. Eng. J., 2019, 362, 561-569.

262 M. T. Pinho, H. T. Gomes, R. S. Ribeiro, J. L. Faria and A. M. Silva, Appl. Catal., B, 2015, 165, 706-714.

263 M. Martin-Martinez, M. F. F. Barreiro, A. M. Silva, J. L. Figueiredo, J. L. Faria and H. T. Gomes, Appl. Catal., $B, 2017,219,372-378$.

264 D. T. Sawyer and J. S. Valentine, Acc. Chem. Res., 1981, 14, 393-400.

265 R. Baum, Chem. Eng. News, 1984, 62, 20-26.

266 A. A. Frimer, T. Farkash-Solomon and G. Aljadeff, J. Org. Chem., 1986, 51, 2093-2098.

267 D. R. Kearns, Chem. Rev., 1971, 71, 395-427.

268 M. J. Thomas and C. S. Foote, Photochem. Photobiol., 1978, 27, 683-693.

269 F. E. Scully, Jr and J. Hoigné, Chemosphere, 1987, 16, 681694.

270 M. Hayyan, M. A. Hashim and I. M. AlNashef, Chem. Rev., 2016, 116, 3029-3085.

271 M. H. Plumlee, K. McNeill and M. Reinhard, Environ. Sci. Technol., 2009, 43, 3662-3668.

272 J. Wang and S. Wang, Chem. Eng. J., 2020, 401, 126158.

273 Y. Wang, Y. Xie, H. Sun, J. Xiao, H. Cao and S. Wang, Catal. Sci. Technol., 2016, 6, 2918-2929.

274 R. Luo, M. Li, C. Wang, M. Zhang, M. A. N. Khan, X. Sun, J. Shen, W. Han, L. Wang and J. Li, Water Res., 2019, 148, 416-424.
275 C. Zhu, Y. Zhang, Z. Fan, F. Liu and A. Li, J. Hazard. Mater., 2020, 393, 122395.

276 X. Cheng, H. Guo, Y. Zhang, X. Wu and Y. Liu, Water Res., 2017, 113, 80-88.

277 F. Qi, B. Xu, Z. Chen, L. Zhang, P. Zhang and D. Sun, Chem. Eng. J., 2010, 165, 490-499.

278 J.-S. Park, H. Choi and J. Cho, Water Res., 2004, 38, 22852292.

279 J. Hoigné and H. Bader, Water Res., 1983, 17, 185-194.

280 M. Heyrovský and S. Vavřička, J. Electroanal. Chem. Interfacial Electrochem., 1972, 36, 203-221.

281 S. Zhu, X. Li, J. Kang, X. Duan and S. Wang, Environ. Sci. Technol., 2018, 53, 307-315.

282 B. Legube and N. K. V. Leitner, Catal. Today, 1999, 53, 6172.

283 P. Wardman, J. Phys. Chem. Ref. Data, 1989, 18, 1637-1755. 284 S. Giannakis, K.-Y. A. Lin and F. Ghanbari, Chem. Eng. J., 2021, 406, 127083.

285 U. Von Gunten, Water Res., 2003, 37, 1469-1487.

286 Z. Zuo, Z. Cai, Y. Katsumura, N. Chitose and Y. Muroya, Radiat. Phys. Chem., 1999, 55, 15-23.

287 A. Nemes, I. Fabian and R. van Eldik, J. Phys. Chem. A, 2000, 104, 7995-8000.

288 R. Huang, H. Yan, L. Li, D. Deng, Y. Shu and Q. Zhang, Appl. Catal., B, 2011, 106, 264-271.

289 K. Zhang and K. M. Parker, Environ. Sci. Technol., 2018, 52, 9579-9594.

290 W. Yang and T. Wu, Ind. Eng. Chem. Res., 2019, 58, 34683477.

291 J. Sotelo, F. Beltran, F. Benitez and J. Beltran-Heredia, Water Res., 1989, 23, 1239-1246.

292 M. Mekic, M. Brigante, D. Vione and S. Gligorovski, Atmos. Environ., 2018, 185, 237-242.

293 Y. Huang, F. Yang, L. Ai, M. Feng, C. Wang, Z. Wang and J. Liu, Chemosphere, 2017, 179, 331-336.

294 M. Mekic, G. Loisel, W. Zhou, B. Jiang, D. Vione and S. Gligorovski, Environ. Sci. Technol., 2018, 52, 1230612315.

295 H. Herrmann, Chem. Rev., 2003, 103, 4691-4716.

296 A. Levanov, I. Kuskov, A. Zosimov, E. Antipenko and V. Lunin, Kinet. Catal., 2003, 44, 740-746.

297 T. Zhang, Y. Chen, Y. Wang, J. Le Roux, Y. Yang and J.-P. Croue, Environ. Sci. Technol., 2014, 48, 5868-5875.

298 Y. S. Al-Degs, M. I. El-Barghouthi, A. H. El-Sheikh and G. M. Walker, Dyes Pigm., 2008, 77, 16-23.

299 M. Sui, L. Sheng, K. Lu and F. Tian, Appl. Catal., B, 2010, 96, 94-100.

300 T. Zhang, C. Li, J. Ma, H. Tian and Z. Qiang, Appl. Catal., B, 2008, 82, 131-137.

301 O. S. Keen, G. McKay, S. P. Mezyk, K. G. Linden and F. L. Rosario-Ortiz, Water Res., 2014, 50, 408-419.

302 H. El-taliawy, M. Ekblad, F. Nilsson, M. Hagman, N. Paxeus, K. Jönsson, M. Cimbritz, J. la Cour Jansen and K. Bester, Chem. Eng. J., 2017, 325, 310-321.

303 I. Michael-Kordatou, C. Michael, X. Duan, X. He, D. Dionysiou, M. Mills and D. Fatta-Kassinos, Water Res., 2015, 77, 213-248. 
304 M. Nihemaiti, D. B. Miklos, U. Hübner, K. G. Linden, J. E. Drewes and J.-P. Croué, Water Res., 2018, 145, 487-497.

305 D. Wang, H. Xu, J. Ma, S. Giannakis, X. Lu, H. Chi, S. Song and J. Qi, Water Res., 2019, 149, 136-148.
306 Y. Yang, J. Jiang, X. Lu, J. Ma and Y. Liu, Environ. Sci. Technol., 2015, 49, 7330-7339.

307 M.-O. Buffle and U. von Gunten, Environ. Sci. Technol., 2006, 40, 3057-3063. 